Stéphanie Perron

\title{
Le macrophage et son implication dans la modulation de la réponse asthmatique dans les voies respiratoires
}

Mémoire présenté à la faculté des études supérieures de l'Université Laval comme exigence partielle du programme de maîtrise en médecine expérimentale-génétique des populations humaines offert à l'Université du Québec à Chicoutimi en vertu d'un protocol d'entente avec l'Université Laval pour l'obtention du grade de maître ès sciences (M.Sc.)

\author{
FACULTÉ DE MÉDECINE \\ UNIVERSITÉ LAVAL \\ QUÉBEC
}

et

\section{DÉPARTEMENT DES SCIENCES HUMAINES UNIVERSITÉ DU QUÉBEC À CHICOUTIMI SAGUENAY}




\section{Résumé}

L'asthme est une affection respiratoire chronique caractérisée par des processus inflammatoires. Ceux-ci sont provoqués par l'interaction de différentes cellules effectrices avec la muqueuse bronchique, ce qui engendre un remodelage des tissus. Le macrophage, étant donné sont implication dans l'autorégulation du processus inflammatoire dans l'asthme, s'est avéré une cible intéressante pour mieux comprendre les bases moléculaires de ce trait. Dans un premier temps, la technologie des puces d'ADN a été utilisée lors de ce projet de recherche pour identifier des biomarqueurs relatifs au rôle du macrophage alvéolaire dans l'asthme, dans le but de mieux documenter le phénotype de cette cellule dans le contexte de l'asthme allergique. D'ailleurs, une famille de gène ayant une implication probable dans la pathologie de l'asthme, les HSP, plus précisément le HSP60, a pu être mis en évidence. Dans un deuxième temps, le potentiel anti-inflammatoire d'un composé isolé d'origine naturelle, la querciméritrine, a pu être testé en utilisant le macrophage comme modèle cellulaire, dans le but de développer de nouvelles approches thérapeutiques. En effet, les recherches ayant pour cible le macrophage ou ses médiateurs pourraient permettre de mieux comprendre sont rôle dans l'asthme et mener au développement de nouvelles thérapies pour le contrôle des maladies inflammatoires. 


\section{Avant-propos}

Je voudrais en premier lieu remercier ma directrice de maîtrise Catherine Laprise. Merci de m'avoir intégrée dans ton équipe et de m'avoir guidée dans les méandres qui ont conduit à la réalisation de ce projet de maîtrise. Ce fut un travail de longue haleine, qui a été accompli grâce à ton sens critique et à tes conseils avisés. J'ai réalisée, grâce à ton soutien, de nombreux apprentissage autant d'ordre académiques que personnels. Merci Catherine d'avoir cru en mes capacités. Tu es une personne habitée par une grande passion pour ce que tu fais et tu sais merveilleusement bien transmettre cette passion. Je te suis reconnaissante de m'avoir donné ma chance. Merci!

Merci également à Jean Legault pour m'avoir accueilli dans son équipe dès mon arrivé à l'UQAC. Merci à David, Maxime, Catherine et Carl pour m'avoir aidée et guidée. Merci aussi au laboratoire LaSEVE pour l'extraction et 1'isolation de la Querciméritrine. Vous faites un travail extraordinaire.

Je voudrais aussi dire un merci très spécial à Anne-Marie et Annie. Merci pour votre patience, pour vos conseils, mais surtout pour votre amitié qui est si précieuse pour moi. Sans vous les filles, je ne me serais surement pas redue si loin! Je voudrais aussi remercier ma famille pour son soutien inconditionnel. Merci à ma mère Diane et ma sœur Tania pour leur aide lors de la rédaction de ce mémoire. Et pour finir, merci à Simon et Samuel pour avoir donné un sens à tout ça. 


\section{Table des matières}

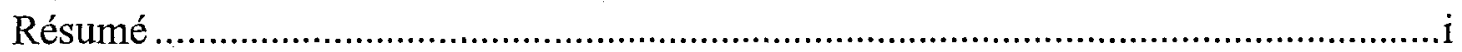

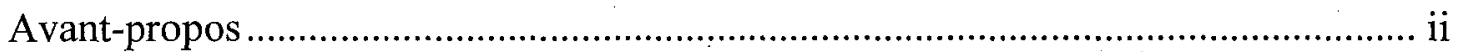

Table des matières ............................................................................................ ii

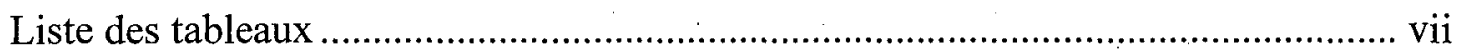

Table des figures ............................................................................................ vii

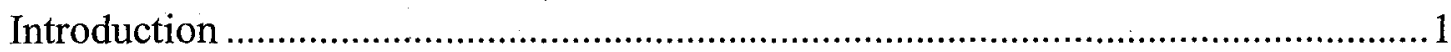

Chapitre I: L'Asthme

1.1 Les facteurs environnementaux et génétiques contribuant au développement de

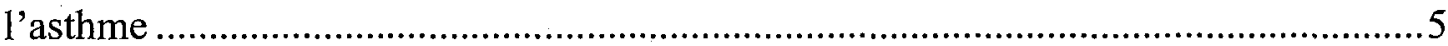

1.2 Physiopathologie de l'asthme ........................................................................6

1.2.1 Différentes phases de la réaction asthmatique ……….....................................

1.2.2 Principaux types cellulaires impliqués dans l'inflammation chez

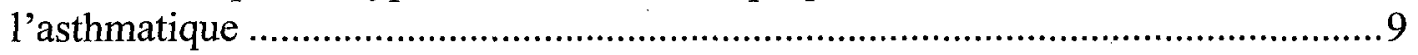

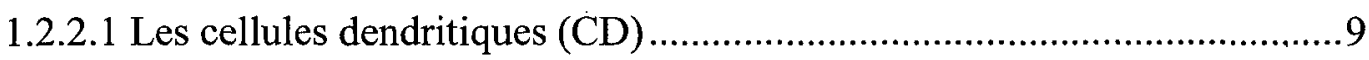

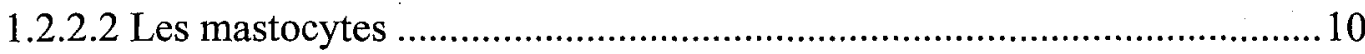

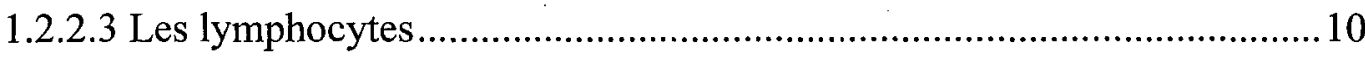

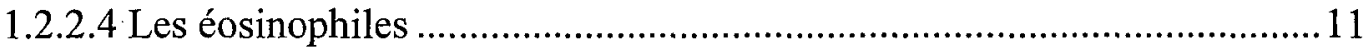

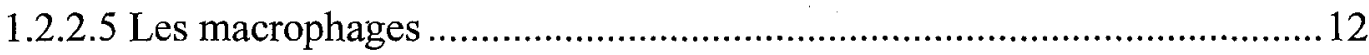

1.2.2.5.1 Les récepteurs de reconnaissance du non-soi................................13

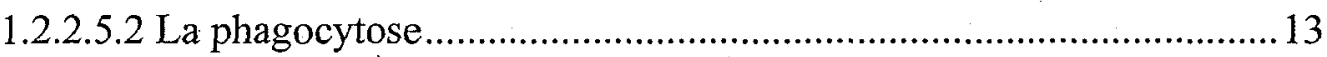


1.2.2.5.4 L'immunomodulation..................................................................

1.2.2.6 Le macrophage alvéolaire ………........................................................

1.3 Principaux symptômes de l'asthme.....................................................................17

1.3.1 L'hyperréactivité bronchique .......................................................................17

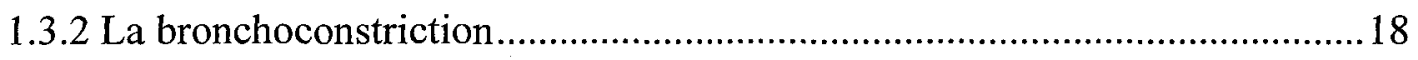

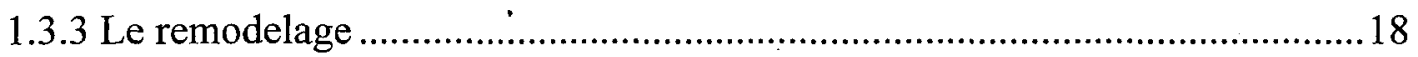

1.4 Prévention et soulagement des symptômes de l'asthme .......................................19

1.4.1 Médication disponible ..........................................................................21

1.5 Asthme corticorésistant ...................................................................................2.

1.5.1 Définition de la corticoresistance et de la corticodépendance ........................28

1.5.2 Mécanismes d'action des corticostéroides ..................................................29

1.5.3 Mécanismes moléculaires de la corticorésistance .......................................30

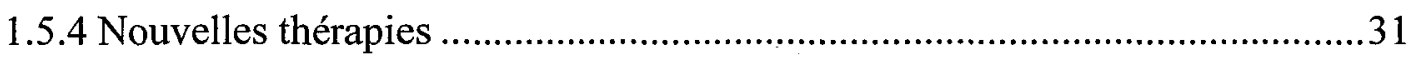

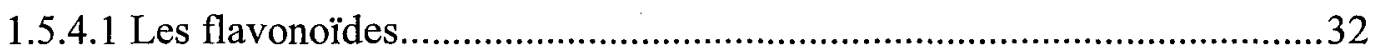

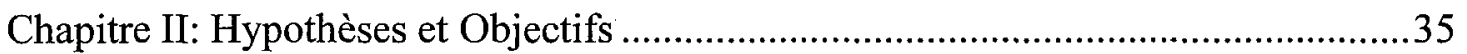

2.1 Hypothèse générale du projet de recherche ..........................................................35

2.2 Objectif général du projet de recherche ………....................................................36

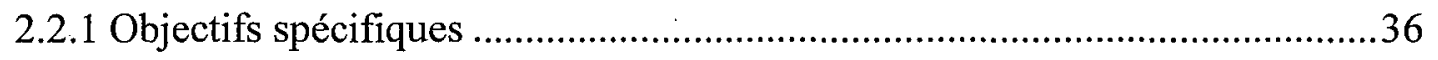

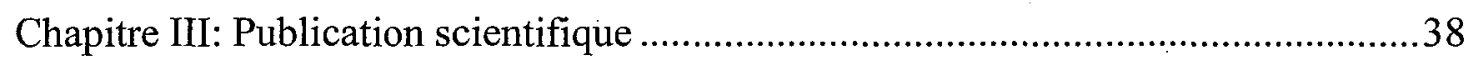

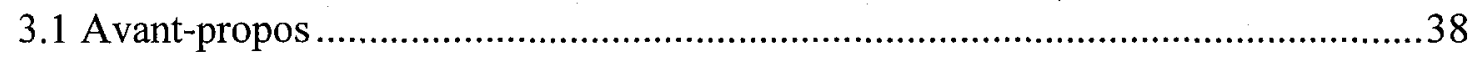

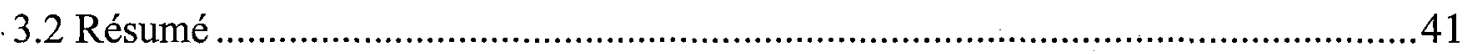




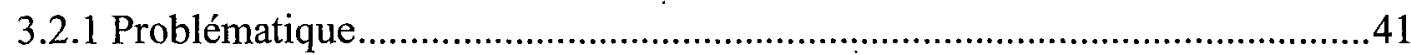

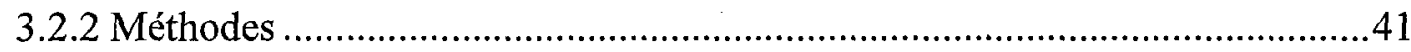

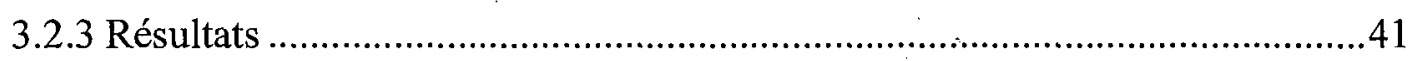

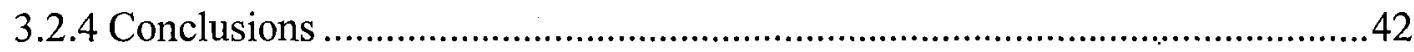

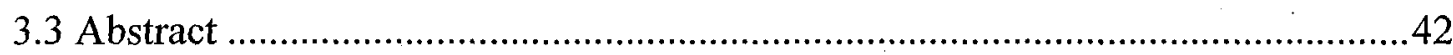

3.3.1 Background ………………………......................................................42

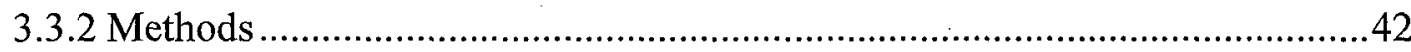

3.3.3 Results

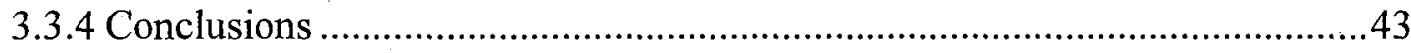

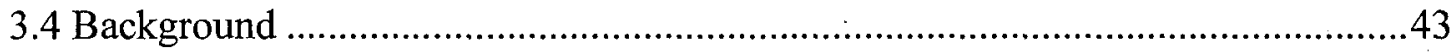

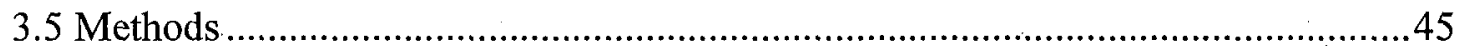

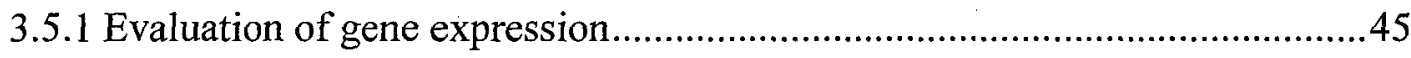

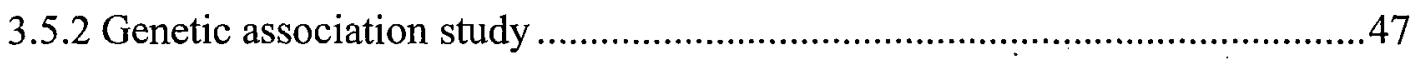

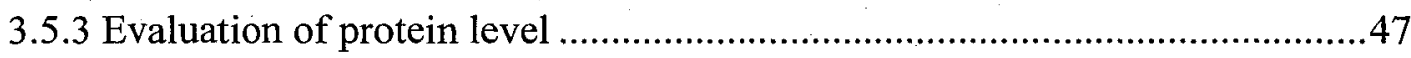

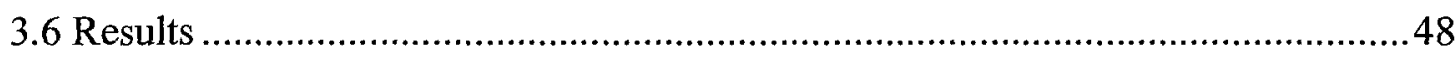

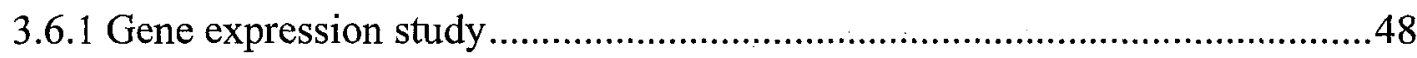

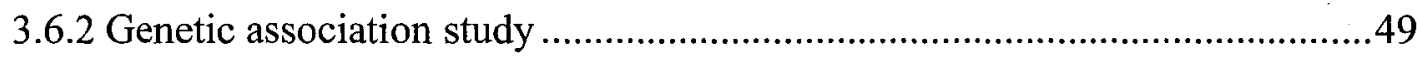

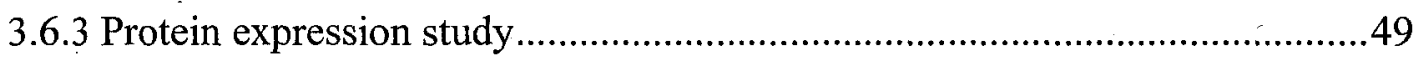

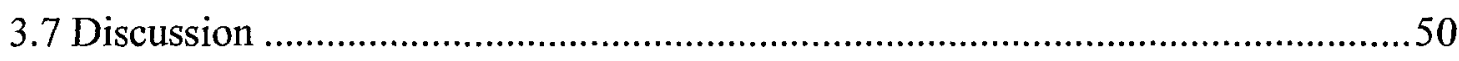

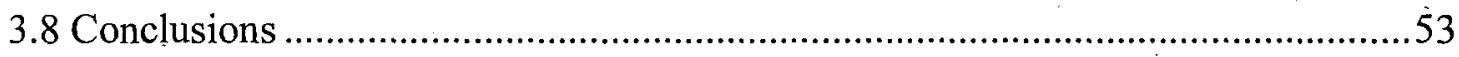

3.9 Authors' contributions .................................................................................5

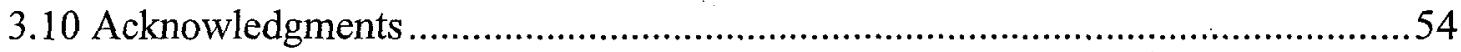

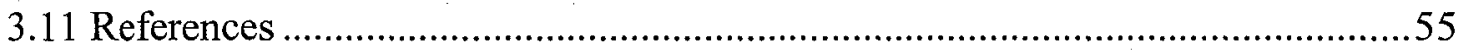

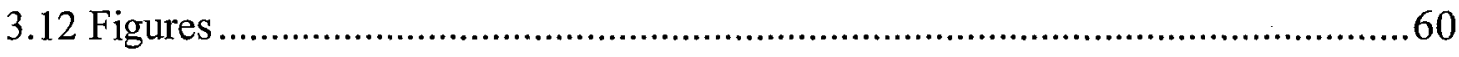




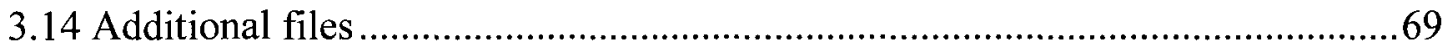

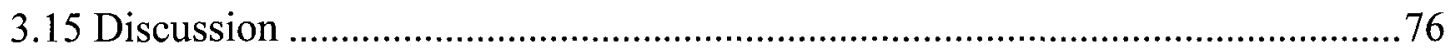

Chapitre IV: Évaluation du potentiel anti-inflammatoire d'un composé isolé d'origine naturelle en utilisant le macrophage comme modèle cellulaire ....................................78

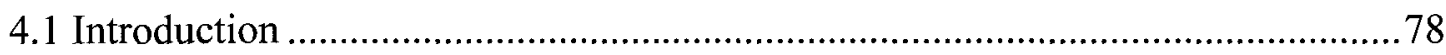

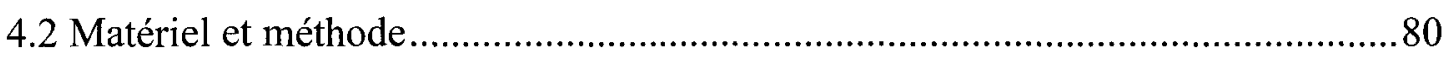

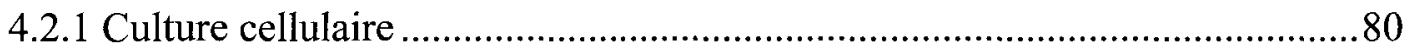

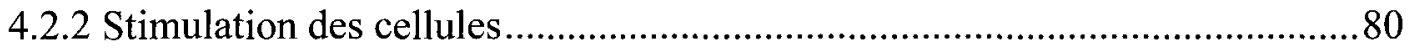

4.2.3 Test d'activité anti-inflammatoire (Griess nitrite assay) ..................................81

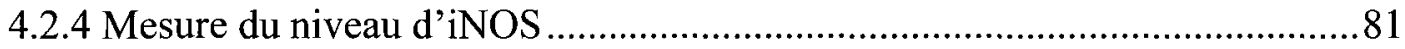

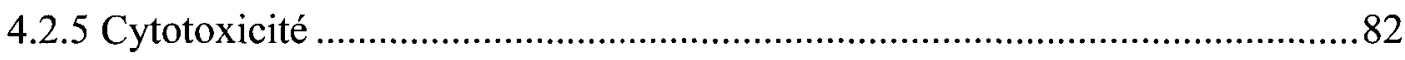

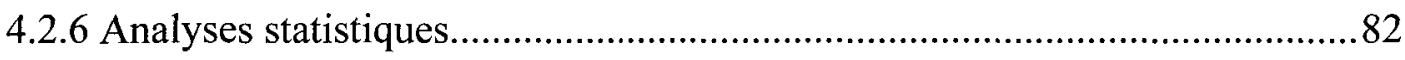

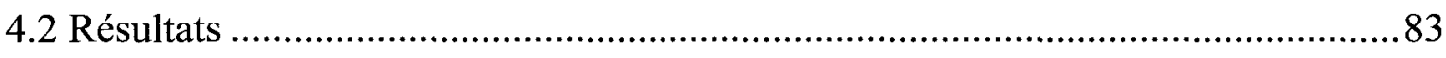

4.3.1 Test d'activité anti-inflammatoire (Griess nitrite assay) ..................................83

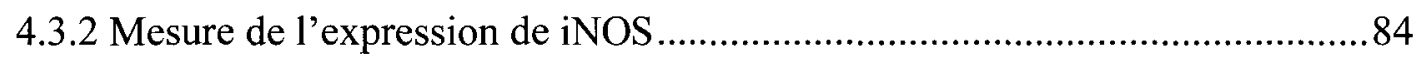

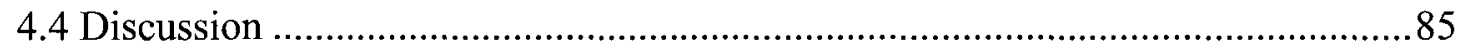

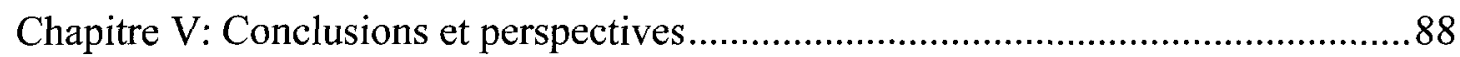

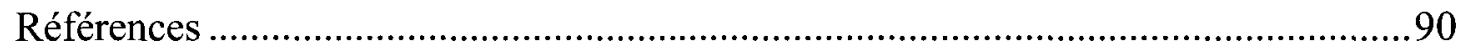




\section{Liste des tableaux}

Tableau I. Médiateurs inflammatoires sécrétés par le macrophage alvéolaire.............16

Tableau II. Mécanismes d'action et effets secondaire potentiels de la médication actuellement disponible pour traiter l'asthme ..........................................................21

Tableau III. Différents domaines de recherches pour le développement de nouvelles thérapies dans l'asthme

Table IV. Clinical characteristics of the subjects involved in microarray analysis and real-time RT-PCR.

Table V. Genes differentially expressed in alveolar macrophages of allergic asthmatic subjects in comparison to control subjects .................................................................64

Table VI. List of the primer pairs used for real-time RT-PCR …..............................70

Table VII. Clinical characteristics of the French-Canadian familial collection...........74

Table VIII. Characteristics of the polymorphisms (TagSNPs) .....................................75 


\section{Table des figures}

Figure 1. Physiopathologie de l'asthme ................................................................

Figure 2. Modèle schématique de la modulation de la signalisation cellulaire par les polyphénols et les flavonoïdes.

Figure 3. Expression of the five selected genes using real-time RT-PCR

Figure 4. HSP60 protein expression by alveolar macrophages (AM) of control and allergic asthmatic subjects.

Figure 5. Protein level of HSP60 in alveolar macrophages (AM) of control and

allergic asthmatic subjects. 62

Figure 6. La Brasenia schreberi Gmel. (Cabombaceae) 79

Figure 7. Inhibition de la production d'oxyde nitrique dans les macrophages de souris RAW264.7 par la querciméritrine sous stimulation à l'IFN- $\gamma .(*=\mathrm{P}<0.05) \ldots \ldots \ldots \ldots . . .83$

Figure 8. Effet de la querciméritrine sur l'expression de iNOS dans les macrophages de souris RAW264.7 sous stimulation à l'IFN- $\gamma$. $(*=\mathrm{P}<0.05)$. .84 


\section{Introduction}

Des millions de Canadiens sont atteints d'asthme. La prévalence de cette maladie est en constante augmentation, faisant de cette affection l'un des plus importants problèmes de santé pour la société. En 2004, le nombre de patients souffrant d'asthme dans le monde était évalué à environ 300 millions (Masoli et al. 2004). Au Canada, ce nombre est estimé à 3 millions, incluant approximativement 700000 québécois (Association pulmonaire du Québec, 2007). En terme de prévalence, 14,1\% de canadiens souffrent d'asthme et le taux de mortalité est estimé à 1,6\% (Masoli, Fabian et al. 2004).

L'asthme est une affection respiratoire chronique qui comporte une composante inflammatoire médiée par différentes cellules structurales et inflammatoires présentes ou recrutées dans le tissu pulmonaire (Bernstein 2008). Cette inflammation chronique entraîne des altérations structurales et physiologiques qui causent le rétrécissement des voies aériennes, ainsi que les deux composantes physiologiques principales reliées à 1'asthme; soit une hyperréactivité des voies bronchiques causée par une variété de stimuli et une obstruction variable et réversible des voies aériennes (Maddox et al. 2002). Les mécanismes sous-jacents au développement de cette affection sont encore mal connus. Cependant, la communauté scientifique s'entend pour dire que l'interaction entre les cellules inflammatoires, principalement les lymphocytes $\mathrm{T}$, les éosinophiles, les mastocytes, les cellules dendritiques, les macrophages et les cellules structurales de la muqueuse bronchique, (cellules épithéliales, fibroblaste, muscle lisse) provoque des changements morphologiques et fonctionnels dans les voies aériennes. Ces changements mènent à la symptomatologie relative à l'asthme soit: l'essoufflement, une oppression thoracique, une respiration sifflante, la surproduction de mucus et la toux (Global initiative for asthma 2007). 
De plus, l'asthme est reconnu comme un trait complexe, c'est-à-dire que son expression est modulée par des facteurs génétiques et des facteurs environnementaux (Maddox and Schwartz 2002; Lemanske et al. 2003). Les symptômes de la maladie peuvent s'exprimer de façon variable d'un individu à l'autre. En fait, l'expression clinique résulte de l'interaction entre plusieurs gènes, que ce soit des gènes de susceptibilité ou de protection, ainsi qu'avec l'environnement, (alimentation, tabagisme, activité physique, médication, etc.) ce qui provoque l'apparition de phénotypes variables, phénomène également nommés hétérogénéité clinique ou phénotypique (Maddox and Schwartz 2002; Wenzel 2006). Ainsi, certains individus présentent peu de symptômes. D'autres, très incommodés, peuvent développer une insuffisance respiratoire tandis que certains asthmatiques sévères peuvent même décéder d'une crise d'asthme (Moore et al. 2006).

Bien que la base du traitement de l'asthme reste le contrôle environnemental, il est possible de traiter et de maîtriser les symptômes par la médication. L'inflammation bronchique est diminuée avec l'aide des anti-inflammatoires stéroïdiens ou corticostéroïdes inhalés tels que le budesonide (Pulmicortß) ou oraux comme le Prednisolone (Dexamethasone ${ }^{\circledR}$ ) (Tantisira et al. 2006; Sobande et al. 2008). Les bronchospasmes peuvent quant à eux être maîtrisés via l'utilisation de bronchodilatateurs de courte ou de longue action tels que le salbutamol (Ventolin $($ ) ou le salmeterol (Serevent $(\mathbb{B})$ (Tantisira and Weiss 2006; Sobande and Kercsmar 2008). Toutefois, puisque certains patients souffrant d'asthme chronique ne répondent pas ou peu aux traitements aux corticostéroïdes disponibles, soit approximativement 25-35\% (Leung et al. 2003; Martin et al. 2007), le besoin de découvrir d'autres thérapies afin de réduire les symptômes et d'accroître la qualité de vie des gens atteints de cette affection est urgent (Catley et al. 2006; Adcock et al. 2008). 
Dans le cadre de ce projet de recherche, deux volets sont traités. Le premier a pour objectif de faire l'étude du transcriptome des macrophages alvéolaires (MA) afin de mieux évaluer le phénotype de cette cellule inflammatoire dans le contexte de l'asthme allergique. Le deuxième, quant à lui, vise à documenter le potentiel anti-inflammatoire d'un composé extrait d'une espèce végétale sur l'activité cellulaire des macrophages.

Pour le premier volet de ce projet de recherche, la technique des puces d'ADN est utilisée pour faire l'étude comparative du patron d'expression de gènes à partir d'ARN extrait de MA de sujets asthmatiques allergiques et témoins. Cette étude comparative a pour but de mieux documenter les différences phénotypiques des MA de sujets atteints d'asthme allergique et de sujets témoins en plus de cibler des biomarqueurs qui pourront devenir des cibles potentielles pour des études fonctionnelles, ainsi que pour le développement de nouvelles approches thérapeutiques.

Pour ce qui est du deuxième volet de ce projet de recherche, il a pour but d'évaluer le potentiel anti-inflammatoire d'un composé isolé provenant d'une espèce végétale de la forêt boréale en utilisant le macrophage comme modèle cellulaire. En effet, la bioactivité de la Querciméritrine, un composé d'origine naturelle extrait des feuilles de la Brasenia schreberi Gmel. (Cabombaceae), a été mesurée.

Afin de bien cerner les notions requises pour les deux volets de ce projet de recherche, le chapitre premier résumera les principaux éléments du processus inflammatoire dans l'asthme, il se compose d'une description de la physiopathologie de la maladie, des différentes cellules impliquées dont le macrophage alvéolaire, des différents traitements disponibles pour son contrôle ainsi que des nouvelles avenues thérapeutiques empruntées en recherche. Le deuxième chapitre sera consacré aux différents objectifs et 
hypothèses émises lors de l'élaboration de ce projet. Dans le troisième chapitre, l'article issu du projet de recherche sur la détermination de nouveaux biomarqueurs d'asthme dans les macrophages alvéolaires sera présenté (volet 1). Le quatrième chapitre sera, quant à lui, consacré à l'évaluation du potentiel anti-inflammatoire de composé isolé d'origine naturel en utilisant le macrophage comme modèle cellulaire (volet 2). Et finalement, les conclusions et perspectives envisagées à ce projet de recherche seront présentées au chapitre cinq. 


\section{Chapitre I: L'Asthme}

\subsection{Les facteurs environnementaux et génétiques contribuant au développement de l'asthme}

Comme énoncé précédemment, l'asthme est reconnu comme un trait complexe, c'està-dire que son expression est modulée par des facteurs génétiques et des facteurs environnementaux (Maddox and Schwartz 2002; Lemanske and Busse 2003). La cause exacte du développement de l'asthme est mal connue. Cependant, cet état semble être la conséquence d'une interaction complexe entre différents éléments soit des facteurs prédisposant, étiologiques et favorisants (Canada 2000).

Un facteur prédisposant est un élément qui rend l'organisme plus susceptible à une maladie ou qui en modifie l'évolution. Le principal facteur prédisposant identifié pour l'asthme est l'atopie (Report 2007). Cet état se définit comme une prédisposition génétique qui se caractérise par une réponse du système immunitaire à des allergènes communs de l'environnement, se traduisant par une production spontanée d'immunoglobulines de type $\mathrm{E}$ (IgE) (Warrier et al. 2008; Gaffin et al. 2009). Par ailleurs, la maladie semble apparaître plus fréquemment chez les individus ayant une histoire familiale d'asthme, ce qui pose l'hérédité comme un autre facteur prédisposant (Ober 2005), en plus du sexe et de l'âge (Horwood et al. 1985). 
Les facteurs étiologiques sont, quant à eux, des facteurs qui sont susceptibles de sensibiliser les voies aériennes tels que les allergènes, comme les phanères de chat ou d'autres animaux, les acariens, la poussière, les coquerelles et les contaminants en milieu de travail (Huss et al. 2001).

Finalement, les facteurs favorisants incluent l'exposition à la fumée de cigarette durant la grossesse et l'enfance, les infections respiratoires (respiratory syncytial virus (RSV)) et la pollution atmosphérique. Ces facteurs sont dit favorisants puisqu'ils ne provoquent pas directement l'asthme, mais sont susceptibles de contribuer à son apparition ou à son exacerbation (Report 2007).

\subsection{Physiopathologie de l'asthme}

L'inflammation joue un rôle central dans la pathologie de l'asthme. Le processus inflammatoire implique l'interaction entre plusieurs types cellulaires, leurs médiateurs et le tissu bronchique (Cohn et al. 2004). C'est de ces interactions que résulte le profil physiopathologique caractéristique de la maladie : la bronchoconstriction, l'hyperréactivité bronchique et le remodelage (Maddox and Schwartz 2002; Lemanske and Busse 2003). En effet, chez les asthmatiques allergiques, l'exposition à certains facteurs environnementaux provoque à la fois une inflammation de la paroi des voies respiratoires et un rétrécissement anormal de celles-ci. Malgré le fait que l'asthme puisse avoir plusieurs phénotypes différents, par exemple ; intermittent, persistant, associé à l'allergie et associé à l'effort, ou de degré de sévérité variables, la composante inflammatoire demeure un modèle cohérent pour expliquer l'apparition de la symptomatologie (Wenzel 2006). 


\subsubsection{Différentes phases de la réaction asthmatique}

$\mathrm{Au}$ point de vue clinique, la réaction asthmatique allergique est caractérisée par trois phases distinctes. La première phase, appelée la phase précoce de la réaction immédiate ou sensibilisation survient lorsqu'un allergène pénètre dans les voies respiratoires. Il est pris en charge par des cellules présentatrices d'antigènes (CPA) et présenté aux lymphocytes $\mathrm{T}$ CD4+ qui vont se différentier en Th2, producteurs notamment d'IL-4 qui va induire la production d'IgE par les lymphocytes B. Les IgE spécifiques des allergènes vont dès lors se fixer sur leur récepteur de haute affinité à la surface des mastocytes (Verstraelen et al. 2008). Lors de la phase immédiate, la co-agrégation des allergènes et des récepteurs de haute affinité par l'intermédiaire des IgE spécifiques va induire une dégranulation des mastocytes et la libération de médiateurs vaso- et broncho-actifs tels l'histamine et les prostaglandines dans les minutes suivant l'exposition (Busse et al. 2001), provocant ainsi la bronchoconstriction et l'obstruction des voies respiratoires. La seconde phase, ou la phase de réponse tardive, implique également la bronchoconstriction et correspond à une réponse inflammatoire qui survient quelques heures après l'exposition à l'agent ayant causé la crise d'asthme. Pendant cette phase il y a recrutement de cellules effectrices telles que les éosinophiles, les macrophages et les lymphocytes $T$ vers le poumon (Metzger et al. 1985; Lemanske and Busse 2003). Ces cellules interagissent ensemble et avec la muqueuse bronchique, ce qui provoque l'exacerbation des symptômes dans les bronches (Bernstein 2008). Cet état inflammatoire, lorsque soutenu, occasionne des dommages aux tissus bronchiques, notamment à cause de la présence continue des éosinophiles qui relâchent le contenu de leurs granules. Les protéines basiques, les médiateurs lipidiques et les radicaux libres de l'oxygène (ROS) ainsi relâchés provoquent à long terme la desquamation de l'épithélium bronchique, ce qui contribue au remodelage et à l'hyperréactivité des voies respiratoires (Sampson 2000). De plus, les nombreux facteurs de croissance relâchés par les éosinophiles vont également participer à l'apparition d'une fibrose, d'une hyperplasie et hypertrophie du muscle lisse et d'une angiogénèse (Bernstein 2008). La figure 1 résume le processus inflammatoire dans l'asthme. 


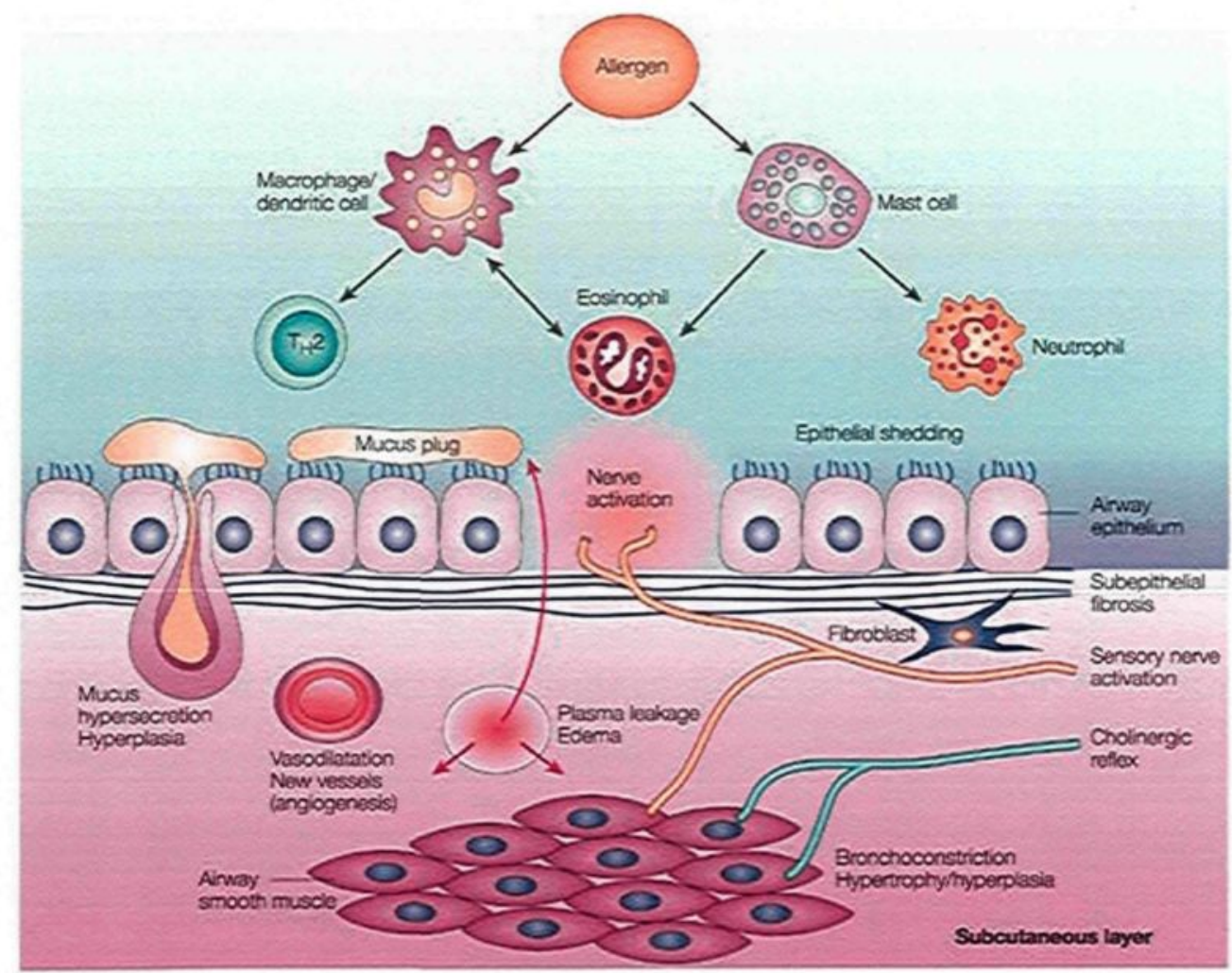

Nature Reviews | Drug Discovery

Figure 1. Physiopathologie de l'asthme: Plusieurs cellules inflammatoires sont recrutées et / ou activées dans les poumons et libèrent une variété de médiateurs inflammatoires qui ont un effet important dans les voies respiratoires (comme l'exsudation de plasma, la vasodilatation, la sécrétion de mucus, l'activation du réflexe cholinergique induisant la bronchoconstriction). Des changements structuraux (remodelage) sont ensuite observés, incluant une fibrose sub-épithéliale, une augmentation du nombre de vaisseaux sanguins et de cellules sécrétant du mucus, et l'épaississement du muscle lisse en raison de l'hyperplasie et l'hypertrophie. Adapté de Barnes, P.J. (2004) " New drugs for asthma." Nature Reviews Drug Discovery 3, $831-844$ 


\subsubsection{Principaux types cellulaires impliqués dans l'inflammation chez l'asthmatique}

Les sous-sections suivantes résument brièvement les principales fonctions des différents types cellulaires impliqués dans la physiopathologie de l'asthme. L'ordre de présentation n'a pas de lien avec la priorité des implications des différentes cellules dans l'asthme. Cependant, puisque le macrophage est la cellule centrale de ce mémoire, une attention particulière lui sera portée.

\subsubsection{Les cellules dendritiques $(C D)$}

Les cellules dendritiques (CD) sont présentes dans divers tissus et jouent un rôle clé dans l'initiation de la réponse allergique. Ils font partie de la famille des cellules présentatrices d'antigène (CPA) et forment, au niveau de la muqueuse bronchique, un réseau très dense de cellules capables de capturer les antigènes inhalés et de les présenter aux lymphocytes T, via le complexe majeur d'histocompatibilité de classe II (CMH II) (Kidd 2003). Elles induisent la prolifération des lymphocytes $T$ ainsi que leur différentiation en Th1 et Th2 (Shurin et al. 1999). En effet, il a été démontré que les CD peuvent subir une polarisation selon le «cocktail» de médiateurs présents dans le milieu (libérés par les fibroblastes, les macrophages et les cellules épithéliales) (Kidd 2003). Un milieu riche en interféron-gamma (IFN- $\gamma$ ) favorise la polarisation des CD en CD1, induisant une réponse de type Th1 tandis qu'une élévation de la concentration de prostaglandines E2 (PGE2) induit leur différentiation en $\mathrm{CD} 2$ et donc une réponse de type Th2 (Moser et al. 2000). 


\subsubsection{Les mastocytes}

Les mastocytes sont des CPA. Par contre, leur rôle le plus important est d'être activés par les allergènes dans les voies respiratoires par le biais de leurs récepteurs de haute affinité aux IgE (FCeRI) (Bradding et al. 2006). L'activation des mastocytes provoque le relâchement de différents bronchoconstricteurs tels que l'histamine, les prostaglandines et les leucotriènes, mais aussi de différentes cytokines, telles que 1'interleukine (IL)-5 et le facteur nécrosant des tumeurs-alpha (TNF- $\alpha$ ) qui sont deux facteurs de différentiation des éosinophiles (Bradding, Walls et al. 2006). Ensemble, ils contribuent à augmenter la réaction inflammatoire ainsi que l'hyperréactivité bronchique (Brightling et al. 2002). Finalement, les mastocytes produisent de la tryptase qui, tout comme l'histamine, favorise la croissance des fibroblastes de même que leur production de collagène. Ce qui suggère une implication indirecte des mastocytes dans le processus de remodelage spécifique à l'asthme (Bradding, Walls et al. 2006).

\subsubsection{Les lymphocytes}

Les lymphocytes $\mathrm{T}$ auxiliaires sont d'importants régulateurs de la réponse immunitaire. Il en existe trois sous-populations caractérisées par un profil de cytokines différents soit les lymphocytes de type Th1, Th2 et Th17 (Bernstein 2008; Kaiko et al. 2008). En effet, les lymphocytes Th1 participent aux développement de la réaction d'hypersensibilité retardée et se caractérise par une production prédominante d'IFN- $\gamma$, mais aussi de TNF- $\alpha$, d'interleukine (IL)-2 et d'IL-18 (Tillie-Leblond et al. 2004; Ngoc et al. 2005). Les lymphocytes Th1 sont impliquées dans la lutte contre les pathogènes intracellulaires et les cellules cancéreuses. Ils sont également à l'origine des maladies autoimmunes (Kidd 2003). Les lymphocytes Th17, identifiés récemment, sécrètent de 1'IL-17, de l'IL-17F, de l'IL-6, de l'IL-22 et du TNF- $\alpha$, et participent à la défense de l'hôte contre des pathogènes extracellulaires en agissant autant sur les cellules immunitaires comme les macrophages que non immunitaires, comme les fibroblastes et les cellules endothéliales et 
épithéliales (Kaiko, Horvat et al. 2008; Louten et al. 2009). Les cellules ainsi activées sécrètent différents médiateurs permettant le recrutement des neutrophiles et le maintien de l'inflammation dans les tissus (Kaiko, Horvat et al. 2008; Louten, Boniface et al. 2009). Les lymphocytes Th17 sont aussi impliqués dans les maladies autoimmunes.

Les lymphocytes Th2 sécrètent principalement l'IL-4 et l'IL-13, cytokines nécessaires à l'activation de la production d'anticorps de type IgE par les lymphocytes $\mathrm{B}$, et sécrètent aussi l'IL-5, responsable de la différentiation, l'activation et l'augmentation de la survie des éosinophiles (Sampson 2000; Ngoc, Gold et al. 2005; Nakajima et al. 2007). Les lymphocytes Th2 sont particulièrement impliqués dans la protection contre les pathogènes extracellulaires (Kidd 2003; Nakajima and Takatsu 2007). Il a été observé que les cytokines produites par la voie Th1 inhibent les fonctions de la voie Th2 et vice-versa (Kidd 2003). De façon générale, il est documenté qu'un débalancement vers la réponse immunitaire de type Th2 soit à l'origine du développement des maladies allergiques telles que l'asthme. Les mécanismes sous-jacents à cette orientation Th2 demeurent hypothétiques. Certains auteurs proposent un possible dérèglement des gènes contrôlant la production d'IL-4, IL-9 et d'IL-13, mais aussi d'IL-12 et d'IL-18 (Yokoe et al. 2001). D'autres suggèrent plutôt une réponse mixte Th1/Th2 pour expliquer la pathogénèse de l'asthme (Busse and Lemanske 2001; Heaton et al. 2005) qui se base sur un déséquilibre de la balance entre les deux groupes de cytokines spécifiques aux sous-types de lymphocytes $\mathrm{T}$.

\subsubsection{Les éosinophiles}

Les éosinophiles migrent à partir de la moelle osseuse jusqu'aux voies respiratoires sous l'influence de molécules attractantes et de cytokines tels que l'IL-5 et le TNF- $\alpha$. Ils génèrent aussi des leucotriènes (Sampson 2000) et expriment une grande variété de cytokines pro-inflammatoires telles que 1'IL-4, l'IL-5, l'IL-12, l'IL-13, le TNF- $\alpha$, l'IFN- $\gamma$ 
et le Granulocyte-macrophage-colony stimulating factor (GM-CSF), des chimiokines comme les Monocyte chemoattractant proteins (MCP)-1, MCP-3, MCP-4 et RANTE, ainsi que différents facteurs de croissance tels que le Transforming growth factor (TGF- $\alpha$ ) et le TGF- $\beta$ (Lacy et al. 1997; Hogan et al. 2008). La quantité de médiateurs sécrétés par les éosinophiles est cependant moins grande que celle des lymphocytes T. Toutefois, ils entreposent leurs médiateurs dans des vésicules intracellulaires qui sont libérées lors de leur activation (Lacy et al. 2000). La sécrétion se fait donc plus rapidement (entre 60 et 120 min.) contrairement à plusieurs heures chez les lymphocytes T (Lacy and Moqbel 1997).

Les éosinophiles rejettent aussi, lorsqu'ils sont activés, des protéines basiques qui causent des dommages à l'épithélium des voies respiratoires, ce qui contribuent à l'hyperréactivité bronchique (Lemanske and Busse 2003; Hogan, Rosenberg et al. 2008). De plus, une augmentation du nombre d'éosinophiles dans le tissu bronchique a été observée chez la plupart des sujets asthmatiques allergiques (Sampson 2000; Williams 2004; Wenzel 2006).

\subsubsection{Les macrophages}

Les macrophages jouent un rôle primordial dans la défense de l'hôte (Chaplin 2003). Ils dérivent de précurseurs sanguins appelés monocytes qui, eux-mêmes, proviennent des cellules souches myéloïdes. Les monocytes provenant de la moelle osseuse sont des cellules circulantes indifférenciées. Lorsque ceux-ci quittent la circulation et rejoignent un tissus extravasculaire, ils se différencient en macrophages de différents types, tout dépendant du tissu cible (Fujiwara et al. 2005). Dans l'inflammation, les macrophages ont trois grandes fonctions: la phagocytose, la présentation antigénique et l'immunomodulation (Fujiwara and Kobayashi 2005; Xia et al. 2006). Les macrophages 
sont considérés comme les principales cellules infiltrées répondant aux infections de corps étrangés dans les tissus (Solheim et al. 2000; Xia and Triffitt 2006).

\subsection{Les récepteurs de reconnaissance du non-soi}

Les macrophages expriment une grande quantité de récepteurs membranaires capables de reconnaître toutes les classes de macromolécules. Ce sont des récepteurs de reconnaissance vis-à-vis des PAMPs (pathogen associated molecular patterns) lesquels représentent des motifs moléculaires hautement conservés provenant de nombreux microorganismes pathogènes (Kopp et al. 1999). Parmi ces récepteurs de l'immunité innée figurent les Toll-like récepteurs (TLR), les Scavenger receptors (SR) et les mannoses receptor (MR) (Xia and Triffitt 2006). Les TLR sont responsables de la reconnaissance des antigènes bactériens, viraux ou fongiques, mais aussi de cellules apoptotiques, des Heat shock proteins (HSP) et du fribrinogène (Gordon 2002). Les SR, quant à eux, sont principalement responsables de la reconnaissance des cellules apoptotiques (Peiser et al. 2002). Ils sont aussi impliqués dans la reconnaissance, la liaison et la phagocytose de particules environnementales par les macrophages alvéolaires sans le bénéfice de l'opsonization par des anticorps spécifiques (Palecanda et al. 2001). Finalement, les MR sont impliqués dans la reconnaissance de différents pathogènes bactériens et viraux, mais aussi dans l'ingestion de particules endogènes. De ce fait, certaines études tentent à prouver qu'ils seraient impliqués dans le nettoyage des molécules inflammatoires aux sites inflammés (Zamze et al. 2002).

\subsection{La phagocytose}

La capacité des macrophages à internaliser des matières exogènes détectées via ses récepteurs par phagocytose en fait un élément essentiel du système de défense immunitaire. En effet, la phagocytose est le mécanisme d'internalisation utilisé par les cellules 
spécialisées du système immunitaire appelées "phagocytes professionnels" qui servent à internaliser et dégrader des microorganismes, des débris cellulaires ou des particules diverses (Aderem 2003). La dégradation permet l'élimination de la particule internalisée, ainsi que la présentation d'antigènes dérivés et la sécrétion de cytokines qui participent à l'activation du système immunitaire (Fujiwara and Kobayashi 2005).

\subsection{La présentation antigénique}

Après avoir digéré un pathogène par phagocytose, le macrophage peut se comporter en CPA, c'est-à-dire présenter un antigène de manière à stimuler un lymphocyte $T$ spécifique. La stimulation lymphocytaire par un macrophage est moindre que celle induite par une cellule dendritique, mais les macrophages sont capables de présenter des antigènes associés aux molécules du CMH de type II, et donc de stimuler des lymphocytes CD4+. Ils participent donc à l'immunité innée en tant que défense non-spécifique, mais sont capables de participer à l'immunité adaptative via l'activation des lymphocytes $\mathrm{T}$ et $\mathrm{B}$ effecteurs (Gordon 2002).

\subsection{L'immunomodulation}

Les macrophages participent activement à la réponse inflammatoire en relâchant des cytokines, chimiokines et facteurs de croissance qui participent au recrutement d'autres cellules aux sites d'infection (Fujiwara and Kobayashi 2005). De plus, les macrophages activés expriment une variété de gènes responsables de la synthèse de $\mathrm{ROS}\left(\mathrm{NO}, \mathrm{O}_{2-}, \mathrm{H}_{2} \mathrm{O}_{2}\right.$ and peroxynitrite) de leukotriènes et de prostaglandines. Tous ces médiateurs contribuent à la régulation de la réponse immunitaire (Bosca et al. 2005). 


\subsubsection{Le macrophage alvéolaire}

Les macrophages alvéolaires (MA) constituent l'une des quatre sous-populations de macrophages présent dans les poumons avec les macrophages interstitiel, les macrophage intravasculaires et les cellules dendritiques (Lohmann-Matthes et al. 1994). Les MA se concentrent dans la mince couche de liquide alvéolaire, ce qui en fait les seuls macrophages à être en contact direct avec le milieu extérieur (Jonsson et al. 1986). Les MA ne sont pas considérés comme des bonnes CPA comparativement aux autres types de macrophages. Cependant, ses capacités phagocytaires et microbicides sont bien développées (Jaffar et al. 1999; Balbo et al. 2001). Étant considérés comme la première barrière immunologique, les MA ont des fonctions de contrôle de l'homéostasie immune (Kraal et al. 1997). En fait, les MA produisent une multitude de cytokines. Thl, Th2, pro-inflammatoires, antiinflammatoires, chimiokines et facteurs de croissance (tableau I) (Kelley 1990; PetersGolden 2004). Par le type de cytokines qu'elles vont produire, ces cellules peuvent considérablement moduler la réponse immunitaire. Par exemple, la phagocytose d'une cellule apoptotique par les MA induit une réponse anti-inflammatoire, alors que la phagocytose de virus ou de bactérie déclenche une réponse pro-inflammatoire (Savill et al. 1989; Kraal, Broug et al. 1997). Chez l'asthmatique, le profil de production des cytokines par les MA diffère des sujets normaux. En effet, plus de cytokines de type Th2 et de type pro-inflammatoires sont produites (Kelley 1990). 
Tableau I. Médiateurs inflammatoires sécrétés par le macrophage alvéolaire

\begin{tabular}{|l|l|}
\hline Cytokines & $\begin{array}{l}\text { IL-12, IL-18, IFN- } \gamma \\
\text { IL-1, IL-4, IL-6, IL-10, IL-13, TNF- } \alpha\end{array}$ \\
\hline Chimiokines & IL-8, MCP-1, MIP-1 $\alpha / \beta$ \\
\hline Facteurs de croissance & PDGF, VEGF, FGF \\
\hline Médiateurs lipidiques & $\mathrm{PGE}_{2}, \mathrm{PGD}_{2}, \mathrm{LTB}_{4}, \mathrm{LXA} 4$ \\
\hline ROS & $\mathrm{H}_{2} \mathrm{O}_{2}, \mathrm{OH}, \mathrm{O}_{2}, \mathrm{NO}, \mathrm{CO}$ \\
\hline
\end{tabular}

De plus, les MA des sujets atteints d'asthme sont de meilleurs présentateurs $\mathrm{d}$ 'antigènes, tandis qu'elles sont de moins bonnes cellules phagocytaires, ce qui suggère une modification des fonctions des MA chez les sujets asthmatiques ou en d'autres termes, un phénotype particulier (Burastero et al. 1999; Alexis et al. 2001). Les MA sont également aptes à diminuer la réponse immunitaire acquise par leur effet inhibiteur sur la capacité des cellules dendritiques à présenter l'antigène ainsi qu'une inhibition plus générale de la voie Th2 (Thepen et al. 1991; Holt et al. 1993). De plus, une étude a mis en évidence le fait que les MA pourraient se subdiviser en différentes sous-populations, pouvant induire une polarisation des lymphocytes en cellules Th1 et Th2 (Mills et al. 2000; Sirois et al. 2001). En effet, la différentiation des cellules $\mathrm{T}$ naïves en cellules Th1 ou Th2 étant dépendante des cytokines se trouvant dans le milieu (Thepen et al. 1989; Thepen, McMenamin et al. 1991), l'aptitude des MA à sécréter certaines cytokines de type Thl, Th2, chimiokines et facteurs de croissance (Kelley 1990; Peters-Golden 2004), pourrait être à la source de leur capacité à induire la polarisation des cellules T naïves. De plus, il a été démontré que des MA provenant de lignées de rat susceptibles et résistants à l'allergie sécrétent un profil de cytokines différent (Sirois et Bissonnette 2001). Une deuxième étude réalisée à partir de ces mêmes lignées a également mis en évidence le fait que les MA pourraient être à l'origine 
d'un transfert de la résistance à l'allergie dans des cas d'hyperréactivité bronchique (Careau et al. 2004).

Enfin, il a également été démontré que les MA des patients asthmatiques possèdent une capacité accrue de générer des ROS comparativement aux sujets normaux (Bissonnette 2000). En plus d'être considérés comme cytotoxiques pour les fibroblastes (LohmannMatthes, Steinmuller et al. 1994), les ROS jouent un rôle essentiel dans l'activation du nuclear factor $\kappa-B(\mathrm{NF} \kappa-\mathrm{B})$, un important facteur de transcription impliqué dans la réponse inflammatoire de l'asthme (Bissonnette 2000).

\subsection{Principaux symptômes de l'asthme}

Chez les asthmatiques, des facteurs déclenchant engendrent une "hyperréactivité bronchique". Cette hyperréactivité se traduit par une contraction des voies aériennes (la bronchoconstriction), ce qui provoque un rétrécissement de la lumière de ces voies et qui rend plus difficile le passage de l'air. De plus, la paroi interne des bronches va s'enflammer et subir des changements structurels appelés le remodelage (Bernstein 2008). Ce sont ces réactions qui causent la crise d'asthme. Les sous-sections suivantes résument ces principaux symptômes qui sont observés chez les asthmatiques dans les périodes de crise.

\subsubsection{L'hyperréactivité bronchique}

L'hyperréactivité bronchique est un des symptômes majeurs de l'asthme faisant partie intégrante de sa définition. Elle se traduit par la capacité qu'ont les bronches des personnes asthmatiques à réagir plus précocement et plus fortement lorsqu'elles sont stimulées (Report 2007). La manifestation la plus importante de cette réaction est une diminution du calibre des voies aériennes qui peut être aisément mesurée au laboratoire par le test de provocation à la méthacholine. Plusieurs facteurs contribuent à l'hyperréactivité bronchique 
observée chez les asthmatiques: la présence de polymorphisme génétiques, l'inflammation, les modifications architecturales du tissu bronchique incluant l'œdème, l'hypertrophie du muscle lisse et les dépôts de collagène, en plus de l'âge et du moment de la journée (Lemanske and Busse 2003).

\subsubsection{La bronchoconstriction}

La bronchoconstriction, l'une des caractéristiques principales de l'asthme, peut être causée par différents évènements. Premièrement, le phénomène de bronchoconstriction survient, chez les personnes souffrant d'asthme, en réponse à une exposition à différents stimuli comme des allergènes ou des irritants (Lemanske and Busse 2003). En effet, en période d'exacerbation, le muscle lisse bronchique se contracte et une diminution significative du diamètre des bronches est observée. L'air passe donc plus difficilement. La bronchoconstriction peut être le résultat de l'activation des mastocytes par les IgE qui relâchent différents médiateurs comme l'histamine, les leukotriènes et les prostaglandines, qui contribuent directement à la contraction du muscle lisse (Busse and Lemanske 2001). Par contre, d'autres stimuli tels que l'exposition à l'air froid, l'exercice physique et la prise de certains médicaments comme l'aspirine peuvent provoquer le phénomène de bronchochonstriction. Le mécanisme responsable de la réponse à ces facteurs environnementaux n'est pas encore complètement documenté. Cependant, selon la littérature, la génération de cytokines pro-inflammatoires représente l'avenue la plus intéressante pour expliquer ce mécanisme (Stevenson et al. 2006).

\subsubsection{Le remodelage}

Malgré le traitement anti-inflammatoire à base de corticostéroïdes, entre 5 et $10 \%$ (selon les pays) de patients asthmatiques présentent un déclin progressif et irréversible de 
leur fonction respiratoire (Lange et al. 1998). Cette dépression de la fonction respiratoire, additionnée d'une obstruction bronchique irréversible, est responsable d'une insuffisance respiratoire chronique et d'un handicap fonctionnel parfois sévère. Ce sont ces cas qui sont à l'origine de la plus grande partie des coûts liés à l'asthme (Vignola et al. 2003). De manière succincte, la survenue de ces altérations fonctionnelles respiratoires serait la conséquence d'un épaississement progressif de la paroi bronchique dû à un processus de remodelage tissulaire (Vignola, Mirabella et al. 2003). Le remodelage est caractérisé par une hypertrophie et une hyperplasie du muscle lisse, une hypertrophie des cellules glandulaires associée à une hypersécrétion de mucus et à une fragmentation des fibres d'élastine du tissu conjonctif (Barnes 2000; Bousquet et al. 2000). Par ailleurs, chez les asthmatiques, un défaut d'élimination des éosinophiles par apoptose occasionne leur accumulation incontrôlée et leur persistance dans les voies aériennes, ce qui contribue au maintien de l'inflammation chronique et des lésions tissulaires (Bousquet, Jeffery et al. 2000).

\subsection{Prévention et soulagement des symptômes de l'asthme}

Bien que l'asthme soit une affection incurable, différents traitements sont disponibles pour son contrôle. Selon la sévérité des symptômes, les lignes directrices internationales recommandent l'utilisation d'anti-inflammatoires comme médication de base pour contrôler l'inflammation des voies aériennes : les glucocorticoïdes ou corticostérö̈des (GC). Ils sont considérés comme un traitement préventif et sont efficaces pour contrôler l'inflammation des bronches, améliorer la fonction pulmonaire, réduire les symptômes respiratoires liés à l'asthme, diminuer les hospitalisations et les risques de décès (Olivieri et al. 1997; Suissa et al. 2000; Busse et al. 2001). D'autres traitements anti-inflammatoires sont présentement disponibles comme par exemple les antagonistes des récepteurs aux leukotriènes (LTRA) et les immunomodulateurs (anticorps anti-IgE). Ils sont cependant considérés secondaires comparativement aux GC (Report 2007). En plus du traitement 
préventif, les patients souffrant d'asthme doivent posséder une médication de secours, soit un agoniste des récepteurs $\beta_{2}$-adrénergiques de courte durée d'action (SABA), ceux-ci permettant de contrôler les crise aigues et les bronchospasmes (Bateman et al. 2008). Les agonistes des récepteurs $\beta_{2}$-adrénergiques de longue durée d'action (LABA) sont quant à eux utilisés dans des cas d'asthme plus sévère (Report 2007; Bateman, Hurd et al. 2008). Le tableau II résume les principaux médicaments disponibles pour traiter l'asthme. Leurs mécanismes d'action ainsi que les effets secondaires les plus souvent observés sont aussi présentés. 


\subsubsection{Médication disponible}

Tableau II. Mécanismes d'action et effets secondaire potentiels de la médication actuellement disponible pour traiter l'asthme

\begin{tabular}{|c|c|c|}
\hline Nom du produit & $\begin{array}{c}\text { Indications et } \\
\text { Mécanismes d'action }\end{array}$ & $\begin{array}{c}\text { Effets secondaires } \\
\text { potentiels }\end{array}$ \\
\hline \multicolumn{3}{|c|}{ Corticostéroïdes (Glucocorticoides) } \\
\hline $\begin{array}{l}\text { inhalés (ICS) : } \\
\text { Fluticasone propionate } \\
\text { (FLOVENT®) } \\
\text { Budésonide } \\
\text { (PULMICORT®) }\end{array}$ & $\begin{array}{l}\text { Indications } \\
\text { - Prévention à long-terme } \\
\text { des symptômes; suppression } \\
\text { et contrôle de } \\
\text { l'inflammation }[1,2] \\
\text { - Réduit le besoin d'une } \\
\text { corticothérapie orale [2] } \\
\\
\text { Mécanismes d'action } \\
\text { - Anti-inflammatoire : } \\
\text { Contrôle l'expression de } \\
\text { gènes spécifique à } \\
\text { l'inflammation (bloque } \\
\text { l'activation de NFkB, } \downarrow \\
\text { iNOS, } \downarrow \text { COX2)[3, } 4 \text { ] } \\
\text { - Inhibe la synthèse de } \\
\text { cytokines (IL-1, IL-6, IL-11, } \\
\text { TNF- } \alpha \text { etc) et des molécules } \\
\text { d'adhésion (ICAM-1, } \\
\text { VCAM-1)[3] }\end{array}$ & $\begin{array}{l}\text { - Toux, dysphonie, muguet } \\
\text { (candidiasis) } \\
\text { - À fortes doses : Des } \\
\text { effets systémiques sont } \\
\text { possible; ostéoporose, } \\
\text { amincissement de la peau et } \\
\text { ecchymoses [4, 6] } \\
\\
\text { doses : Une suppression de } \\
\text { la vitesse de croissance peut } \\
\text { être observée chez l'enfant, } \\
\text { mais cet effet est } \\
\text { probablement transitoire [4, } \\
6,7]\end{array}$ \\
\hline
\end{tabular}




\begin{tabular}{|c|c|c|}
\hline & $\begin{array}{l}\text { - Inhibe l'activation et la } \\
\text { migration des cellules } \\
\text { inflammatoires[3] }\end{array}$ & \\
\hline $\begin{array}{l}\text { Oraux: } \\
\text { Methylprednisolone } \\
\text { (MEDROL®) } \\
\text { Prednisolone } \\
\text { (DEXAMETHASONE®) }\end{array}$ & $\begin{array}{l}\text { Indications } \\
\text { - Courte période (3 à } \mathbf{1 0} \\
\text { jours) : Obtention rapide du } \\
\text { contrôle d'un asthme } \\
\text { incontrôlé }[3,5] \\
\text { - Longue période : } \\
\text { Prévention des symptômes } \\
\text { d'asthme sévère : } \\
\text { suppression et contrôle de } \\
\text { 1'inflammation [3, 5] } \\
\text { Mécanismes d'action } \\
\text { - Mêmes qu'inhalés }\end{array}$ & $\begin{array}{l}\text { - Courte période : } \\
\text { Anomalies de la glycémie, } \\
\text { augmentation de l'appétit, } \\
\text { rétention liquidienne, gain } \\
\text { de poids, troubles de } \\
\text { l'humeur, hypertension et } \\
\text { ulcère gastro-duodénal [8] } \\
\text { - Longue période : } \\
\text { suppression de la croissance, } \\
\text { amincissement cutané, } \\
\text { hypertension, diabète, } \\
\text { syndrome de Cushing, } \\
\text { faiblesse musculaire, et, } \\
\text { dans de rares cas, altération } \\
\text { de la fonction immunitaire } \\
\text { [4, 8] }\end{array}$ \\
\hline \multicolumn{3}{|c|}{$\begin{array}{l}\text { Agonistes des récepteurs } \beta_{2} \text {-adrénergiques de longue durée d'action } \\
\qquad(\mathrm{LABA})\end{array}$} \\
\hline $\begin{array}{l}\text { Salmétérol } \\
\text { (SEREVENT®) }\end{array}$ & $\begin{array}{l}\text { Indications } \\
\text { - Prévention à long-terme } \\
\text { des symptômes de l'asthme } \\
\text { en conjugaison avec un ICS } \\
\text { [9] } \\
\text { - Prévention des Exercise- } \\
\text { induced bronchoconstriction } \\
\text { (EIB) [4] }\end{array}$ & $\begin{array}{l}\text { - Tremblement des } \\
\text { extrémités, crampes } \\
\text { musculaires, hypokaliémie } \\
\text { et tachycardie à fortes doses } \\
{[10]}\end{array}$ \\
\hline
\end{tabular}




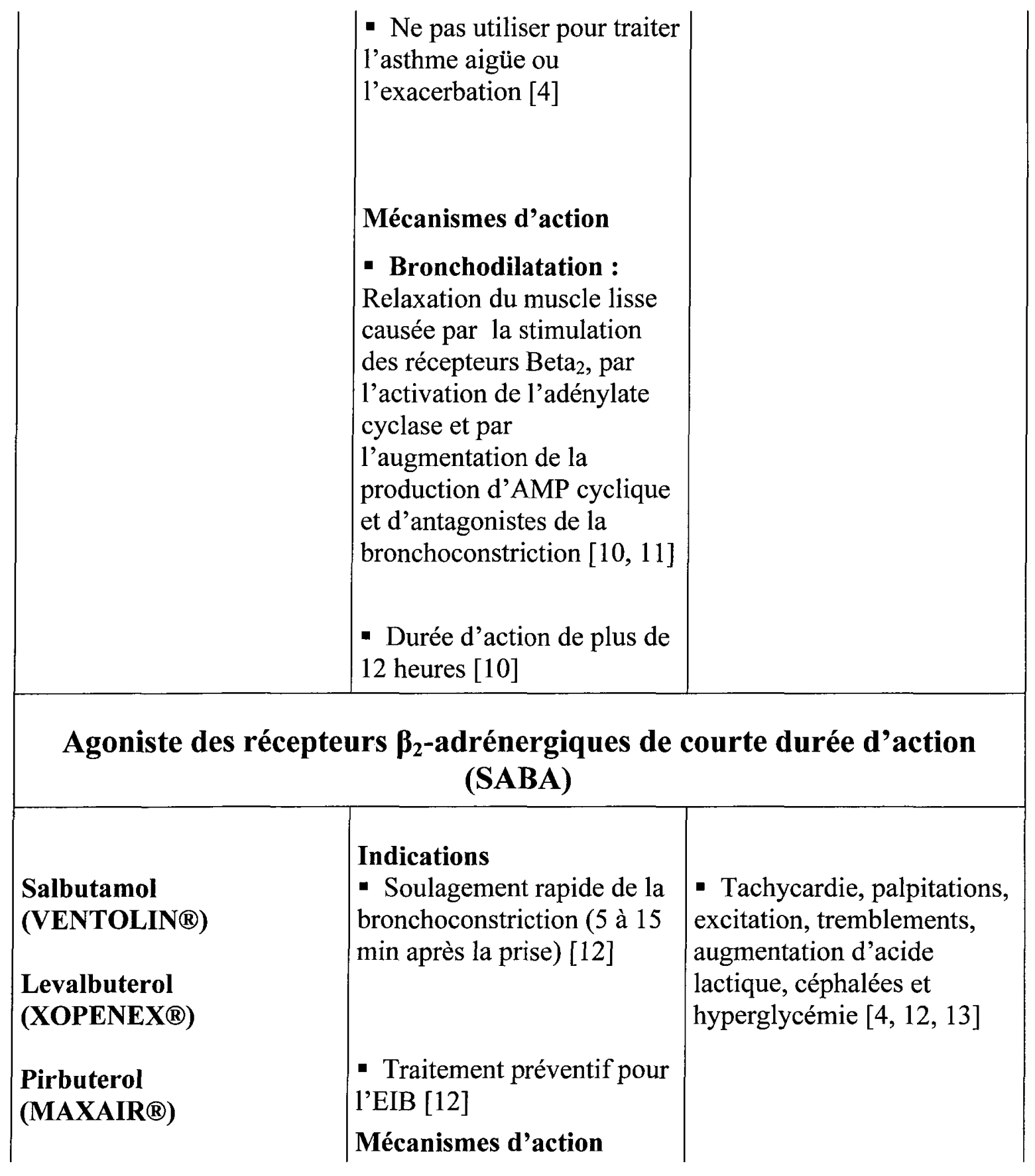




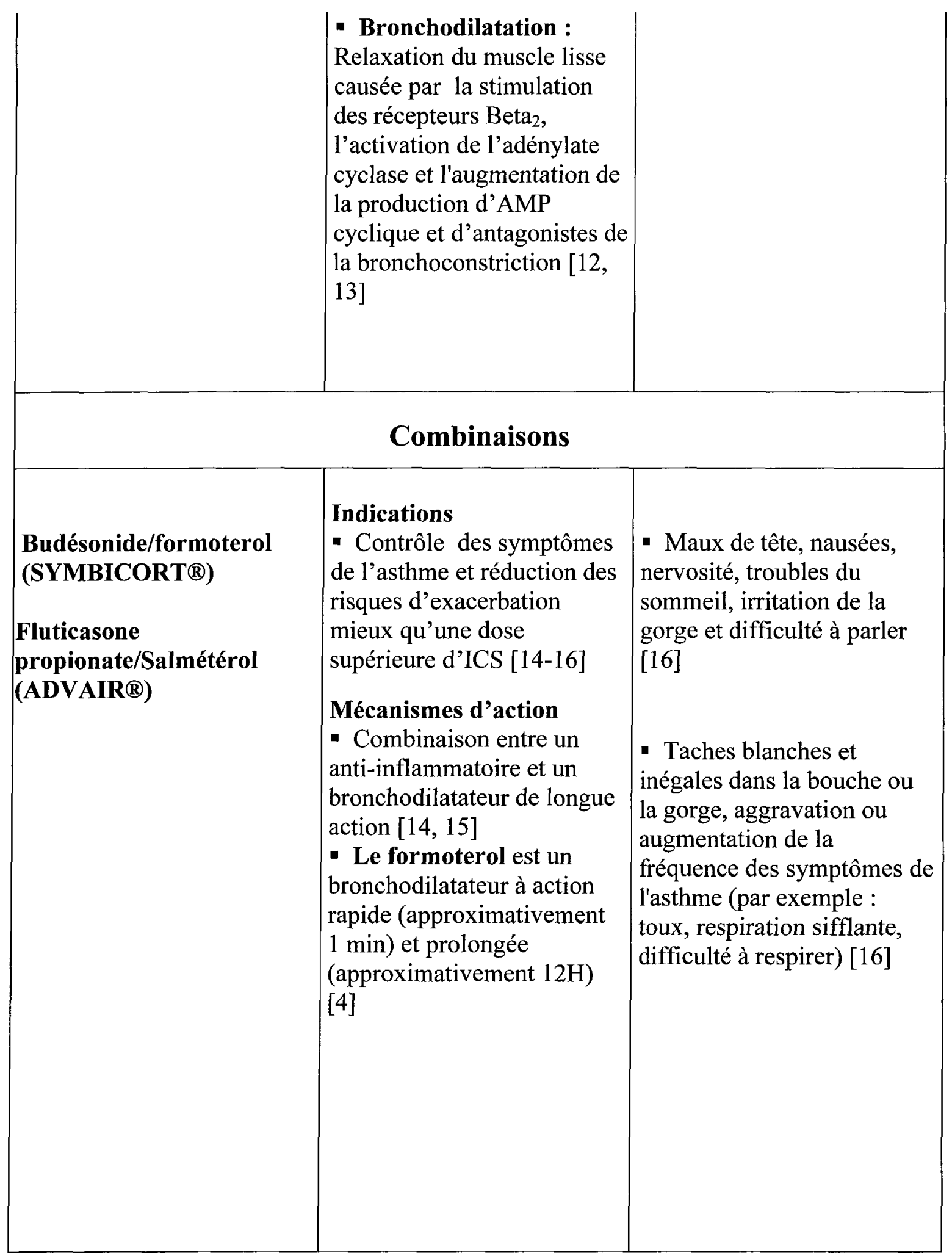




\begin{tabular}{|c|c|c|}
\hline \multicolumn{3}{|c|}{ Antagonistes des récepteurs aux leukotriènes (LTRA) } \\
\hline $\begin{array}{l}\text { Montelukast } \\
\text { (SINGULAIR }{ }^{\circledR} \text { ) }\end{array}$ & $\begin{array}{l}\text { Indications } \\
\text { - Traitement préventif de } \\
\text { l'asthme en association avec } \\
\text { des corticoïdes ou des } \\
\text { bronchodilatateurs bêta2 } \\
\text { mimétiques }[17,18] \\
\text { - Utilisé dans l'asthme } \\
\text { induit par l'effort [18] } \\
\text { Mécanismes d'action } \\
\text { - Inhibiteur compétitif et } \\
\text { sélectif des récepteurs } \\
\text { CysLT }_{1}[17,18]\end{array}$ & $\begin{array}{l}\text { - Céphalées, syndrome } \\
\text { grippal, douleurs } \\
\text { abdominales et toux }[18,19]\end{array}$ \\
\hline \multicolumn{3}{|c|}{ Inhibiteurs de la 5-Lipoxygénase } \\
\hline Zileuton (ZYFLO®) & $\begin{array}{l}\text { Indications } \\
\text { - Prévention à long terme } \\
\text { des symptômes de l'asthme } \\
\text { léger [20,21] } \\
\\
\text { - En combinaison avec des } \\
\text { ICS, peu prévenir les } \\
\text { sympômes de l'asthme } \\
\text { modéré [22] } \\
\text { Mécanismes d'action } \\
\text { - Inhibe la production des } \\
\text { leukotriènes (LTB4 et } \\
\text { cystéinyl) à partir de l'acide } \\
\text { arachidonique [4, 21] }\end{array}$ & $\begin{array}{l}\text { - Élévation du niveau } \\
\text { d'enzymes du foie, certains } \\
\text { cas d'hépatite et } \\
\text { d'hyperbilirubinémie [21, } \\
22]\end{array}$ \\
\hline
\end{tabular}




\begin{tabular}{|c|c|c|}
\hline \multicolumn{3}{|c|}{ Immunomodulateurs } \\
\hline $\begin{array}{l}\text { Omalizumab (anti-IgE) } \\
\text { (XOLAIR } ®)\end{array}$ & $\begin{array}{l}\text { Indications } \\
\text { - (Usage sous-cutané) } \\
\text { Améliore le contrôle de } \\
\text { l'asthme allergique } \\
\text { persistant sévère si } \\
\text { incontrôlé par ICS [4, 23] } \\
\\
\text { Mécanismes d'action } \\
\text { - IgG monoclonales se liant } \\
\text { aux IgE prévenant ainsi leur } \\
\text { liaison aux FcERI des } \\
\text { mastocytes [23] } \\
\text { - Diminue le relâchement } \\
\text { des médiateurs des } \\
\text { mastocytes après une } \\
\text { exposition à l'allergène [23] }\end{array}$ & $\begin{array}{l}\text { - Réaction au point } \\
\text { d'injection (douleur, } \\
\text { gonflement, irritation), } \\
\text { maux de tête, } \\
\text { étourdissements, } \\
\text { somnolence, paresthésies } \\
{[23,24]}\end{array}$ \\
\hline \multicolumn{3}{|c|}{ Mehylxanthines } \\
\hline $\begin{array}{l}\text { Théophylline } \\
\text { (UNIPHIL@) }\end{array}$ & $\begin{array}{l}\text { Indications } \\
\text { - Prévention à long-terme } \\
\text { des symptômes de l'asthme } \\
\text { léger ou en conjugaison } \\
\text { avec un ICS pour traiter } \\
\text { l'asthme modéré persistant } \\
{[4,25]} \\
\\
\text { Mécanismes d'action } \\
\text { - Bronchodilatation : } \\
\text { Relaxation du muscle lisse } \\
\text { causée par une inhibition de } \\
\text { la phosphodiestérase et d'un } \\
\text { antagoniste de l'adénosine } \\
\text { [25] }\end{array}$ & $\begin{array}{l}\text { - Toxicité dose-dépendante } \\
\text { provoquant : vomissements, } \\
\text { irritations gastriques, } \\
\text { nausées, céphalées } \\
\text { irritabilité, agitation, } \\
\text { insomnies et accélération du } \\
\text { rythme cardiaque [4] } \\
\text { - Traitement alternatif mais } \\
\text { peu recommandé [4] }\end{array}$ \\
\hline
\end{tabular}




$\left|\begin{array}{l}\text { - Peut affecter l'infiltration } \\ \text { des éosinophiles dans la } \\ \text { muqueuse bronchique et } \\ \text { diminuer le nombre de } \\ \text { lymphocytes-T dans } \\ \text { l'épithélium [25] } \\ \text { - Augmente la capacité de } \\ \text { contraction du diaphragme } \\ {[25]}\end{array}\right|$

1. Am Rev Respir Dis, 1993. 148(4 Pt 2): p. S1-26. 2. Am J Respir Crit Care Med, 1996. 153(6 Pt 1): p. 1739-48. 3. J Allergy Clin Immunol, 2003. 111(1): p. 3-22; quiz 23. 4. J Allergy Clin Immunol, 2007. 120(5 Suppl): p. S94-138. 5. Allergy Asthma Proc, 1996. 17(6): p. 341-50. 6. Thorax, 2004. 59(9): p. 761-8. 7. N Engl J Med, 2006. 354(19): p. 1985-97. 8. Pediatrics, 2003. 111(2): p. $376-83.9$. Cochrane Database Syst Rev, 2005(4): p. CD005533. 10. Am J Respir Crit Care Med, 2001. 164(6): p. 923-32. 11. Clin Pharmacokinet, 2002. 41(1): p. 19-30. 12. Am J Health Syst Pharm, 2006. 63(10 Suppl 3): p. S5-13. 13. Lancet, 2001. 357(9271): p. 1882; author reply 1882-3. 14. Chest, 2006. 129(2): p. 246-56. 15. Curr Med Res Opin, 2007. 23(11): p. 2887-95. 16. Drugs, 2009. 69(2): p. 137-50. 17. Am Fam Physician, 2007. 75(1): p. 65-70. 18. Expert Opin Pharmacother, 2007. 8(13): p. 2173-87. 19. Thorax, 2008. 63(5): p. 453-62. 20. Am J Respir Crit Care Med, 1998. 157(4 Pt 1): p. 1187-94. 21. Am J Manag Care, 1998. 4(6): p. 841-8. 22. Int J Clin Pract, 2007. 61(4): p. 663-76. 23. Rev Mal Respir, 2005. 22(6 Pt 1): p. 983-90. 24. Am J Respir Crit Care Med, 2004. 170(6): p. 583-93. 25. Respir Med, 2002. 96(6): p. 432-8.

\subsection{Asthme corticorésistant}

Selon Santé Canada, le succès de la prise en charge de l'asthme dépend entre autres de l'évitement ou du contrôle des facteurs déclenchant et de l'emploi individualisé des médicaments (agents de prévention et de secours) selon le mode correct d'administration. Cependant, pour une importante proportion, la thérapie ne donne pas les résultats escomptés. En effet, selon une étude effectué sur 10428 canadiens asthmatiques en 2008 , $59 \%$ des personnes consultées étaient incapables de contrôler leurs symptômes (Chapman et al. 2008). Plusieurs facteurs peuvent expliquer ces résultats. Le traitement prescrit peut être inadapté au patient (Legorreta et al. 1998), mal administré par le patient ou bien celuici n'adhère tout simplement pas à la thérapie (non compliance au traitement) (Williams et al. 2004). Cependant, il existe une proportion d'asthmatiques qui ne répondent simplement pas aux GC. Ils sont dit résistants aux GC. Dans l'asthme, cette résistance a d'abord été 
rapportée chez un groupe de patients asthmatiques porteurs d'un asthme mal contrôlé qui présentaient indiscutablement une réponse aux ß-agonistes inhalés et pourtant pas de réponse à de fortes doses de corticoïdes oraux (Schwartz et al. 1968). L'asthme corticorésistant apparait souvent à l'intérieur de cohortes de patients atteints d'un asthme sévère (Bumbacea et al. 2004). En effet, ces patients rapportent de fréquents épisodes d'attaques d'asthme ou souffrent de symptômes chroniques partiellement contrôlés par les corticoïdes systémiques.

\subsubsection{Définition de la corticoresistance et de la corticodépendance}

Ceux qui répondent bien au traitement sont dit sensibles aux $\mathrm{GC}$, c'est-à-dire que le volume expiratoire maximal en une seconde (VEMS) mesuré au cours d'un traitement de prednisolone pendant deux semaines augmente de $30 \%$ ou plus par rapport à la valeur de départ. Ceux dont l'amélioration du VEMS reste inférieure à $15 \%$ de la valeur de base sont classés comme résistants aux GC (Sher et al. 1994).

Cependant, il existe probablement des degrés variables de la résistance ou de la réponse aux GC. En effet, chez certains asthmatiques sévères un état de corticodépendance peut aussi être observé. Cet état nécessite l'usage journalier de fortes doses de médication pour contrôler les symptômes et toute tentative de réduire la dose de GC oraux ou inhalés entraîne une dégradation de l'asthme (Adcock et al. 2008). Les patients corticodépendants souffrent beaucoup des effets secondaires liés aux GC (Bumbacea, Campbell et al. 2004). Il a été rapporté que $25 \%$ des patients ayant un asthme difficile à contrôler ou un asthme sévère avaient en fait un asthme corticorésistant (Chan et al. 1998), tandis qu'une autre étude rapporte que jusqu'à $60 \%$ des patients d'une cohorte d'asthme sévère avaient un asthme corticodépendant (Robinson et al. 2003). 
En plus de l'asthme, la corticorésistance a été décrite dans d'autres conditions telles que la polyarthrite rhumatoïde (30 \%) (van Schaardenburg 1995) et les colites ulcérantes (Honda et al. 2000). Elle a aussi été mise en évidence chez $30 \%$ des sujets d'une étude effectuée sur des lymphocytes de volontaires sains, suggérant donc que la corticorésistance peut survenir indépendamment d'une affection et est plus commune que ce qui était affirmé auparavant (Hearing et al. 1999).

\subsubsection{Mécanismes d'action des corticostéroides}

Classiquement, les GC exercent leurs effets en se liant à des récepteurs aux glucocorticoïdes (GCR) présents dans le cytoplasme. Ces récepteurs possèdent plusieurs domaines fonctionnels dont un de liaison au ligand et un de liaison à l'ADN. Le GCR inactif est lié à un complexe protéique incluant deux sous-unités de HSP90 qui agissent comme une chaperone en empêchant le récepteur d'aller au noyau. Quand un ligand se lie à un GCR, HSP90 se dissocie, ce qui permet au complexe GCR-GC activé de se transloquer dans le noyau et de se lier en duplex à des séquences spécifiques d'ADN appelées élément de réponse aux glucocorticoïdes (GRE) (Adcock et al. 2001). Néanmoins, seuls quelques gènes inflammatoires sont directement régulés par les $\mathrm{GC}$ via la liaison avec l'ADN tandis qu'un bien plus grand nombre sont régulés de manière indirecte via une interaction avec d'autres facteurs de transcription soit le NF-kB ou l'activator protein-l (AP-1). Ils peuvent également supprimer l'inflammation en augmentant l'expression de protéines antiinflammatoires telles que l'annexine 1 (ANX1), l'IL-10 ou l'inhibiteur du facteur nucléaire kappa B, I-אB (Leung and Bloom 2003). 


\subsubsection{Mécanismes moléculaires de la corticorésistance}

Les mécanismes moléculaires responsables de la corticorésistance et de la corticodépendance chez les asthmatiques sont nombreux. En premier lieu, un défaut de liaison entre le GCR, son ligand et le GRE présent sur l'ADN a été rapporté (Kam et al. 1993). Le défaut de liaison peut être attribué à une surexpression des ARNm de l'IL-2 et de l'IL-4 dans les lavages broncho-alvéolaire (LBA) de patients avec un asthme corticorésistant. En fait, la combinaison d'IL-2 et d'IL-4 induit l'expression de l'isoforme négatif du GCR soit le GCR $\beta$, celui-ci étant incapable de se lier au GC et donc d'activer la transcription de gènes (Webster et al. 2001). De plus, le GCR $\beta$ a la capacité de transloquer dans le noyau sans activation avec le ligand, de se lier au GRE et d'inhiber l'activité du GCRa (Strickland et al. 2001). Deuxièmement, un défaut dans la stimulation de l'acétylation de l'histone $\mathrm{H} 4$ a également été rapporté chez les asthmatiques corticorésistants (Matthews et al. 2004). L'acétylation de l'histone 4 est une étape importante de la transcription puisqu'elle permet à l'ADN de s'ouvrir pour donner la possibilité aux facteurs de transcription d'agir avec leur site de liaison. Elle est contrôlée par les histones acétyltransférases et les histones désacétylases. Un déséquilibre de l'activité de ces enzymes pourrait être à la base de l'inflammation bronchique chez les asthmatiques puisqu'on retrouve une réduction de l'activité et de l'expression des histones désacétylases alors que celles des histones acétyltransférases sont augmentées dans les monocytes et les macrophages alvéolaires (Ito et al. 2002; Cosio et al. 2004). Il a aussi été démontré que la suppression des gènes inflammatoires est dépendante du recrutement de l'histone désacétylase 2 (HDAC2) au complexe transcriptionnel actif par le GCR. Ce défaut expliquerait l'incapacité des corticoïdes à avoir un effet anti-inflammatoire (Ito et al. 2000). Finalement, une altération de la localisation du GCR au noyau a été rapportée dans des cellules sanguines mononucléées périphériques provenant de patients porteurs d'un asthme corticodépendant. Ces altérations pourraient être dû aux changements de phosphorylation du GCR par les mitogen-activated protein (MAP) kinases (Matthews, Ito et al. 2004). 
En outre, les mécanismes sous-jacents à la corticorésistance dans l'asthme sont complexes et restent encore mal connus. Les raisons pour lesquelles les corticoïdes ne fonctionnent pas peuvent s'avérer différentes d'un patient à l'autre et plusieurs mécanismes peuvent contribuer à la corticorésistance chez un même individu. Toutefois, la compréhension de ces mécanismes ainsi que la recherche de nouveaux anti-inflammatoires pouvant remplacer les thérapies existantes, représente de nouvelles avenues en faveur des patients qui ne répondent pas de manière optimale aux GC.

\subsubsection{Nouvelles thérapies}

La communauté scientifique est très intéressée par le développement de nouveaux médicaments pour traiter l'asthme. Le besoin clinique et la taille du marché potentiel représentent un incitatif important. Les perspectives à court terme pour de nouveaux traitements de l'asthme sont cependant limitées. La plupart des activités de développement sont centrées sur la reformulation de molécules déjà disponibles dans des nouveaux dispositifs ou dans des combinaisons. Les progrès dans la compréhension de la physiopathologie de l'inflammation dans les voies respiratoires dans l'asthme ont toutefois révélé de nouvelles cibles pour le développement de médicaments. Le tableau III résume ces nouvelles cibles. 


\subsubsection{Les flavonoïdes}

Les flavonoïdes sont des composés phénoliques largement distribués dans le règne végétal. Ils sont présentement étudiés pour leur grande variété de propriétés cliniquement pertinentes. En effet, les composés phénoliques sont principalement reconnus pour leur importante activité antioxydante, laquelle est d'un intérêt général avec les récentes découvertes sur la prévention des cancers (Karakaya 2004). Certains possèdent également des propriétés anti-inflammatoires, anti-allergiques, hépatoprotecteurs, hypocholestérolémiants, diurétiques, antibactériens et antiviraux (Avila et al. 1994; Gerritsen et al. 1995). Ils agissent aussi parfois comme piégeurs de radicaux libres et comme inhibiteurs enzymatiques (Mora et al. 1990; Hodnick et al. 1994). Ces composés auraient donc un effet potentiellement modulateur sur les différentes fonctions du système immunitaire. Ils constituent donc des cibles intéressantes dans la recherche sur les maladies à caractères inflammatoires comme l'asthme. 


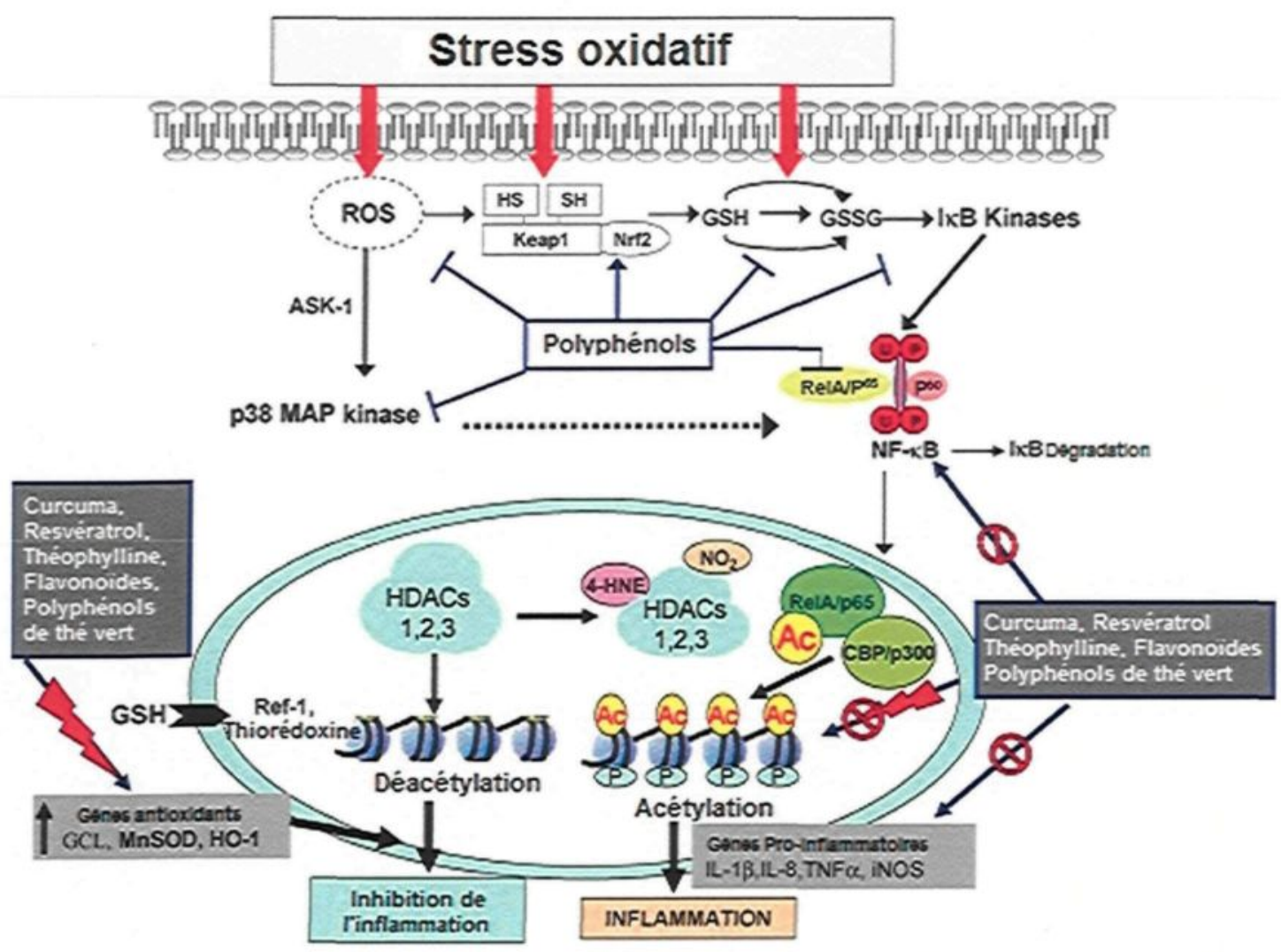

Figure 2. Modèle schématique de la modulation de la signalisation cellulaire par les polyphénols et les flavonoïdes. L'inflammation induite par le stress oxydatif est médié par l'activation de NF- $\mathrm{KB}$ et des MAP kinase et affecte ne grande variété de processus de signalisation cellulaires conduisant à la production de médiateurs de l'inf́lammation tel que I $\beta-1 b$, IL-8, TNF- $\alpha$ et iNOS ainsi qu'au remodelage de la chromatine. D'un autre coté, pour contrer les effets du stress oxydatif, les cellules expriment des gènes qui possèdent des effets antioxydant protecteur tels que GCL, MnSOD, HO-1. Les polyphénols et les flavonoïdes inhibent l'expression des gènes pro-inflammatoires par l'inhibition d'IkB, ce qui inhnibe la transactivation de NF- $\mathrm{BB}$, et par l'activation des histones déacétylase, en plus d'induirent l'expession de gènes antioxydant tel que GCL, MnSOD, HO-1 via la modulation de la voie des MAPK-ARE-Nrf2 .(Rahman, Biswas et al. 2006) 
Tableau III. Différents domaines de recherches pour le développement de nouvelles thérapies dans l'asthme

\section{Signalisation intracellulaire}

- Antagoniste des récepteurs muscariniques

- Antagoniste des récepteurs $\beta_{2}[1]$

- Nouveaux corticostéroïdes $[2,3]$

- Inhibiteurs des liaisons phosphodiester [4]

- Inhibiteurs de la lipoxygénase [5]

- Inhibiteurs de NFkB [6]

- Inhibiteurs de Syk kinase [6]

- Inhibiteurs de STAT-6 [6]

\section{Signalisation extracellulaire}

- Inhibiteurs des E-selectin, p-selectin, and L-selectin [7]

Inhibition de médiateurs inflammatoire

- Inhibiteurs des interleukines (IL-4, IL-5, IL-9, and IL-13) $[8,9]$

- Antagonistes des prostaglandines (D2, LTD4, LTC4, and TxA2) [5]

- Antagonistes de l'Adenosine, la neurokinine, l'histamine et la bradykinine [7]

\section{Présentation de l'antigène}

- Oligonucléotides immunomodulateurs [10]

- Inhibiteurs des cytokines Th2 $[8,11]$

- Antagonistes des récepteurs des chimioattractants sur les lymphocytes Th2 [7]

1. Drugs, 2007. 67(4): p. 503-15. 2. Mol Endocrinol, 1997. 11(9): p. 1245-55. 3. Proc Natl Acad Sci U S A, 2004. 101(1): p. 227-32. 4. Am J Respir Cell Mol Biol, 2003. 29(2): p. 163-71. 5. Prostaglandins Other Lipid Mediat, 2007. 83(3): p. 188-97. 6. Allergy, 2007. 62(6): p. 605-10. 7. Respir Care, 2008. 53(6): p. 688-96; discussion 696-8. 8. Curr Opin Investig Drugs, 2003. 4(11): p. 1320-6. 9. Lancet, 2000. 356(9248): p. 2144-8. 10. Am J Respir Crit Care Med, 2001. 163(4): p. 989-93. 11. Am J Respir Crit Care Med, 2006. 174(7): p. $753-62$. 


\section{Chapitre II: Hypothèses et Objectifs}

\subsection{Hypothèse générale du projet de recherche}

La nouvelle technologie des puces à ADN permet de caractériser le transcriptome de différents types cellulaires (Volet 1). Ainsi, il est possible d'étudier l'ensemble des cellules inflammatoires qui sont activées dans l'asthme. Elle permet aussi de faire des études comparatives entre des sujets atteints et des sujets témoins, afin de déterminer le patron d'expression relatif à une pathologie et de cibler des biomarqueurs, qui, une fois les études fonctionnelles faites, pourraient permettre de mieux définir l'histoire naturelle du trait. Ainsi, s'il est possible de définir un patron d'expression distinct dans un contexte étiologique précis (ici l'asthme) comparativement aux témoins (sans asthme ni allergies), il n'est pas faux de croire que l'étude comparative de ce patron d'expression puisse permettre d'identifier des biomarqueurs, de définir des mécanismes d'action ou de cibler des voies biologique potentiellement intéressante pour la découverte de nouvelles thérapies. C'est dans ce contexte qu'un composé d'origine naturelle, la querciméritrine, sélectionné sur la base des données recueillies par les peuples autochtones, qui pourrait avoir un potentiel modulateur sur la sécrétion de différents médiateurs tels que les cytokines ou les chimiokines a été ciblé pour le volet 2 de ce projet. Ce nouveau composé pourrait permettre de bloquer la cascade inflammatoire, de diminuer les altérations de la muqueuse bronchique et le remodelage et donc de diminuer les symptômes de l'asthme. 


\subsection{Objectif général du projet de recherche}

L'objectif visé par cette étude est d'utiliser la technologie des puces d'ADN pour la découverte de biomarqueurs relatifs au rôle du macrophage alvéolaire dans l'asthme, dans le but de mieux documenter le phénotype de cette cellule dans le contexte de l'asthme allergique. Dans un deuxième temps, ce projet de recherche vise à évaluer le potentiel antiinflammatoire d'un composé d'origine naturelle, la querciméritrine, en utilisant le macrophage comme modèle cellulaire.

\subsubsection{Objectifs spécifiques}

Pour le premier volet, les objectifs spécifiques sont :

Faire une liste des biomarqueurs ayant une fonction biologique pouvant être liée à l'implication des macrophages alvéolaires dans le mécanisme inflammatoire relatif à l'asthme, obtenue à l'aide de puce d'ADN lors d'une étude de comparaison du profil d'expression génique de sujets asthmatiques et témoins ;

De cette liste, cibler 5 candidats intéressants pour leur rôle dans l'inflammation pour valider leurs résultats d'expression en PCR en temps réel (real time-polymerase chain reaction: RT-PCR);

Réaliser une étude d'association génétique entre l'asthme et les candidats dont la différence d'expression est validée dans une collection familiale d'asthmatiques provenant du Saguenay-Lac-St-Jean ;

Comparer la différence d'expression génétique observée avec le niveau protéique chez les macrophages alvéolaires de sujets asthmatiques et témoins pour un des gènes validés. 
Pour le deuxième volet, les objectifs spécifiques sont:

Effectuer un test de toxicité de la querciméritrine, un composé d'origine naturelle isolé à partir d'une espèce végétale provenant de la forêt boréale, sur la lignée de macrophages de souris RAW 264.7;

$>$ Mesurer le potentiel anti-inflammatoire de la querciméritrine par l'évaluation du niveau d'oxyde nitrique (NO) produit après stimulation avec de l'IFN- $\gamma$ (Griess nitric assay) sur la sur la lignée de macrophages de souris RAW 264.7;

$>$ Mesurer le potentiel anti-inflammatoire de la querciméritrine par la quantification de la protéine inductible-nitric oxide synthétase (iNOS) à l'aide de la technique du western blot. 


\title{
Chapitre III: Publication scientifique
}

\author{
Alveolar macrophages in allergic asthma; an expression \\ signature characterized by heat shock protein pathways
}

\subsection{Avant-propos}

Le présent chapitre présente les principaux résultats obtenus lors de cette étude visant à mieux documenter le phénotype du macrophage alvéolaire dans le contexte de l'asthme allergique. Cette étude avait pour but d'identifier de nouvelles voies biologiques possiblement impliquées dans le développement et la chronicité de l'inflammation dans les voies aériennes des sujets asthmatiques allergiques. Ce projet de recherche s'intègre dans un vaste projet mené par Anne-Marie Madore, étudiante au doctorat à l'Université Laval.

Les différentes étapes de ce projet ont permis d'identifier plusieurs gènes d'intérêt différemment exprimés dans les macrophages alvéolaires des sujets asthmatiques allergiques dont celui codant pour la protéine prion ( $P R N P)$, protéine impliquée dans la modulation de l'apoptose cellulaire, la serine proteinase inhibitor clade $H$ member 1 (SERPINH1) ainsi que la heat shock 60kD protein 1 (HSPDI), ces derniers codant chacun pour une protéine de la famille des HSPs, soit HSP47 et HSP60. Ces HSPs jouent un rôle de chaperonne, mais sont également impliquées dans la régulation de la réponse immunitaire. Ces biomarqueurs identifiés pour une première fois dans le macrophage alvéolaire chez des individus asthmatiques pourront devenir des cibles potentielles pour des 
études fonctionnelles ainsi que pour le développement de nouvelles approches thérapeutiques.

Ma contribution dans cet article a été d'effectuer le génotypage et les analyses de trois différents polymorphismes du gène SERPINH1, de réaliser une étude d'association génétique entre l'asthme et ces polymorphismes dans un échantillon familial d'asthmatiques provenant du Saguenay-Lac-St-Jean, ainsi qu'une contribution au manuscrit en plus de la révision du manuscrit final.

Cet article est publié dans la revue Human Immunology (Hum Immunol 2010 Feb;71(2):144-50). Il a nécessité la collaboration de plusieurs chercheurs appartenant à différents domaines. Premièrement, Anne-Marie Madore, étudiante au doctorat à l'université Laval, a réalisé l'analyses des puces à ADN, la validation des gènes par RTPCR en temps réel, les analyses d'associations génétiques et l'immunocytochimie, et l'écriture de la plus grande partie du manuscrit. Véronique Turmel, assistante de recherche du Dr. Bissonnette à l'Unité de recherche en pneumologie de Québec, a effectué les extractions d'ARN et de protéines à partir des LBA et a réalisée les ELISA. Le Dr. Michel Laviolette, professeur titulaire de médecine de l'université Laval et pneumologue à l'Hôpital Laval, a participé au recrutement et à l'évaluation clinique des sujets. Il a aussi effectué les LBA et a participé à la révision du manuscrit. Le Dr. Élyse Y. Bissonnette, professeure et chercheure à l'université Laval, a, quant à elle, co-conçu le projet, participée à son élaboration et à la rédaction du manuscrit. Finalement, le Dr. Catherine Laprise, professeure et chercheure au département des sciences fondamentales de l'université du Québec à Chicoutimi (UQAC) dirige le projet qu'elle a conçu avec l'aide des Drs Bissonnette et Laviolette C'est aussi le Dr. Laprise qui a dirigée le recrutement et l'évaluation clinique des sujets de l'échantillon familial d'asthme, ainsi que la construction et la gestion de la biobanque. Elle a aussi dirigé la rédaction du manuscrit. Tous les auteurs ont lu et approuvé la version finale du manuscrit. 


\section{Alveolar macrophages in allergic asthma; an expression signature characterized by heat shock protein pathways}

Anne-Marie Madore ${ }^{1,2,3}$, Stéphanie Perron ${ }^{2}$, Véronique Turmel ${ }^{4}$, Michel Laviolette ${ }^{1,4}$, Élyse Y. Bissonnette ${ }^{1,4}$, Catherine Laprise $\mathrm{L}^{2,3 *}$

${ }^{1}$ Département de médecine, Université Laval, Québec, Canada; ${ }^{2}$ Département des sciences fondamentales, Université du Québec à Chicoutimi, Saguenay, Canada; ${ }^{3}$ Université de Montréal Community Genomic Medicine Center, Saguenay, Canada; ${ }^{4}$ Unité de recherche en pneumologie, Centre de recherche de l'Institut universitaire de cardiologie et pneumologie de Québec, Québec, Canada

* Corresponding author:

Email addresses:

AMM: anne-marie.madore.1@ulaval.ca

SP: stephanie.perron3@uqac.ca

VT: Veronique.Turmel@,crhl.ulaval.ca

ML: michel.laviolette@med.ulaval.ca

EYB: Elyse.Bissonnette@med.ulaval.ca

CL: catherine laprise@uqac.ca 


\subsection{Résumé}

\subsubsection{Problématique}

L'implication des macrophages alvéolaires (MA) dans l'asthme, une maladie de type Th2, n'est pas encore bien caractérisés. Cependant, l'hétérogénéité phénotypique des MA et leur implication dans l'homéostasie immune sont à même de justifier l'étude de leur implication possible dans la pathogenèse de l'asthme. Cette étude vise à mieux caractériser le phénotype des MA de sujets asthmatiques par rapport à des sujets normaux via l'utilisation des analyses d'expression génétique.

\subsubsection{Méthodes}

Le profil d'expression génétique des MA de sujets asthmatiques allergiques et témoin a été caractérisé à l'aide de puces à $\mathrm{ADN}$ effectuées à partir de MA isolés de lavage bronchoalvéolaires. Les différences observées ont été validées par les techniques du RTPCR en temps réel et de l'ELISA.

\subsubsection{Résultats}

L'étude comparative du profil d'expression génétique des MA de sujet asthmatiques et témoins a mis en évidence 50 gènes différemment exprimés. Dix-neuf de ces gènes ont été classés dans la catégorie de la réponse immunitaire ou la réponse au stress. Parmis ceuxci, neuf font partie de la famille des protéines du choc thermique (heat shock protein (HSP)). La différence d'expression de trois (HSPD1, PRNP, SERPINH1) des cinq gènes sélectionnés a été validées à l'aide de la technique du PCR en temps réel. L'ELISA a été 
utilisée pour mesurer le niveau de la protéine codée par HSPD1, le HSP60, et a démontré une différence dans le niveau de protéine entre les asthmatiques allergiques et les témoins.

\subsubsection{Conclusions}

La donnée la plus originale apportée par cette étude est la mise en évidence d'une nouvelle famille de gènes impliquée dans l'asthme allergique, les HSP, et plus précisément le HSP60. Ces résultats appuient également l'implication de MA dans le développement d'une réaction asthmatique allergique

\subsection{Abstract}

\subsubsection{Background}

The implication of alveolar macrophages (AM) in asthma, a Th2 disease, has not been well characterized. However, phenotypic heterogeneity of AM and their implication in immune homeostasis justify studying their possible involvement in asthma pathogenesis. This study aimed to better characterize AM phenotype of asthmatic subjects compared with normal subjects using genomic expression analyses.

\subsubsection{Methods}

Genomic expression profiling of AM of allergic asthmatic and non-allergic healthy subjects were characterized using microarrays performed with AM isolated from bronchoalveolar lavages. Differences observed were confirmed using quantitative RT-PCR and ELISA. 


\subsubsection{Results}

The gene expression study comparing AM of allergic asthmatic and control subjects showed 50 differentially expressed genes. Nineteen have been classified in categories linked to stress or immune responses and among them, nine are part of the heat shock protein family (HSP). Three (HSPD1, PRNP, SERPINH1) of the five selected genes were validated using real-time RT-PCR. ELISA was used to measure the protein level of heat shock protein 60 (HSP60), the protein encoded by one of the three validated gene, HSPD1, and showed difference in AM protein level between allergic asthmatic and control subjects.

\subsubsection{Conclusions}

The most original data of this study is the highlight of a new gene family involved in allergic asthma, the HSP, and particularly HSP60. These results also support the implication of AM in the development of an allergic asthmatic response.

\subsection{Background}

Asthma is a chronic disorder of the airways characterized by reversible airflow obstruction, airway inflammation, remodelling, and hyperresponsiveness [1]. Several functional aspects of alveolar macrophages (AM) justify their study in allergic asthma. These cells, distributed from the alveoli to the upper airways, are the main immune cells in the airway lumen and are in direct contact with exogenous agents. They participate to lung immune homeostasis through phagocytosis and the release of mediators in response to these agents [2]. They can produce both pro- and anti-inflammatory mediators as well as Th1 and Th2 cytokines and, consequently, have the capacity to orientate the type of immune response triggered $[3,4]$. Moreover, they modulate immune response by inhibiting 
antigen presentation by dendritic cells, $\mathrm{T}$ cell activation, and $\mathrm{B}$ cell antibody production $[5$, $6]$.

Allergic asthmatic AM show a lower phagocytic activity and a greater antigen presentation activity than control cells $[7,8]$. Moreover, the transfer of AM from allergyresistant rats (Sprague Dawley) to allergy-susceptible rats (Brown Norway) demonstrates the importance of $\mathrm{AM}$ in inhibiting the early phase reaction and airway hyperresponsiveness in response to allergen challenge. It also suggests a different phenotype for AM of allergy-susceptible rats [9].

Microarray analyses of gene expression have already demonstrated their effectiveness in the characterization of tissue or cellular phenotype in asthma and other complex traits [10]. One of its principal advantages is to allow the discovery of novel possible pathways as this technique looks at all genes independently of their respective known functions [10]. According to this, gene expression microarrays have been chosen to achieve the principal goal of this study, which was to characterize AM phenotype of allergic asthmatic subjects. Our results demonstrated a possible implication particularly for heat shock proteins (HSP) in the immune functions of AM in asthma physiopathology, as nine HSP were underexpressed by AM of allergic asthmatic subjects. Moreover, protein level of HSP60 suggests specially a role for this biomarker in immune functions of this cell type. 


\subsection{Methods}

\subsubsection{Evaluation of gene expression}

Subjects and samples: Five control subjects without allergy or asthma and five allergic asthmatic subjects meeting the criteria of the American Thoracic Society for the diagnosis of asthma [11] participated to microarray and real-time RT-PCR studies. See Table IV for clinical characterization of the subjects. All allergic asthmatic subjects presented asthmatic symptoms that only required treatment with inhaled short-acting $\beta_{2}$ agonist or histamine-antagonist on demand and all subjects were positive for the skin prick test. RNA was available for four subjects per phenotype to run real-time RT-PCR.

Genomic expression: AM were purified by adherence $(2 \mathrm{~h})$, giving purity $>98 \%$. Cell purity was verified using Diff-Quik staining. RNA was isolated using a silica gelbased RNeasy spin column protocol (Qiagen Inc., Valencia, CA). Microarray analysis was performed with Affymetrix Genechip® HG-U133A microarrays containing 22,283 oligonucleotide target probes (Affymetrix, Santa Clara, CA). Hybridization and scanning of image were performed at the McGill University and Genome Quebec Innovation Centre (www.genomequebec.mcgill.ca). To minimize technical variability, RNA processing steps (RNA extraction, probe labelling and chip hybridization) were performed in parallel for control and asthmatic samples. Detailed probe synthesis hybridization and washing protocol have been previously described [12]. The scanned images were analyzed using the Microarray Analysis Suite 5.0 (MAS5, Affymetrix) and the raw image files obtained (CEL format) were used for statistical analysis. Analyses were performed with the "affy" and "limma" packages available in Bioconductor (http://www.bioconductor.org), which uses R language (http://www.R-project.org) [13,14]. Quality tests to look at artefact or variability among microarrays have been done with the "affy" package. Probe intensities from the ten chips were first normalized using robust multi-array analysis (RMA), which comprises 
background correction, quantile normalization and median polish steps. Use of the RMA method in conjunction with $\mathrm{p}$ value and fold change cut-off ( $\mathrm{p}$ value $<0.05$ and absolute fold change $>1.50$ ) allowed us to not perform multi-testing correction $[15,16]$. To even better decrease false discovery rate, Smyth's moderated t-test was used instead of standard t-test [15].

Relative quantification of genetic expression by real-time RT-PCR: Five genes (chemokine CC beta receptor 1 (CCRl), HSPDI, 2,5-oligoadenylate synthetase 1 (40-46 kD) (OAS1), PRNP and SERPINH1) were selected to be tested using real-time RT-PCR. First, RNA integrity was evaluated using capillary electrophoresis. Sensiscript RT (Invitrogen, Burlington, Canada) with oligo-dT(20) primers was used for cDNA synthesis. The SYBR Green RT-PCR reaction was performed in 72-wells in the Rotor-Gene 3000 (Corbett Research, Sydney, Australia) with $1.5 \mathrm{ng}$ of genomic DNA and 1.5 to $2.5 \mathrm{mM}$ $\mathrm{MgCl}_{2}$, Buffer $1 \mathrm{X}(1.5 \mathrm{mM} \mathrm{MgCl}$ ), $0.8 \mathrm{mM}$ dNTPs, $0.4 \mu \mathrm{M}$ gene-specific primers (see Additional file 1), 0.5X SYBR Green, and 1 unit of Taq DNA Polymerase (Qiagen Inc.) for a final volume of $20 \mu \mathrm{l}$. For SERPINH1, QuantiTect SYBR Green PCR Kit was used with QuantiTect Primer Assay (Hs_SERPINH1_1_SG, (Qiagen Inc.)). Each sample was run in triplicate with a negative control and averaged for final RNA quantification. A standard curve was done with three serial dilutions in triplicate for each selected gene and for glyceraldehyde-3-phosphate dehydrogenase $(G A P D H)$ which was used as housekeeping gene. Quantification obtained from standard curves of each gene was normalized to the relative amount of GAPDH using the two standard curves method implemented in the Rotor-Gene 6 software (version 6.0). Measures of expressions for the two phenotypes expressed as mean \pm SEM were compared by Student's unilateral $t$-test. $P$ value $<0.05$ was considered significant. 


\subsubsection{Genetic association study}

See the Additional file 2 for the description of the subjects and the methodology.

\subsubsection{Evaluation of protein level}

Subjects and samples: Cells for immunocytochemistry and AM protein extracts for ELISA were obtained from bronchoalveolar lavage fluids of nine control subjects without allergy and asthma as well as nine allergic asthmatic subjects (Table IV). All allergic asthmatic subjects presented asthmatic symptoms that required only treatment with inhaled short-acting $\beta_{2}$-agonist or histamine-antagonist on demand and all subjects were positive for the skin prick test.

Validation of protein expression by immunocytochemistry: Protein expression was observed using ABComplex/AP method (Dako Cytomation Inc., Ontario, Canada) as previously described [17]. Slides were fixed with PLP-sucrose and coloration was done using Fast Red and Mayer's Hematoxylin (Dako Cytomation Inc.). Isotype-matched immunoglobulin was used as control.

Quantification of protein level by ELISA: Concentrations of HSP60 were measured in cell lysates using HSP60 ELISA Kit (Stressgen Bioreagents, Ann Arbor, MI) according to the manufacturer's protocol. Protein level was expressed as mean \pm standard error. Differences of expression were analyzed by Student's t-test and considered significant when $\mathrm{p}<0.05$. The sensitivity of the assay has been determined to be $3.125 \mathrm{ng} / \mathrm{ml}$.

This study was approved by the Centre de santé et de services sociaux de Chicoutimi and the Laval Hospital Human Ethic Committees. A written consent was obtained from each subject before participation. 


\subsection{Results}

\subsubsection{Gene expression study}

AM gene expression of allergic asthmatic and control subjects showed significant ( $p$ $<0.05$ ) differences in the expression of 50 genes (58 transcripts), which were classified into nine biological function categories (Table V). Nineteen of these genes were classified into categories linked to stress or immune responses (38\%). It is interesting to note that nine members of the HSP family are under-expressed in allergic asthmatic compared with control subjects.

Because of the large quantity of genes tested simultaneously, before going further with analyses of differentially expressed genes, results have to be validated by another technique to avoid false positives. Consequently, five genes (CCR1, HSPD1, OAS1, PRNP and SERPINH1) were selected from the two immune and stress categories to be tested using real-time RT-PCR. Two of the five genes selected are part of the HSP family (HSPDI and SERPINH1). They were selected according to known functions suggesting a possible implication in asthma pathogenesis (Table V). Of these genes, only CCRI has been shown to be expressed in AM and asthma $[18,19]$, but a possible difference of expression has not been documented yet. Real-time RT-PCR showed expression of all five genes in AM from control and asthmatic subjects and confirmed the difference in gene expression between asthmatic and control for three of them: HSPDI, PRNP and SERPINH1 (Figure 1). Real-time RT-PCR data showed that these three genes were significantly underexpressed in AM of asthmatic subjects (2.16-, 1.52-, and 3.84-fold, respectively, with $\mathrm{p}<0.05$ ), as observed in microarray data (2.08- and 1.52-fold for two HSPD1 transcripts, and 1.75- and 1.80-fold for PRNP and SERPINH1 respectively, with $\mathrm{p}<0.05$, Table 5). 


\subsubsection{Genetic association study}

To determine whether the difference of expression for these three genes in asthmatic subjects can be explained by SNPs, genetic association tests were performed between tagSNPs distributed in each of these genes and asthma (Additional file 2, Table VIII). Family-based association testing revealed no significant association for asthma, suggesting that no tagSNP seems to be responsible of the lower expression observed for the three genes in asthmatic subjects (data not shown).

\subsubsection{Protein expression study}

Given that nine HSPs were differentially expressed in AM of asthmatic subjects in our microarray results; proteins of this family may play an important role in asthma pathophysiology. Among them, HSP60, which is encoded by HSPD1, has been recently linked to the regulation of immune response [20-24], but its involvement in AM functions and asthma pathogenesis has not been investigated yet. Therefore, this gene was selected for subsequent analyses to compare its protein and genetic expression in control and asthmatic subjects. The immunocytochemistry data showed similar expression of HSP60 protein in AM of controls and asthmatics $(90 \pm 5 \%$ and $90 \pm 4 \%$ of positive cells for control and asthmatic subjects, respectively), suggesting a difference in each cellular protein level instead of a difference in the number of cells expressing the protein (Figure 4). Thus, HSP60 protein level in cell lysates of AM from control and asthmatic subjects was measured using ELISA. HSP60 level was significantly higher in AM of asthmatics (35.0 \pm $14.5 \mathrm{ng} / \mathrm{ml}$ ) compared with controls $(15.4 \pm 10.8 \mathrm{ng} / \mathrm{ml}$ ) (Figure 5). This represents a 2.27fold increase, which contrasts with the 2.16-fold decrease of HSPD1 mRNA level observed in AM of asthmatic subjects (Figure 3). 


\subsection{Discussion}

Genomic expression profiling of AM presented in this study correspond to basic state of asthmatic subjects (unchallenged) and should help to understand the implication of this cell type in the development of airway allergic asthmatic response. Interestingly, 38\% of the differentially expressed genes are part of the stress and immune responses (Table V), supporting the hypothesis of an implication of $\mathrm{AM}$ in the development of asthma physiopathology. Moreover, the nine genes of the HSP family that are under-expressed in allergic asthmatic subjects suggest an implication for this gene family particularly. Indeed, even if endogen HSP have been firstly known for their chaperone functions, studies have now demonstrated implication for some of them (HSP60, 70, 90 and 110) in the immune response (for a review, see Pockley and coworkers 2008 [25]). More precisely, endogen HSP60 and HSP70 have shown anti-inflammatory properties in studies in rheumatoid or juvenile arthritis and in animal models [25].

Differences of expression observed may be explained by different biological mechanisms. In some cases, it can be the effect of mutations in regulatory regions of the differentially expressed genes. However, the family-based association analysis done in this study for the three validated gene by real-time RT-PCR (HSPDI, PRNP and SERPINH1) indicated that tagSNP do not seem to explain differences of gene expression observed (data not shown). Though, as these differences of expression have been validated by a second technique, it suggests that they probably are the result of other mechanisms as modulation above in their respective biological pathway or epigenetic regulation [26].

Real-time RT-PCR was selected to validate genomic expression data because this technique usually confirm about $87 \%$ of microarray results done using RMA analyses [27]. Then, it is consistent with the confirmation of the under-expression of three of the five 
genes (HSPD1, PRNP and SERPINH1) in allergic asthmatic compared with control AM, according to the small number of genes tested (Figure 3). Consequently, it is interesting to note that genetic expression of none of the validated genes has been documented in AM yet. Moreover, they all have functions possibly linked to the implication of AM in asthma pathogenesis.

One of the differentially expressed genes, PRNP, encodes PRP, a prion protein. Cellular PRP, in opposition to scrapie PRP, is involved in the modulation of cell apoptosis [28], negatively modulates peritoneal macrophage phagocytosis activity [29], and has superoxide dismutase activity [30]. These functions have a direct impact on the number of inflammatory cells in the airways and suggest an implication for cellular PRP in the regulation of airway inflammation in asthma.

One of the HSP differentially expressed genes, SERPINHI; encodes HSP47, a collagen-specific chaperone. This protein is associated with inflammatory diseases such as pulmonary fibrosis, vascular and rheumatoid diseases, and cancer [31]. However, its possible immune functions, such as those recently documented for other members of the HSP family, have not been studied yet.

The second HSP validated gene, HSPD1, encodes HSP60. This protein has a regulatory effect on $\mathrm{T}$ cell immune functions by three principal ways. Firstly, it stimulates $\mathrm{T}$ cell, regulatory $\mathrm{T}$ cell (Treg), and $\mathrm{B}$ cell secretion of the anti-inflammatory cytokine interleukin 10 (IL-10) [21-23]. Secondly, HSP60-stimulated Treg also inhibits two proinflammatory cytokine secretion by $\mathrm{T}$ cell; tumor necrosis factor (TNF) and interferon- $\gamma$ (IFN- $\gamma$ ) [23]. Thirdly, HSP60 has the capacity to inhibit T cell chemotaxis [24]. It may also have an autocrine effect on AM as direct binding of this protein on a specific receptor on 
this cell type has been demonstrated [32]. Consequently, all these functions support an implication for this protein in immune roles of AM in asthma pathogenesis. Indeed, it suggests that HSP60 may down-regulate the immune response, preventing asthma development.

For all the reasons mentioned above, HSP60 was selected to document its protein level in asthmatic and control AM. As observed in this study, genetic expression and protein level for a specific gene are often ( $>50 \%$ of the time) contrasting [33]. To explain the dissimilarity between the decrease in mRNA expression and the increase in protein level observed in AM of asthmatic compared with control subjects, we hypothesised that an auto-inhibition process occur, as seen in some cytokine level regulation [34]. Another reason may be an imbalance between translation and degradation for this protein. However, this increase in HSP60 protein level should limit the immune response. This effect is not observed in asthmatic subjects of this study even if their AM contain 56\% more HSP60 than control AM. The immune response triggered in asthmatic subjects may induce an increase in AM HSP60 production in order to regulate their functions, but HSP60 may not be able to achieve its regulatory role in allergic asthmatic AM. However, to understand the effect of a difference in intracellular level of HSP60 in AM, functional studies have to be performed. Indeed, until now only effects of extracellular HSP60 on immune cell functions have been observed [21-24]. 


\subsection{Conclusions}

In conclusion, genomic expression profiling performed in this study highlights the implication of a new gene family in allergic asthma, the HSPs, and also supports a role for AM immune regulatory functions in the development of allergic asthma response. Moreover, protein level analysis targets HSP60 as a novel biomarker specific to AM activities in the context of allergic asthma. Obviously, it will be necessary to perform functional research to clearly determine the role and impact of the HSP60 in AM activities in allergic asthma biology. 


\subsection{Authors' contributions}

A.-M.M. performed microarray analysis and real-time RT-PCR assays and analysis, genetic association analysis and immunocytochemistry, and drafted the manuscript. S.P. carried out SERPINH1 tagSNPs genotyping and analysis. V.T. performed RNA and protein extraction from bronchoalveolar lavages and performed ELISA assays. M.L. participated to the design of the study, directed the recruitment and clinical evaluation of the subjects for genetic and protein expression, carried out bronchoalveolar lavages and participated to the manuscript redaction. E.Y.B. co-conceived the study, participated to its design and to the manuscript redaction. C.L. co-conceived the study, participated to its design, directed the recruitment and clinical evaluation of the subjects of the familial collection and helped to draft the manuscript. All authors read and approved the final manuscript.

\subsection{Acknowledgments}

We express our gratitude to all subjects that accepted to participate in the study. This study was supported by Canadian Institutes of Health Research (CIHR). AMM received a studentship from CIHR. CL is the chairholder of the Canada Research Chair for genetic determinants in asthma (www.chairs.gc.ca) and the director of the Inflammation and Remodeling Strategic Group of the Respiratory Health Network of the Fonds de la Recherche en Santé du Québec (FRSQ). We thank Julie Saint-Laurent for her help for immunocytochemistry developments, Alexandre Tremblay for his participation to real-time RT-PCR technique and Luce Trépanier for recruitment and ascertainment of participants for genetic expression study. 


\subsection{References}

1. National Institute of Health: Guidelines for the diagnosis and management of asthma. Rep. No. 97-4051. In. Washington, DC: U.S. Dep. Health Hum. Serv., Natl. Heart Lung Blood Inst.; 1997.

2. Thepen T, Kraal G, Holt PG: The role of alveolar macrophages in regulation of lung inflammation. Ann N Y Acad Sci 1994, 725:200-206.

3. Mosser DM: The many faces of macrophage activation. J Leukoc Biol 2003, 73(2):209-212.

4. Sirois J, Bissonnette EY: Alveolar macrophages of allergic resistant and susceptible strains of rats show distinct cytokine profiles. Clin Exp Immunol 2001, 126(1):9-15.

5. Holt PG: Down-regulation of immune responses in the lower respiratory tract: the role of alveolar macrophages. Clin Exp Immunol 1986, 63(2):261-270.

6. Holt PG, Oliver J, Bilyk N, McMenamin C, McMenamin PG, Kraal G, Thepen T: Downregulation of the antigen presenting cell function(s) of pulmonary dendritic cells in vivo by resident alveolar macrophages. $J \operatorname{Exp}$ Med 1993, 177(2):397-407.

7. Alexis NE, Soukup J, Nierkens S, Becker S: Association between airway hyperreactivity and bronchial macrophage dysfunction in individuals with mild asthma. Am J Physiol Lung Cell Mol Physiol 2001, 280(2):L369-375.

8. Balbo P, Silvestri M, Rossi GA, Crimi E, Burastero SE: Differential role of CD80 and CD86 on alveolar macrophages in the presentation of allergen to $T$ lymphocytes in asthma. Clin Exp Allergy 2001, 31(4):625-636.

9. Careau E, Bissonnette EY: Adoptive transfer of alveolar macrophages abrogates bronchial hyperresponsiveness. Am J Respir Cell Mol Biol 2004, 31(1):22-27. 
10. Rolph MS, Sisavanh M, Liu SM, Mackay CR: Clues to asthma pathogenesis from microarray expression studies. Pharmacology \& therapeutics 2006, 109(1-2):284294.

11. ATS: Standards for the diagnosis and care of patients with chronic obstructive pulmonary disease (COPD) and asthma. This official statement of the American Thoracic Society was adopted by the ATS Board of Directors, November 1986. Am Rev Respir Dis 1987, 136(1):225-244.

12. Novak JP, Sladek R, Hudson TJ: Characterization of variability in large-scale gene expression data: implications for study design. Genomics 2002, 79(1):104113.

13. Gautier L, Cope L, Bolstad BM, Irizarry RA: affy--analysis of Affymetrix GeneChip data at the probe level. Bioinformatics 2004, 20(3):307-315.

14. Smyth GK: Linear models and empirical bayes methods for assessing differential expression in microarray experiments. Statistical applications in genetics and molecular biology 2004, 3:Article3.

15. Gregory Alvord W, Roayaei JA, Quinones OA, Schneider KT: A microarray analysis for differential gene expression in the soybean genome using Bioconductor and R. Briefings in bioinformatics 2007, 8(6):415-431.

16. Bolstad BM, Irizarry RA, Astrand M, Speed TP: A comparison of normalization methods for high density oligonucleotide array data based on variance and bias. Bioinformatics 2003, 19(2):185-193.

17. Gauvreau GM, Lee JM, Watson RM, Irani AM, Schwartz LB, O'Byrne PM: Increased numbers of both airway basophils and mast cells in sputum after allergen inhalation challenge of atopic asthmatics. Am J Respir Crit Care Med 2000, 161(5):1473-1478. 
18. Amin K, Janson C, Harvima I, Venge P, Nilsson G: CC chemokine receptors CCR1 and CCR4 are expressed on airway mast cells in allergic asthma. $J$ Allergy Clin Immunol 2005, 116(6):1383-1386.

19. Opalek JM, Ali NA, Lobb JM, Hunter MG, Marsh CB: Alveolar macrophages lack CCR2 expression and do not migrate to CCL2. Journal of inflammation (London, England) 2007, 4:19.

20. Zanin-Zhorov A, Nussbaum G, Franitza S, Cohen IR, Lider O: T cells respond to heat shock protein 60 via TLR2: activation of adhesion and inhibition of chemokine receptors. Faseb $J$ 2003, 17(11):1567-1569.

21. Zanin-Zhorov A, Bruck R, Tal G, Oren S, Aeed H, Hershkoviz R, Cohen IR, Lider O: Heat shock protein 60 inhibits Th1-mediated hepatitis model via innate regulation of Th1/Th2 transcription factors and cytokines. J Immunol 2005, 174(6):3227-3236.

22. Cohen-Sfady M, Nussbaum G, Pevsner-Fischer M, Mor F, Carmi P, ZaninZhorov A, Lider O, Cohen IR: Heat shock protein 60 activates B cells via the TLR4-MyD88 pathway. $J$ Immunol 2005, 175(6):3594-3602.

23. Zanin-Zhorov A, Cahalon L, Tal G, Margalit R, Lider O, Cohen IR: Heat shock protein 60 enhances CD4+CD25+ regulatory T cell function via innate TLR2 signaling. J Clin Invest 2006, 116(7):2022-2032.

24. Zanin-Zhorov A, Tal G, Shivtiel S, Cohen M, Lapidot T, Nussbaum G, Margalit R, Cohen IR, Lider O: Heat shock protein 60 activates cytokineassociated negative regulator suppressor of cytokine signaling 3 in T cells: effects on signaling, chemotaxis, and inflammation. J Immunol 2005, 175(1):276-285.

25. Pockley AG, Muthana M, Calderwood SK: The dual immunoregulatory roles of stress proteins. Trends in biochemical sciences 2008, 33(2):71-79. 
26. Wilson AG: Epigenetic regulation of gene expression in the inflammatory response and relevance to common diseases. Journal of periodontology 2008, $79(8$ Suppl):1514-1519.

27. Dallas PB, Gottardo NG, Firth MJ, Beesley AH, Hoffmann K, Terry PA, Freitas JR, Boag JM, Cummings AJ, Kees UR: Gene expression levels assessed by oligonucleotide microarray analysis and quantitative real-time RT-PCR -- how well do they correlate? BMC Genomics 2005, 6(1):59.

28. Sunyach C, Checler F: Combined pharmacological, mutational and cell biology approaches indicate that p53-dependent caspase 3 activation triggered by cellular prion is dependent on its endocytosis. $J$ Neurochem 2005, 92(6):1399-1407.

29. de Almeida CJ, Chiarini LB, da Silva JP, PM ES, Martins MA, Linden R: The cellular prion protein modulates phagocytosis and inflammatory response. $J$ Leukoc Biol 2005, 77(2):238-246.

30. Rachidi W, Riondel J, McMahon HM, Favier A: [Prion protein and copper: a mysterious relationship]. Pathol Biol (Paris) 2005, 53(4):244-250.

31. Sauk JJ, Nikitakis N, Siavash H: Hsp47 a novel collagen binding serpin chaperone, autoantigen and therapeutic target. Front Biosci 2005, 10:107-118.

32. Habich C, Kempe K, van der Zee R, Burkart V, Kolb H: Different heat shock protein 60 species share pro-inflammatory activity but not binding sites on macrophages. FEBS Lett 2003, 533(1-3):105-109.

33. Chuaqui RF, Bonner RF, Best CJ, Gillespie JW, Flaig MJ, Hewitt SM, Phillips JL, Krizman DB, Tangrea MA, Ahram M et al: Post-analysis follow-up and validation of microarray experiments. Nat Genet 2002, 32 Suppl:509-514. 
34. Zhang SQ, Luo X, Yang S, Liu JL, Yang CJ, Yin XY, Huang HL, Zhang XJ: Autoinhibition of IL-15 expression in KC cells is ERK1/2 and PI3K dependent. Scand J Immunol 2008, 68(4):397-404.

35. Talati M, Meyrick B, Peebles RS, Jr., Davies SS, Dworski R, Mernaugh R, Mitchell D, Boothby M, Roberts LJ, 2nd, Sheller JR: Oxidant stress modulates murine allergic airway responses. Free Radic Biol Med 2006, 40(7):1210-1219.

36. Matthaei KI, INABIS'98: The modulation of allergic airways disease by interleukin-4 et -5 : studies using cytokine deficient mice. http://wwwmcmasterca/inabis98/denburg/foster0232/twohtml 1998. 


\subsection{Figures}

Figure 3. Expression of the five selected genes using real-time RT-PCR

Chemokine (C-C motif) receptor 1 (CCRI), heat shock $60 \mathrm{kD}$ protein 1 (HSPDI), 2,5oligoadenylate synthetase $1(40-46 \mathrm{kD})(O A S 1)$, prion protein $(P R N P)$ and serpin peptidase inhibitor, clade $\mathrm{H}$ (heat shock protein 47), member 1 (SERPINH1) mRNA expression by alveolar macrophages (AM) isolated from bronchoalveolar lavages of control (grey bars) and allergic asthmatic (black bars) subjects. Measure of the mRNA expression by real-time RT-PCR was done in triplicates with negative control and normalized to GAPDH expression using two-standard curves method $(\mathrm{n}=4)$. Data are expressed as mean $\pm \mathrm{SEM}$ values. HSPD1, PRNP and SERPINH1 mRNA are significantly (* $\mathrm{p}<0.05)$ underexpressed in AM of asthmatic subjects compared with controls.

\section{Figure 4. HSP60 protein expression by alveolar macrophages (AM) of control and allergic asthmatic subjects.}

Bronchoalveolar cells of four control subjects and four allergic asthmatic subjects were fixed with PLP-sucrose and immuncytochemistry was done using ABComplex/AP method and Fast-Red coloration with Mayer's Hematoxylin counterstaining. X1000. Immunocytochemistry for HSP60 expression of A) isotypic negative control, B) control subjects, and C) allergic asthmatic subjects. Results shown are representative. There was no difference in positive AM cell count for HSP60 between control and asthmatic subjects.

Figure 5. Protein level of HSP60 in alveolar macrophages (AM) of control and allergic asthmatic subjects.

AM were purified from bronchoalveolar lavage and lysed to measure HSP60 by ELISA. Protein levels for control (grey bars) and allergic asthmatic (black bars) subjects are shown $(n=5)$. Data are expressed as mean \pm SEM values. Level of HSP60 is significantly higher $(* \mathrm{p}<0.05)$ in $\mathrm{AM}$ of asthmatic subjects compared with controls. 


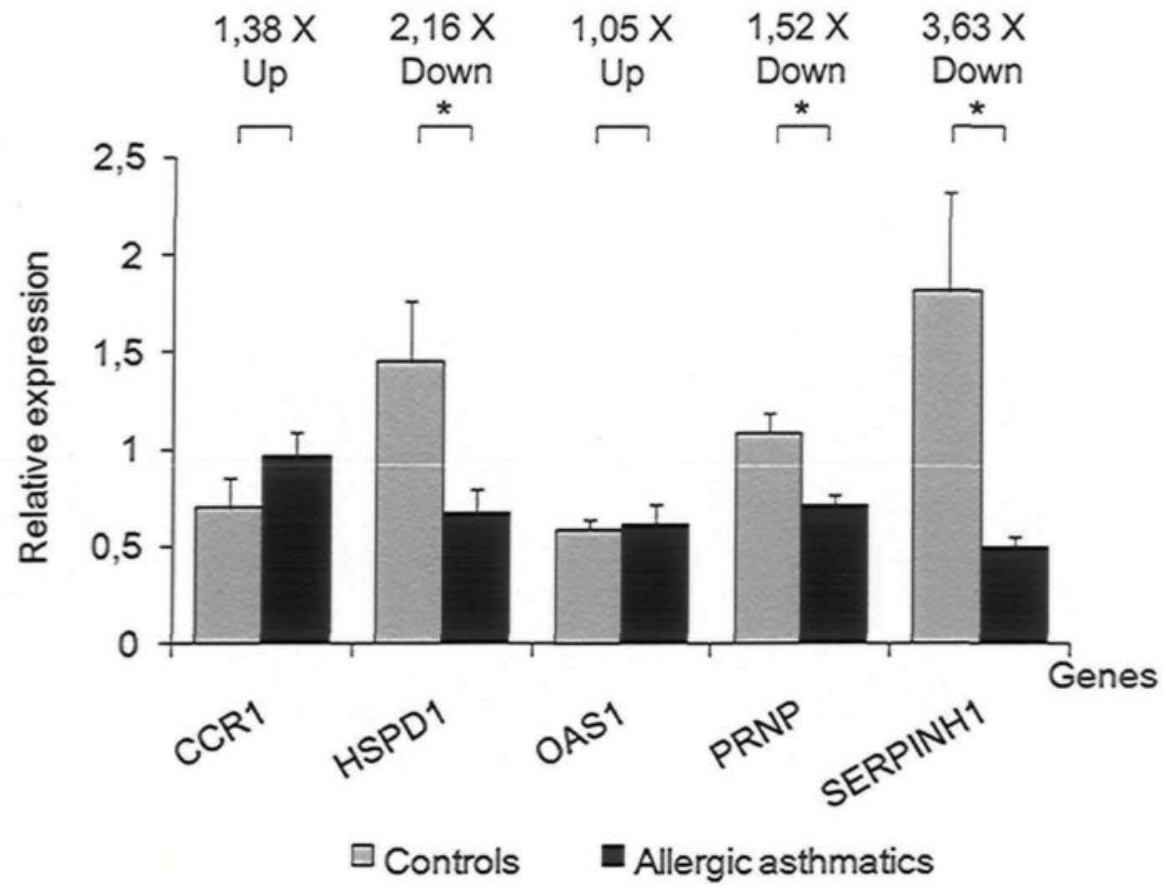

Figure 3. Expression of the five selected genes using real-time RT-PCR
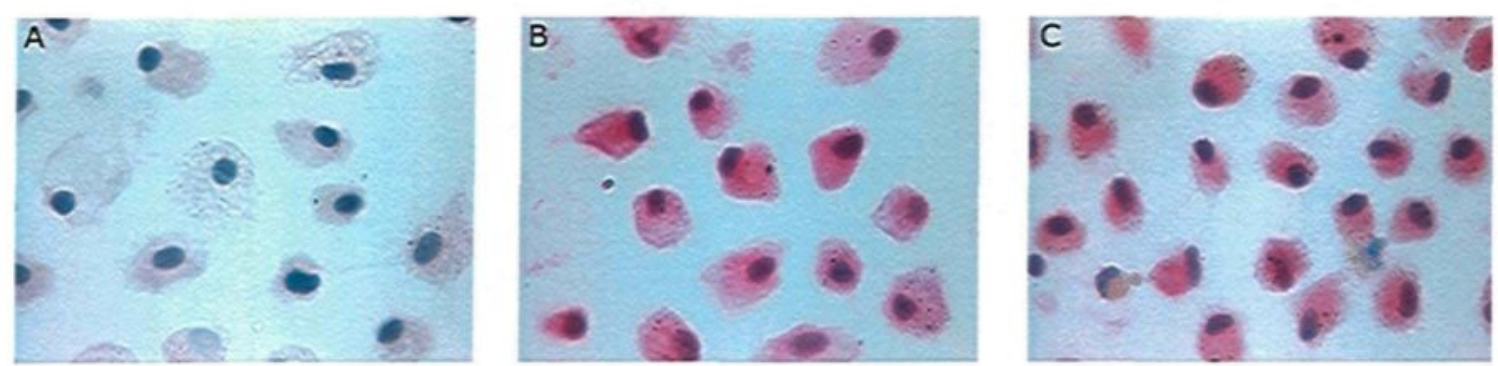

Figure 4. HSP60 protein expression by alveolar macrophages (AM) of control and allergic asthmatic subjects. 


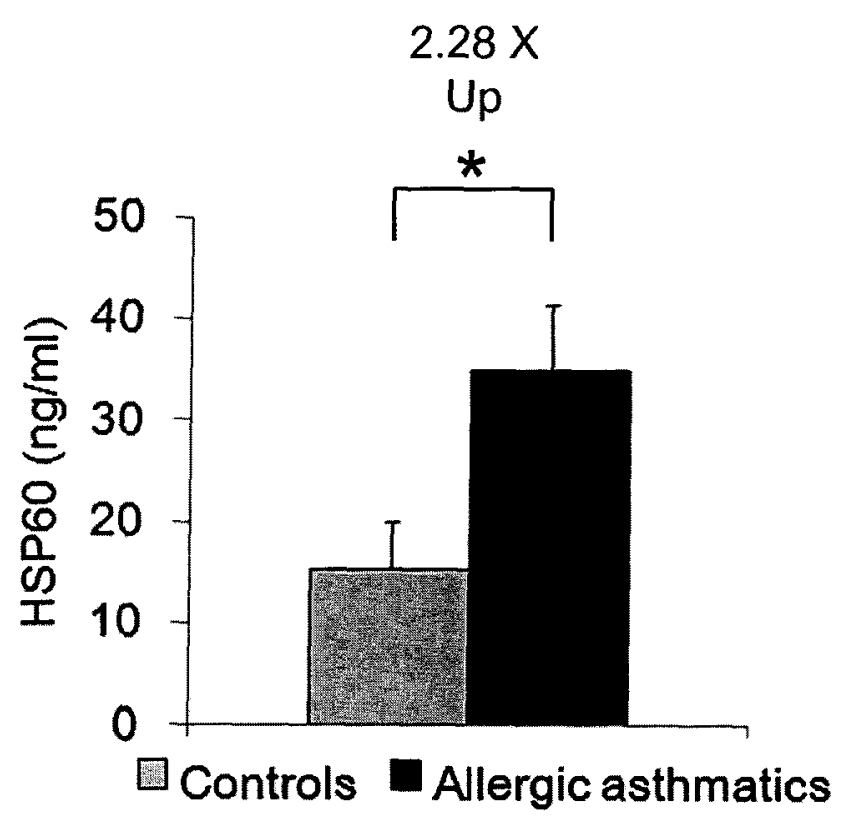

Figure 5. Protein level of HSP60 in alveolar macrophages (AM) of control and allergic asthmatic subjects. 


\subsection{Tables}

Table IV. Clinical characteristics of the subjects involved in microarray analysis and real-time RT-PCR.

\begin{tabular}{|c|c|c|c|c|c|c|}
\hline & \multicolumn{2}{|c|}{$\begin{array}{l}\text { Microarrays }(n=5) \\
\text { and } \\
\text { qRT-PCR }(n=4)^{a}\end{array}$} & \multicolumn{2}{|c|}{$\begin{array}{l}\text { Immunohistochemistry } \\
\qquad(\mathrm{n}=4)\end{array}$} & \multicolumn{2}{|c|}{ ELISA $(n=5)$} \\
\hline & Controls & $\begin{array}{c}\text { Allergic } \\
\text { asthmatics }\end{array}$ & Controls & $\begin{array}{c}\text { Allergic } \\
\text { asthmatics }\end{array}$ & Controls & $\begin{array}{c}\text { Allergic } \\
\text { asthmatics }\end{array}$ \\
\hline Male : Female ratio & $3 / 2$ & $3 / 2$ & $2 / 2$ & $2 / 2$ & $4 / 1$ & $4 / 1$ \\
\hline Mean age, year (range) & $\begin{array}{c}26 \\
(20-37)\end{array}$ & $\begin{array}{c}29 \\
(24-36)\end{array}$ & $\begin{array}{c}25 \\
(20-30)\end{array}$ & $\begin{array}{c}28 \\
(20-34)\end{array}$ & $\begin{array}{c}28 \\
(23-36)\end{array}$ & $\begin{array}{c}24 \\
(18-29)\end{array}$ \\
\hline $\mathrm{AM} \%(\mathrm{SD})$ & $76(10)$ & $86(10)$ & $75(9)$ & $70(6)$ & $79(16)$ & $81(9)$ \\
\hline $\begin{array}{l}\text { FEV1\% predicted } \\
\text { (SD) }\end{array}$ & $94(10)$ & $103(19)$ & $96(9)$ & $90(6)$ & $102(4)$ & $102(18)$ \\
\hline $\mathrm{PC}_{20} \mathrm{mg} / \mathrm{ml}(\mathrm{SD})^{\mathrm{c}}$ & $\begin{array}{l}>16 \text { to } \\
>128\end{array}$ & $\begin{array}{l}2.13 \\
(2.45)\end{array}$ & $\begin{array}{l}>16 \text { to } \\
51.54\end{array}$ & $\begin{array}{c}0.59 \\
(2.54)\end{array}$ & $\begin{array}{l}>32 \text { to } \\
>128\end{array}$ & $\begin{array}{c}1.35 \\
(3.74)\end{array}$ \\
\hline Allergy & No & Yes & No & Yes & No & Yes \\
\hline
\end{tabular}

Abbreviation used: $\mathrm{FEV}_{1}=$ Forced expiratory volume in one second, $\mathrm{PC}_{20}=$ Provocative concentration of methacholine that induces a $20 \%$ fall in $\mathrm{FEV}_{1}, \mathrm{SD}=$ Standard deviation.

${ }^{\text {a }}$ Microarray experiment: $n=5$; real-time RT-PCR: $n=4$.

${ }^{\mathrm{b}}$ Geometric mean calculated for 14 controls and 14 allergic asthmatic subjects.

${ }^{\mathrm{c}}$ Geometric mean calculated for 13 controls and 14 allergic asthmatic subjects. 
Table V. Genes differentially expressed in alveolar macrophages of allergic asthmatic subjects in comparison to control subjects

\begin{tabular}{|c|c|c|c|c|c|c|}
\hline Gene $^{\mathbf{a}}$ & Cytoband $^{b}$ & ACCNUM & Probe set & Fle $^{\mathrm{c}}$ & $\mathbf{P}$ & Function $^{d}$ \\
\hline \multicolumn{7}{|c|}{ Cell growth and proliferation } \\
\hline CDKNIB & $\begin{array}{l}12 \mathrm{p} 13.1- \\
\mathrm{p} 12\end{array}$ & NM_004064 & 209112_at & 1.56 & 0.024 & Cell cycle $[1]$ \\
\hline$R R E B I$ & $6 \mathrm{p} 25$ & NM_001003699 & 203704_s_at & 1.61 & 0.007 & Cell differentiation [37] \\
\hline \multicolumn{7}{|c|}{ Genetic transcription and translation } \\
\hline DICER1 & $14 q 32.13$ & $\begin{array}{l}\text { NM_177436 } \\
\text { NM_030621 }\end{array}$ & 212888 at & 1.52 & 0.036 & RNA interference [3] \\
\hline MRPLI8 & $6 \mathrm{q} 25.3$ & NM_014161 & 217907_at & -1.66 & 0.008 & Mitochondrial ribosome [4] \\
\hline$P A I P 1$ & $5 \mathrm{p} 12$ & NM_006451 & 210283_x_at & 1.59 & 0.015 & Translational initiation [5] \\
\hline$P H F 3$ & $6 \mathrm{q} 12$ & NM_015153 & 217954_s_at & 1.59 & 0.020 & Transcription factor [6] \\
\hline RNF6 & $13 \mathrm{q} 12.2$ & NM_005977 & 203403_s_at & 1.55 & 0.001 & Transcription regulation [7] \\
\hline SFRS3 & $6 \mathrm{p} 21$ & NM_003017 & 202899_s_at & -1.55 & 0.015 & mRNA splicing factors [38] \\
\hline$S P 3$ & $2 q 31$ & XM_092672 & 213168_at & 1.55 & 0.008 & Transcriptional regulation [38] \\
\hline UPF3A & $13 q 34$ & NM_023011 & $214323 \_s \_$at & 1.50 & 0.006 & Export of spliced mRNA [10] \\
\hline
\end{tabular}

Immune signaling molecules

$\begin{array}{lllllll}\text { *CCRI } & \text { 13p21 } & \text { NM_001295 } & \text { 205098_at } & 1.69 & 0.009 & \begin{array}{l}\text { Binds CC chemokines [11]; } \\ \text { Expressed by AM [12] }\end{array} \\ & & & \text { 205099_s_at } & 1.73 & 0.014 & \\ \text { CYTIP } & \text { 2q11.2 } & \text { NM_004288 } & \text { 209606_at } & 1.93 & 0.024 & \text { IL-2, IL-12-stimulated Tcell [13] } \\ \text { * } \boldsymbol{O A S 1} & \text { 12q24.2 } & \text { NM_016816 } & \text { 202869_at } & 1.79 & 0.002 & \begin{array}{l}\text { Antivirus activity[14]; Severe } \\ \text { acute respiratory syndrome [15] }\end{array}\end{array}$




\begin{tabular}{|c|c|c|c|c|c|c|}
\hline *PRNP & 20pter-p12 & $\begin{array}{l}\text { NM_000311 } \\
\text { NM_183079 }\end{array}$ & / 215707_s_at & -1.75 & 0.002 & $\begin{array}{l}\text { Phagocytosis [16]; Superoxide } \\
\text { dismutase activity [17] }\end{array}$ \\
\hline SAMSN1 & $21 \mathrm{q} 11$ & NM_022136 & 220330_s_at & 1.50 & 0.006 & B cell activation [18] \\
\hline \multicolumn{7}{|c|}{ Immune and stress responses } \\
\hline$B A G 3$ & $\begin{array}{l}10 \mathrm{q} 25.2- \\
\mathrm{q} 26.2\end{array}$ & NM_004281 & 217911_s_at & -2.08 & 0.028 & HSP70 and HSC70 partner [19] \\
\hline$D N A J B I$ & $19 \mathrm{p} 13.2$ & NM_006145 & 200666_s_at & -2.33 & 0.006 & $\begin{array}{l}\text { HSP70 partner }[20] ; \quad \text { IL-10 } \\
\text { production [21] }\end{array}$ \\
\hline$D N A J B 4$ & $1 \mathrm{p} 31$ & NM_007034 & 203811_s_at & -1.72 & 0.018 & \\
\hline DUSPI & $5 q 34$ & NM_004417 & 201044_x_at & -1.87 & 0.046 & $\begin{array}{l}\text { Induced by heat stress [22] and IL- } \\
10[23] \text {; MAPK pathway [24] }\end{array}$ \\
\hline DUSPG & $12 q 22-q 23$ & $\begin{array}{l}\text { NM_022652 } \\
\text { NM_001946 }\end{array}$ & / 208891_at & 1.80 & 0.030 & \\
\hline$G A D D 45 B$ & $19 \mathrm{p} 13.3$ & NM_015675 & 209305_s_at & -1.57 & 0.038 & Damage, growth stresses [25] \\
\hline HSPAIA & $6 \mathrm{p} 21.3$ & NM_005345 & 200800_s_at & -2.42 & 0.002 & $\begin{array}{l}\text { Anti-inflammatory [26]; AM and } \\
\text { asthma [27] }\end{array}$ \\
\hline HSPA1B & $6 \mathrm{p} 21.3$ & NM_005346 & 202581_at & -2.96 & 0.004 & \\
\hline \multirow[t]{2}{*}{ HSPA6 } & $1 \mathrm{q} 23$ & NM_002155 & 213418 at & -7.00 & 0.007 & \\
\hline & & & 117_at & -5.60 & 0.008 & \\
\hline$H S P C B$ & $6 \mathrm{p} 12$ & NM_007355 & 214359_s_at & -1.56 & 0.018 & $\begin{array}{l}\text { Anti-inflammatory } \\
\text { Childhood asthma [29] }\end{array}$ \\
\hline \multirow[t]{2}{*}{ * HSPD1 } & $2 \mathrm{q} 33.1$ & $\begin{array}{l}\text { NM_002156 } \\
\text { NM_199440 }\end{array}$ & / 200806_s_at & -2.08 & 0.004 & $\begin{array}{l}\text { Anti-inflammatory } \\
\text { Asthma [34] }\end{array}$ \\
\hline & & & 200807_s_at & -1.52 & 0.008 & \\
\hline \multirow[t]{2}{*}{ HSPHI } & $\begin{array}{l}13 \mathrm{q} 12.2- \\
\mathrm{q} 13.3\end{array}$ & NM_006644 & 206976_s_at & -1.69 & 0.028 & Regulation of inflammation [35] \\
\hline & & & 208744_x_at & -2.35 & 0.009 & \\
\hline * SERPINHI & $11 \mathrm{q} 13.5$ & NM_001235 & 207714_s_at & -1.80 & 0.014 & Collagen-specific [36] \\
\hline STIP1 & $11 \mathrm{q} 13$ & NM_006819 & 212009_s_at & -1.89 & 0.039 & HSP70 and HSP90 partner [37] \\
\hline
\end{tabular}

Intracellular signaling molecules

$\boldsymbol{C A L U}$ 7q32 NM_001219 214845_s_at $\quad-1.55 \quad 0.002$ CA2+ binding proteins [38] 


\begin{tabular}{|c|c|c|c|c|c|c|}
\hline INSIGI & $7 \mathrm{q} 36$ & $\begin{array}{l}\text { NM_005542 } \\
\text { NM_198336 } \\
\text { NM_198337 }\end{array}$ & $\begin{array}{l}/ 201625 \text { _s_at } \\
\text { 201627_s_at }\end{array}$ & $\begin{array}{l}-1.62 \\
-1.74\end{array}$ & $\begin{array}{l}0.028 \\
0.042\end{array}$ & Cholesterol biosynthesis [39] \\
\hline PEX6 & $6 \mathrm{p} 21.1$ & NM_000287 & 204545_at & -1.60 & 0.025 & Peroxisomal targeting [40] \\
\hline YWHAZ & $8 \mathrm{q} 23.1$ & $\begin{array}{l}\text { NM_003406 } \\
\text { NM_145690 }\end{array}$ & / 200641_s_at & -1.63 & 0.012 & Insuline pathway [41] \\
\hline
\end{tabular}

Metabolic enzymes

\begin{tabular}{|c|c|c|c|c|c|c|}
\hline GNPTAB & $12 q 23.2$ & NM_024312 & 212959_s_at & 1.63 & 0.020 & Lysosomal hydrolases [42] \\
\hline LIMKI & $7 \mathrm{q} 11.23$ & NM_002314 & 208372_s_at & -1.57 & 0.002 & Actin cytoskeletton [43] \\
\hline MAT2A & $2 \mathrm{p} 11.2$ & NM_005911 & 200769_s_at & -1.70 & 0.025 & $\begin{array}{l}\text { S-adenosylmethionine } \\
\text { [44] }\end{array}$ \\
\hline NQO2 & 6 pter-q12 & NM_000904 & 203814_s_at & 1.69 & 0.003 & NADH, NADPH oxydation [45] \\
\hline RNASE6 & $14 q 11.2$ & NM_005615 & 213566 at & 1.83 & 0.012 & Degradation of RNA [46] \\
\hline$S C D$ & $10 \mathrm{q} 23-\mathrm{q} 24$ & NM_005063 & $211162 \_x$ at & -1.75 & 0.002 & Fatty acid desaturase [47] \\
\hline & & & 211708_s_at & -1.82 & 0.002 & \\
\hline$T P P 1$ & $11 \mathrm{p} 15$ & NM_000391 & 214196_s_at & -1.54 & 0.047 & Lysosomal exopeptidase [48] \\
\hline
\end{tabular}

\section{Structural proteins}

$\begin{array}{lllllll}\text { DOCK4 } & \text { 7q31.1 } & \text { NM_014705 } & \text { 205003_at } & 1.52 & 0.022 & \text { Adherens junctions [49] } \\ \text { HIST2H2AA3 } & 1 \mathrm{q} 21-\mathrm{q} 23 & \text { NM_003516/ } & \text { 214290_s_at } & -1.54 & 0.014 & \text { Nucleosomes formation [50] } \\ \text { HIST2H2AA4 } & & \text { NM_001040874 } & & & \\ & & & & & & \\ \text { MFN1 } & \text { 3q26.23 } & \text { NM_033540 } & \text { 207098_s_at } & 1.64 & 0.019 & \text { Mitochondria morphology [51] }\end{array}$

\section{Transmembrane proteins}

$\begin{array}{lllllll}\boldsymbol{A P P} & \begin{array}{l}21 \mathrm{q} 21.2- \\ \mathrm{q} 21.3\end{array} & \text { NM_000484 } & \text { 200602_at } & 2.02 & 0.032 & \begin{array}{l}\text { Transcriptional activation, amyloid } \\ \text { plaques [52] }\end{array} \\ \boldsymbol{L} \boldsymbol{L} \boldsymbol{L} \boldsymbol{R} & 19 \mathrm{p} 13.3 & \text { NM_000527 } & \text { 202067_s_at } & -1.61 & 0.045 & \text { LDL endocytosis [53] } \\ & & & & 217173 \text { _s_at } & -1.55 & 0.020\end{array}$




\begin{tabular}{|c|c|c|c|c|c|c|}
\hline MSRI & $8 \mathrm{p} 22$ & NM_002445 & 208423_s_at & -1.60 & 0.011 & Negative molecule transport [54] \\
\hline & & & 211887_x_at & -1.63 & 0.003 & \\
\hline$S L C 16 A 3$ & $17 q 25$ & $\begin{array}{l}\text { NM_001042422 } \\
/ \text { NM_004207 / } \\
\text { NM_001042423 }\end{array}$ & 202855_s_at & -1.90 & 0.045 & Lactic acid, pyruvate transport [55] \\
\hline$S L C 7 A 5$ & $16 \mathrm{q} 24.3$ & NM_003486 & 201195_s_at & -1.62 & 0.041 & Neutral amino acids transport [56] \\
\hline
\end{tabular}

Vesicle transport

EXOC5 14q23.1 NM_006544 218748_s_at $-1.73 \quad 0.029$ Targets exocytic vesicles [57]

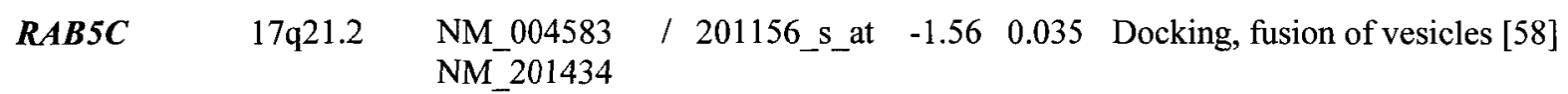

${ }^{a}$ Genes marked by an asterisk were selected to be tested by real-time RT-PCR

b Gene location obtained from National Center for Biotechnology Information public database build 128 (http://www.ncbi.nlm.nih.gov).

${ }^{c}$ Fold changes $(\mathrm{Flc})$ are indicated for each probe set significantly under- or over-expressed $(\mathrm{p}<0.05$; absolute Flc $>1.5)$ by alveolar macrophages of allergic asthmatic subjects compared with control subjects. Positive data indicate genes which are over-expressed and negative data indicate genes which are under-expressed by alveolar macrophages of allergic asthmatic subjects.

d References that allow classification of differentially expressed genes in function categories:

1: Genes Dev 1997; 11 : 1464-1478.

2: Molec Cell Biol 1996; 16: 5335-5345.

3: J Biol Chem 2009; 284: 2535-48.

4: J Biol Chem 2001; 276: 43958-43969.

5: Nature 1998; 392: 520-523.

6: Cytogenet Cell Genet 2001; 94: 131-6.

7: Mol Cell Biol 2002; 22: 3488-96.
8: Genes Dev 1992; 6: 837-847.

9: Molec Cell Biol 1992; 12: 4251-44261.

10: Science 200I; 293: 1832-1836.

11: Current opinion in pharmacology 2003; 3: 443-8.

12: Journal of inflammation (London, England) 2007; 4: 19.
13: Proc Nat Acad Sci 2002; 99: $2625-$ 2629.

14: Genomics 1998; 52: 267-277.

15: Biochem Biophys Res Commun 2005; 329: 1234-9.

16: J Leukoc Biol 2005; 77: 238-46.

17: Pathol Biol (Paris) 2005; 53: 244-50. 
18: J Exp Med 2004; 200: 737-47.

19: J Biol Chem 1999; 274: 781-786.

20: Cell Mol Life Sci 2006; 63: 2560-70.

21: Arthritis and rheumatism 2007; 56: 1648-57.

22: Nature 1992; 359: 644-647.

23: Eur J Immunol 2005; 35: 2991-3001.

24: Science 1999; 286: 2514-2517.

25: Cell 1998; 95: 521-530.

26: Nat Rev Immunol 2005; 5: 318-330

27: Am J Respir Cell Mol Biol 1995; 13: 683-91.

28: Trends Biochem Sci 2008; 33: 71-9.

29: Clinical biochemistry 2007; 40: 1168-

71.

30: J Immunol 2005; 175: 3594-602.
31: J Clin Invest 2006; 116: 2022-32.

32: J Immunol 2005; 175: 276-85.

33: J Immunol 2005; 174: 3227-36.

34: Respiratory research 2005; 6: 18.

35: Nippon rinsho 2003; 61: 1317-22.

36: EMBO J 2000; 19: 2204-11.

37: J Biol Chem 1998; 273: 35194-35200.

38: J Biol Chem 1997; 272: 18232-18239.

39: Cell 2002; $110: 489-500$.

40: Am J Hum Genet 1996; 59: 1210-

1220.

41: J Biol Chem 1997; 272: 25267-25274.

42: Nature Med 2005; 11: 1109-1112.

43: J Mol Med 2007; 85:555-68.

44: J Biol Chem 1953; 204:403-416.

45: Biochemistry 1990; 29: 1899-1906.
46: Nucleic Acids Res 1996; 24: $3507-$ 3513.

47: J Biol Chem 2005; 280: 25339-25349. 48: J Biol Chem 2005; 280: 7550-7561.

49: Cell 2003; 112: 673-684.

50: Histochem Cell Biol 1997; 107: 1-10.

51: Science 2004; 305: 1747-1752.

52: Science 2001; 293: 115-120.

53: Cell 1982; 30: 715-724.

54: J Biol Chem 1993; 268: 2120-2125.

55: Biochem J 1998; 329: 321-328.

56: Biol Chem 1998; 273: 23629-23632.

57: FEBS Lett 1997; 404: 135-139

58: Cytogenet Cell Genet 1996; 73: $137-$ 139. 


\subsection{Additional files}

\section{Additional file 1 - Real-time RT-PCR primers}

This additional file comprises one table which shows primer pairs and annealing temperature used for the five genes tested by real-time RT-PCR.

File format: .doc

Additional file 2 - Genetic association study; methods and tables

This additional file comprises complete description of the subjects and methodology for the genetic association study.

File format: .doc 


\section{Alveolar macrophages in allergic asthma; an expression signature characterized by heat shock protein pathways}

Anne-Marie Madore, Stéphanie Perron, Véronique Turmel, Michel Laviolette, Élyse Y. Bissonnette, Catherine Laprise.

\section{Additional file 1}

Table VI. List of the primer pairs used for real-time RT-PCR

\begin{tabular}{|c|c|c|c|c|}
\hline Gene & Description $^{a}$ & RefSeq $^{b}$ & $\begin{array}{l}\text { Primers } \\
\text { forward/reverse }\end{array}$ & $\begin{array}{l}\text { Annealing } \\
\text { temperature }\end{array}$ \\
\hline$\overline{C C R 1}$ & $\begin{array}{l}\text { Chemokine, } \quad \mathrm{CC} \\
\text { motif, receptor } 1\end{array}$ & NM_001295 & $\begin{array}{l}\text { aggatttgggctcttggaat } \\
\text { ttagcccactccctgaattg }\end{array}$ & $60^{\circ} \mathrm{C}$ \\
\hline HSPDI & $\begin{array}{l}\text { Heat-Shock } 60-\mathrm{kd} \\
\text { Protein } 1\end{array}$ & $\begin{array}{l}\text { NM_199440 / } \\
\text { NM_002156 }\end{array}$ & $\begin{array}{l}\text { gtggaatgggaggtggtatg } \\
\text { / tgattttcagccagcctttt }\end{array}$ & $59^{\circ} \mathrm{C}$ \\
\hline$O A S 1$ & $\begin{array}{l}\text { 2-prime,5-prime } \\
\text { oligoadenylate } \\
\text { synthetase } \\
40 / 46 \mathrm{kDa}\end{array}$ & NM_016816 & $\begin{array}{l}\text { cggaccctacaggaaacttg } \\
\text { / tctgatacctcctgggatcg }\end{array}$ & $60^{\circ} \mathrm{C}$ \\
\hline PRNP & Prion protein & $\begin{array}{l}\text { NM_000311/ } \\
\text { NM_183079 }\end{array}$ & $\begin{array}{l}\text { gaggcaacctcccattttaga } \\
\text { / tcacaactgcagctctcetg }\end{array}$ & $61^{\circ} \mathrm{C}$ \\
\hline SERPINHI & $\begin{array}{l}\text { Serpin peptidase } \\
\text { inhibitor, clade } H \\
\text { (heat shock protein } \\
47 \text { ), member } 1\end{array}$ & NM_001235 & $\begin{array}{l}\text { Hs_SERPINH1_1_SG } \\
\text { QuantiTect } \\
\text { Assay }^{\dagger}\end{array}$ & $55^{\circ} \mathrm{C}$ \\
\hline
\end{tabular}

${ }^{a}$ From Public database: NCBI (Gene).

b Purchased at Applied Biosystems, Foster City, CA. 


\section{Alveolar macrophages in allergic asthma; an expression signature characterized by heat shock protein pathways}

Anne-Marie Madore, Stéphanie Perron, Véronique Turmel, Michel Laviolette, Élyse Y. Bissonnette, Catherine Laprise.

\section{Additional file 2}

\section{Methods}

\section{Genetic association study}

Subjects and samples: The sample comprised 253 families (probands and their relatives) originating from Saguenay-Lac-Saint-Jean for a total of 1,275 DNAs. A proportion of $37.0 \%$ of relatives were affected by asthma and $51.3 \%$ were atopic. All information concerning sample recruitment and clinical evaluation of the subjects were described in a recent report [1] and clinical characterization is available in the Table VIII.

Genotyping: Blood samples were drawn from all participants and DNA was extracted from blood leukocytes using Genomic-tip 100/G kit (Qiagen Inc.) according to manufacturer's instructions. Tagging single nucleotide polymorphisms (tagSNP), are SNPs that are in linkage disequilibrium with other SNPs nearby along the DNA, and are considered representative of them. Four, six and three tagSNPs were selected for HSPD1, $P R N P$ and SERPINH1 respectively, from the International HapMap project release 16c.1 
(CEU population) using Haploview software (version 3.31) with $\mathrm{R}^{2}$ and minor allele frequency cutoff of 0.8 and 0.05 respectively (Table 3) [2]. Genotyping of the rs608585, rs614604, and rs652054 SNPs was performed with TaqMan® SNP Genotyping Assays using the Rotor-Gene 3000 and the Rotor-Gene 6000 (Corbett Research) following manufacturer instructions (c_1029884_10, c_3220169_10 and c_3220177_10 respectively (Applied Biosystems)). The Rotor-Gene software (version 6.0) was used to determine genotypes using the scatter graph analysis option.

Genotyping for the ten remaining tagSNPs (rs6434930, rs788016, rs6745660, rs787983, rs6076714, rs6084833, rs6107516, rs1799990, rs12625444 and rs2756267) was done using the Sequenom $(\mathbb{B}$ matrix-assisted laser desorption/ionization time-of-flight (MALDI-TOF) mass array spectrometer (Sequenom Inc., San Diego, CA, USA). Primers were designed using the Sequenom SNP Assay Design software version 3.0 for iPLEX reactions. The protocol and reaction conditions are in accordance with the manufacturer [3]. The genotypes were viewed and analyzed using the MassARRAY Typer software version 3.4 (Sequenom).

Statistical analyses: Mendelian errors and allele distribution patterns were assessed by FBAT software (version 1.7) under additive model using the empirical variance estimator "-e" [4]. Hardy-Weinberg equilibrium for each tagSNP was done using Haploview software (3.31 version) [2].

Genotyping quality assessment: The genotyping mean success rate was $98.76 \%$ and all tagSNPs were in Hardy-Weinberg equilibrium. Thirteen mendelian errors were found across the entire dataset, leading to the exclusion of twelve families from the analysis. 


\section{References}

[1] Begin P, Tremblay K, Daley D, Lemire M, Claveau S, Salesse C, et al. Association of urokinase-type plasminogen activator with asthma and atopy. Am J Respir Crit Care Med. 2007 Jun 1;175(11):1109-16.

[2] Barrett JC, Fry B, Maller J, Daly MJ. Haploview: analysis and visualization of LD and haplotype maps. Bioinformatics. 2005 Jan 15;21(2):263-5.

[3] Oeth P, Beaulieu M, Park C, Kosman D, del Mistro G, van den Boom D, et al. iPLEX assay: Increased plexing efficiency and flexibility for MassArray system through single base primer extension with mass-modified terminators.; 2005.

[4] Lake SL, Blacker D, Laird NM. Family-based tests of association in the presence of linkage. Am J Hum Genet. 2000 Dec;67(6):1515-25. 


\section{Tables}

Table VII. Clinical characteristics of the French-Canadian familial collection

\begin{tabular}{|c|c|c|c|}
\hline & \multicolumn{3}{|c|}{ Families } \\
\hline & Probands $^{\mathrm{a}}$ & Affected relatives $^{\mathrm{a}}$ & Unaffected relatives $^{a}$ \\
\hline & $n=253$ & $\mathrm{n}=379$ & $n=643$ \\
\hline Male : Female ratio & $1: 1.12$ & $1: 1.27$ & $1: 1.10$ \\
\hline Mean age, yr (range) & $17(2-50)$ & $39(2-83)$ & $46(3-93)$ \\
\hline Median age, yr & 15 & 40 & 46 \\
\hline \multicolumn{4}{|l|}{ Smoking status, n (\%) } \\
\hline Never & $212(85)$ & $192(51)$ & $272(43)$ \\
\hline Ex-smoker ${ }^{b}$ & $12(5)$ & $112(30)$ & $234(37)$ \\
\hline Smoker & $25(10)$ & $71(19)$ & $128(20)$ \\
\hline $\mathrm{FEV}_{1}, \%$ predicted (SD) ${ }^{\mathrm{c}}$ & $92.7(16.0)$ & $88.9(22.4)$ & $99.1(17.2)$ \\
\hline $\mathrm{PC}_{20}, \mathrm{mg} / \mathrm{ml}(\mathrm{SD})^{\mathrm{d}}$ & $2.50(3.63)$ & $3.35(4.43)$ & $21.36(3.215)$ \\
\hline
\end{tabular}

Abbreviation used: $\mathrm{FEV}_{1}=$ Forced expiratory volume in one second, $\mathrm{PC}_{20}=$ Provocative concentration of methacholine that induces a $20 \%$ fall in $\mathrm{FEV}_{1}, \mathrm{SD}=$ Standard deviation.

a Probands are first affected family member recruited in the familial collection and affected and unaffected relatives referred to other family members of these probands who joined the study.

${ }^{\mathrm{b}}$ Ex-smokers are individuals who smoked less than 10 years.

${ }^{c}$ Geometric mean calculated for 218 probands, 325 affected relatives and 440 unaffected relatives.

${ }^{\mathrm{d}}$ Geometric mean calculated for 193 probands, 285 affected relatives and 418 unaffected relatives. 
Table VIII. Characteristics of the polymorphisms (TagSNPs)

\begin{tabular}{|c|c|c|c|c|}
\hline $\begin{array}{l}\text { Gene } \\
\text { symbol }\end{array}$ & TagSNP & Genomic feature $^{a}$ & $\begin{array}{l}\text { Chromosomal } \\
\text { location (bases) }^{a}\end{array}$ & $\begin{array}{l}\text { Reference allele } \\
\text { frequency in the } \\
\text { CEU population }\end{array}$ \\
\hline \multirow[t]{4}{*}{$H S P D 1$} & rs6434930 & Upstream 5'UTR & $198,077,615$ & 0.25 \\
\hline & rs 788016 & Intron 11 & $198,060,538$ & 0.43 \\
\hline & rs6745660 & Downstream 3' UTR & $198,057,781$ & 0.43 \\
\hline & rs 787983 & Downstream 3' UTR & $198,054,042$ & 0.25 \\
\hline \multirow[t]{6}{*}{$P R N P$} & rs6076714 & Upstream 5'UTR & $4,609,143$ & 0.89 \\
\hline & rs 6084833 & Intron 1 & $4,620,759$ & 0.94 \\
\hline & rs6107516 & Intron 1 & $4,625,092$ & 0.75 \\
\hline & rs1799990 & Exon $2(\mathrm{G} 129 \mathrm{~A})$ & $4,628,251$ & 0.65 \\
\hline & rs 12625444 & Downstream 3'UTR & $4,630,507$ & 0.80 \\
\hline & rs2756267 & Downstream 3'UTR & $4,636,713$ & 0.31 \\
\hline \multirow[t]{3}{*}{ SERPINHI } & rs 608585 & Upstream 5' UTR & $74,946,352$ & 0.84 \\
\hline & rs652054 & Intron 1 & $74,953,180$ & 0.68 \\
\hline & rs614604 & Intron 4 & $74,958,857$ & 0.48 \\
\hline
\end{tabular}

Abbreviations used: $\mathrm{CEU}=$ One of the four population of the HapMap project which contain thirty United States trios provided samples, which were collected from United States residents with northern and western European ancestry by the Centre d'Etude du Polymorphisme Humain $(\mathrm{CEPH}), H S P D 1=$ Heat shock $60 \mathrm{kDa}$ protein 1 (chaperonin), $P R N P=$ Prion protein, SERPINH1 = serpin peptidase inhibitor, clade $\mathrm{H}$ (heat shock protein 47), member 1 , tagSNP = Tagging single nucleotide polymorphism.

a According to National Center for Biotechnology Information public database build 128 (http://www.ncbi.nlm.nih.gov) 


\subsection{Discussion}

Le profil d'expression génétique des macrophages alvéolaires présenté dans cette étude devrait aider à mieux comprendre l'implication de ce type cellulaire dans le développement de la réponse asthmatique allergique dans les voies respiratoires. En effet, lors de l'expérimentation, 50 gènes (58 transcrits) se sont révélés différemment exprimés et $38 \%$ de ceux-ci ont des fonctions biologiques liées au stress ou la réponse immunitaire. Ces résultats suggèrent donc une implication du macrophage alvéolaire dans le développement de l'inflammation dans l'asthme.

Cette étude a aussi mis en évidence une sous-expression, dans les macrophages alvéolaires des sujets asthmatiques allergiques, de neuf gènes de la famille des HSP suggérant ainsi une implication particulière de cette famille de gènes. En effet, même si les HSP sont principalement connus pour leur fonction de chaperonne, des études ont maintenant démontré l'implication de certains d'entre eux (HSP60, 70, 90 et 110) dans la réponse immunitaire (Tsan et al. 2004; Tsan et al. 2004; Pockley et al. 2008). Plus précisément, le HSP60 et le HSP70 ont démontré des propriétés anti-inflammatoires dans des études sur la polyarthrite rhumatoïde ou d'arthrite juvénile et dans des modèles animaux (Pockley, Muthana et al. 2008). De plus, il a été démontré que le HSP60 stimule la sécrétion de différentes cytokines chez les lymphocytes T (Zanin-Zhorov et al. 2003) et B (Cohen-Sfady et al. 2005). Des récepteurs spécifiques au HSP60 ont aussi été identifiés sur certaines lignées de macrophages (Habich et al. 2002). De sont coté, HSP47 a été associé avec certaines affections respiratoires et inflammatoires telles que des fibroses, des maladies rhumatismales ainsi que des cancers (Sauk et al. 2005).

Finalement, les différences d'expression observées lors de cette étude peuvent s'expliquer par différents mécanismes biologiques. Dans certains cas, il peut être l'effet de 
mutations dans les régions régulatrices des gènes différemment exprimés. Toutefois, les études d'association génétiques effectuées pour les trois gènes validés soit PRNP, HSPDI et SERPINH1, indiquent qu'aucun polymorphisme ne semble être responsable de la différence d'expression observée. Ces données suggèrent donc qu'elle est probablement le résultat d'autres mécanismes dans leur voie biologique ou d'une régulation épigénétique (Wilson 2008).

Pour conclure, la caractérisation du rôle des nouveaux gènes d'intérêt identifiés lors de cette étude dans les voies biologiques liées à la réponse immunitaire du macrophage alvéolaires dans l'asthme pourrait donc permettre d'élaborer de nouvelles stratégies de prévention ou de contrôle de cette affection. 


\section{Chapitre IV: Évaluation du potentiel anti- inflammatoire d'un composé isolé d'origine naturelle en utilisant le macrophage comme modèle cellulaire}

\subsection{Introduction}

La médecine traditionnelle utilise depuis très longtemps les plantes pour soulager divers maux. C'est aux plantes que l'on doit beaucoup de composés actifs utilisés comme médicaments. Approximativement $60 \%$ de la population mondiale voit leur médication presque entièrement composée de médicaments de source naturelle (Harvey 2000). Selon les estimations, seulement $10 \%$ le nombre d'espèces végétales étudiées actuellement pour leurs activités biologiques (Harvey 2000). La forêt boréale constitue le plus vaste biôme ou (unité biogéographique) du Canada. Elle représente, à elle seule, $35 \%$ de la superficie totale $\mathrm{du}$ Canada et $77 \quad \%$ des forêts canadiennes (http://atlas.gc.ca/site/francais/learning_resources).

La Brasenia schreberi Gmel. (Cabombaceae), plante aquatique de la forêt boréale, s'est avérée intéressante pour ses vertues médicinales lors de ce projet de recherche (Figure 6). Cette plante se retrouve principalement en Amérique du Nord et, par stations isolées, dans certaines régions du sud-ouest de l'Afrique, de l'est de l'Australie, de l'Inde et du Japon (Marie-Victorin 1964). Dans la médecine folklorique, les feuilles de cette plante 
étaient utilisées pour soigner les abcès ou les furoncles (Duke 1985), pour le traitement de la tuberculose (Chopra 1986) et du cancer de l'estomac (Hartwell 1982). Au cours de cette étude, une extraction à partir des feuilles de $B$. schreberi a été effectuée et un composé aux propriétés bioactives, la quercetin-7-O- $\beta$-glucopyranoside, aussi appelé querciméritrine, a pu être isolé.

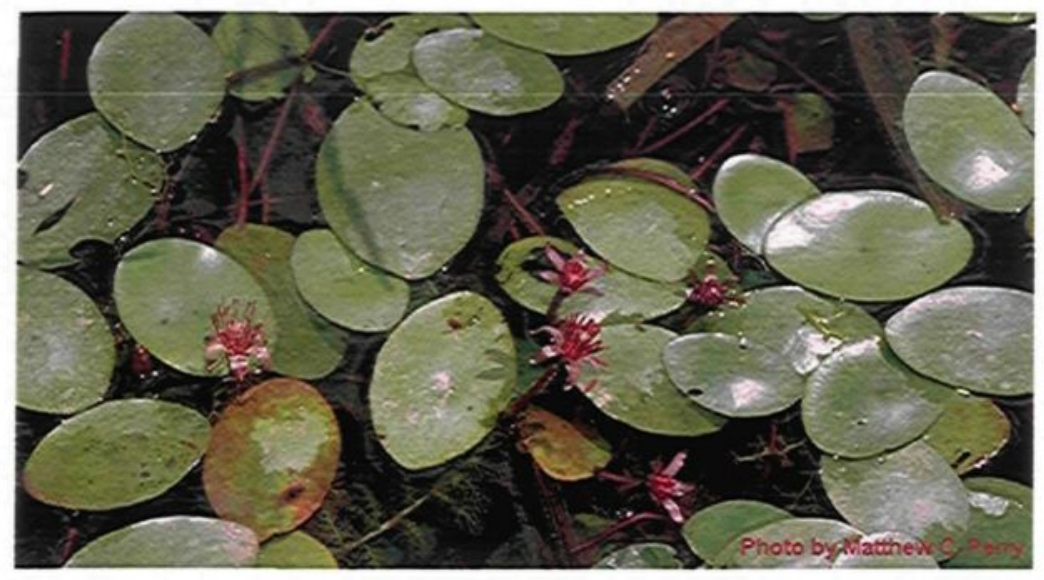

Figure 6. La Brasenia schreberi Gmel. (Cabombaceae)

Plus précisément, la querciméritrine, est un dérivé glycosylé de la quercétine, un flavonoïde aux propriétés anti-oxydantes et anti-inflammatoires bien connue (Bischoff 2008). Dans le deuxième volet de ce projet de recherche, le potentiel anti-inflammatoire de la quercirémitrine a été évalué en utilisant le macrophage comme modèle cellulaire afin de traiter des pathologies comme l'asthme allergique. En effet, la découverte de nouveaux composés naturels ayant un effet modulateur sur les différentes fonctions des macrophages pourrait permettre de bloquer la cascade inflammatoire observée dans l'asthme et ainsi diminuer les symptômes de la maladie. La découverte de nouveaux traitements antiinflammatoires alternatifs aux corticostéroïdes est un enjeu important dans la recherche sur les affections à caractère inflammatoire. 


\subsection{Matériel et méthode}

\subsubsection{Culture cellulaire}

La lignée cellulaire de macrophages murins RAW 264.7 (ATCC \#TIB-71) a été cultivée dans du milieu DMEM (Dulbecco's modified Eagle's medium) (Mediatech Cellgro, VA), auquel ont été ajoutés $10 \%$ de sérum fœetal de bovin (FBS) (Hyclone), des vitamines (1X), des antibiotiques (penicilline $100 \mathrm{I} . \mathrm{U} . / \mathrm{mL}$ et streptomycine $100 \mu \mathrm{g} / \mathrm{mL}$ ), des acides aminés $(1 \mathrm{X})$ ainsi que du sodium pyruvate (1X) (Mediatech Cellgro, VA). Les cellules ont été cultivées à $37^{\circ} \mathrm{C}$ dans une atmosphère contenant $5 \%$ de $\mathrm{CO}_{2}$ et utilisées en phase exponentielle de croissance

\subsubsection{Stimulation des cellules}

Les macrophages en phase exponentielle ont été ensemencés dans des microplaques de 24 puits (BD Falcon) à une densité de $2 \times 10^{4}$ cellules par puits. Ils ont ensuite été incubés pendant 24 heures afin de leur permettre d'adhérer. Les cellules ont par la suite été traitées avec quatre différentes concentrations de querciméritrine $(30 \mu \mathrm{g} / \mathrm{mL}, 15 \mu \mathrm{g} / \mathrm{mL}, 7,5$ $\mu \mathrm{g} / \mathrm{mL}$ et $3,75 \mu \mathrm{g} / \mathrm{mL})$. Le L-NAME (N(G)-nitro-L-arginine methyl ester) $(1 \mathrm{mM}$ et 250 $\mu \mathrm{M})$ a été utilisé comme contrôle positif pour l'expérimentation. Les macrophages ont ensuite été stimulés avec de l'IFN- $\gamma(0,078 \mathrm{ug} / \mathrm{mL})$ pour $24 \mathrm{~h}$ à $37^{\circ} \mathrm{C}$. Le surnageant a été récolté pour la détermination de la quantité de NO selon la méthode de révélation au réactif de GRIESS (Green et al. 1990). Les cellules ont été récoltées afin de mesurer le niveau de la nitric oxide synthase (iNOS). Tous les tests ont été effectués en triplicata. 


\subsubsection{Test d'activité anti-inflammatoire (Griess nitrite assay)}

En résumé, $100 \mu \mathrm{L}$ du surnageant des cellules a été incubé avec $100 \mu \mathrm{L}$ de réactif de GRIESS $\quad(50 \mu \mathrm{L}$ de sulfanilamide $1 \%$ et $50 \mu \mathrm{L}$ de N-1-naphtylethylenediamine dihydrochloride $0,1 \%$ dans $2,5 \% \mathrm{H}_{3} \mathrm{PO}_{4}$ ) à température ambiante, pendant 30 minutes. L'absorbance à $540 \mathrm{~nm}$ a été mesurée à l'aide du Varioskan Ascent plate reader (Thermo Electron, US) et la présence de nitrite a été quantifiée à partir d'une courbe standard de $\mathrm{NaNO}^{2}$. Chaques tests a été effectués trois fois en triplicatas.

\subsubsection{Mesure du niveau d'iNOS}

Afin de mesurer la niveau de la nitric oxide synthase (iNOS), les extraits protéiques ont été préparés dans du tampon d'extraction contenant $10 \mathrm{mM}$ d'Hepes, $1,5 \mathrm{mM}$ de $\mathrm{MgCl}_{2}$ , $10 \mathrm{mM}$ de $\mathrm{KCl}, 0,5 \mathrm{mM}$ de DTT, $10 \mathrm{mM}$ de $\mathrm{Na}_{4} \mathrm{P}_{2} \mathrm{O}_{7}, 50 \mathrm{mM}$ de NaF, $1 \mathrm{mM}$ de Na3VO4 et 1,5 mM de EGTA, ainsi qu'un cocktail d'inhibiteurs de protéase/peptidase contenant 5 $\mathrm{mg} / \mathrm{mL}$ de phenylmethanesulfonyl fluoride (PMSF), $100 \mu \mathrm{g} / \mathrm{mL}$ de Approtinin et 15,5 $\mathrm{mg} / \mathrm{mL}$ de Benzamidine hydrochloride hydrate dans du ETOH et un «cocktail» d'inhibiteurs (Sigma-Aldrich). Après une centrifugation de $10 \mathrm{~min}$ à $13000 \mathrm{~g}$, le surnageant a été recueilli et entreposé à $-80^{\circ} \mathrm{C}$. La concentration en protéines a été mesurée selon la méthode décrite par Bradford (Bradford 1976) (Bradford Dye reagent obtenu chez Bio-Rad Laboratory Inc, Ontario, Canada), et quantifiée par comparaison avec une courbe standard d'albumine provenant du sérum de bovin (BSA).

Vingt microgrammes de proteines ont été mélangées à un tampon de chargement contenant, en concentration finale, $100 \mathrm{mM}$ de Tris- $\mathrm{HCl}, 4 \%$ de SDS, $20 \%$ de glycerol, $0.2 \%$ de Bromophenol Blue, $200 \mathrm{mM}$ de DTT, et ont été chauffées à $100^{\circ} \mathrm{C}$ pendant $4 \mathrm{~min}$. L'électrophorèse a été effectuée sur un gel SDS-PAGE $4 \%$ concentration/10\% séparation (migration de $30 \mathrm{~min}$ à 60 Volts, suivi de $90 \mathrm{~min}$ à 155 Volts) et transférée sur une 
membrane de type PVDF (polyvinylidenedifluoride) de $0,45 \mathrm{~mm}$ (30 Volts pour $24 \mathrm{~h}$ à $4^{\circ} \mathrm{C}$ ). Le blocage a été effectué dans une solution de $5 \%$ de lait écrémé en poudre dans du TBS-T (Tris-buffered saline) (25 mM Tris-base, $137 \mathrm{mM} \mathrm{NaCl}$ additionné de $0.1 \%$ Tween 20) pour $1 \mathrm{~h}$ et incubé avec un anticorps primaire anti-iNOS (anticorps (IgG) polyclonaux provenant du lapin, Sigma-Aldrich) (1:10000) pour $1 \mathrm{~h}$ à température ambiante. L'incubation avec l'anticorps primaire anti- $\beta$-actin (anticorps (IgG) polyclonaux provenant du lapin, Sigma-Aldrich) (1:150) a été de $24 \mathrm{~h}$ à $4^{\circ} \mathrm{C}$. Les membranes ont ensuite été incubées 1 heure avec un anticorps secondaire anti-lapin couplé à une molécule HRP (HorseRadish Peroxidase) (Amersham) (1:5000). Les membranes ont ensuite été exposées au réactif ECL Plus (Amersham) pendant $5 \mathrm{~min}$. Le signal a pu être visualisé à l'aide du Système ChemiDoc ${ }^{\mathrm{TM}}$ XRS (Bio-Rad). La quantification densitométrique a été analysée avec le logitiel Quantity One (4.5.2). Chaque test a été effectué trois fois en triplicata.

\subsubsection{Cytotoxicité}

La cytotoxicité de la querciméritrine a été évalué à l'aide du test à la rézasurine développé par O'Brien et al. 2000 ( O'Brien et al. 2000). En bref, les macrophages RAW 264.7 préalablement traités et non traités ont été resuspendus dans une solution de rézasurine dans du HBSS (Hank's Buffered Salt Solution). Après une incubation de 60 min, La fluorescence a été mesurée à l'aide du Varioskan Ascent plate reader (Thermo Electron).

\subsubsection{Analyses statistiques}

Pour les analyses statistiques, des tests de Student ont été effectués pour chaque expérience avec un seuil de signification de $95 \%$. 


\subsection{Résultats}

\subsubsection{Test d'activité anti-inflammatoire (Griess nitrite assay)}

La figure 7 démontre que la querciméritrine inhibe significativement la production de NO dans la lignée de macrophages de souris RAW264.7. En effet, afin de mesurer l'effet du composé sur les macrophages de souris, les cellules ont été stimulées avec de l'IFN- $\gamma$, et traitées avec différentes concentrations de querciméritrine pendant 24 heures. Les cellules stimulées à l'IFN- $\gamma$ mais non traitées avec le composé ont démontré une augmentation drastique de la production de NO. Tandis que la production de NO induite par l'IFN- $\gamma$ a été significativement inhibée par les différentes concentrations de querciméritrine, et ce de manière dose-dépendante jusqu'à $68 \%$ d'inhibition pour une concentration de $30 \mathrm{ug} / \mathrm{mL}$ et ce, sans toxicité cellulaire observable. La survie cellulaire a été déterminée par le test de transformation de la rézasurine. Aucune différence significative dans la viabilité des cellules traitées avec la querciméritrine par rapport au contrôle n'a été observée (données non présentées). Les résultats présentés sont représentatifs de trois expériences différentes.

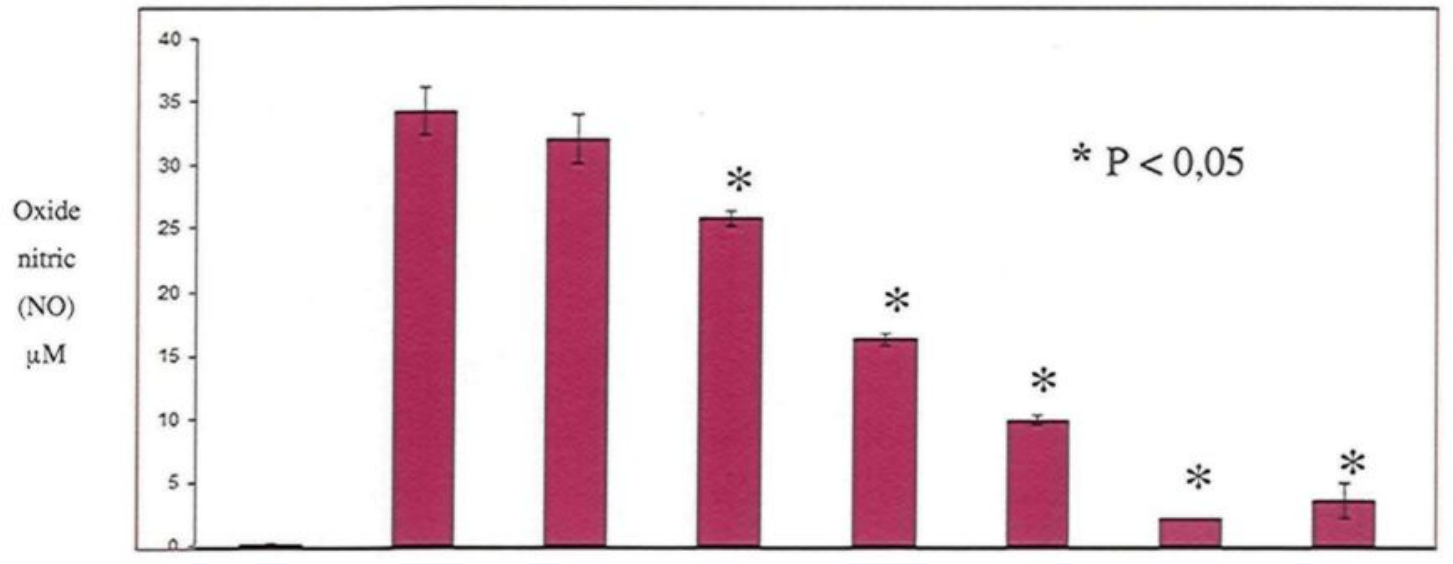

\begin{tabular}{|c|c|c|c|c|c|c|c|}
\hline & \multicolumn{4}{|c|}{ IFN- $78 \mathrm{ng} / \mathrm{mL}$ + Quercimeritrin $(\mathrm{ug} / \mathrm{mL})$} & \multicolumn{2}{c|}{$\begin{array}{c}\text { L-NAME } \mathrm{mM}+ \\
\text { IFN- } \gamma(78 \mathrm{ng} / \mathrm{mL})\end{array}$} \\
\hline DMEM & 0 & 3.75 & 7.5 & 15 & 30 & 1 & 0,25 \\
\hline
\end{tabular}

Figure 7. Inhibition de la production d'oxyde nitrique dans les macrophages de souris RAW264.7 par la querciméritrine sous stimulation à l'IFN- $\left.\gamma .{ }^{*}=\mathrm{P}<0.05\right)$. 


\subsubsection{Mesure de l'expression de iNOS}

Étant donné l'inhibition de la production de NO par la querciméritrine dans des macrophages de souris RAW264.7 sous stimulation à l'IFN- $\gamma$, l'expression de l'enzyme responsable de sa production, la forme inductible de l'iNOS a aussi été mesurée afin d'élucider le mécanisme d'inhibition du composé. La figure 8 démontre qu'après stimulation à l'IFN- $\gamma$ et traitement avec différentes concentrations de querciméritrine, une diminution significative de l'expression de iNOS a pu être observée, et ce de manière dosedépendante. Les résultats présentés sont représentatifs de 3 expériences différentes.

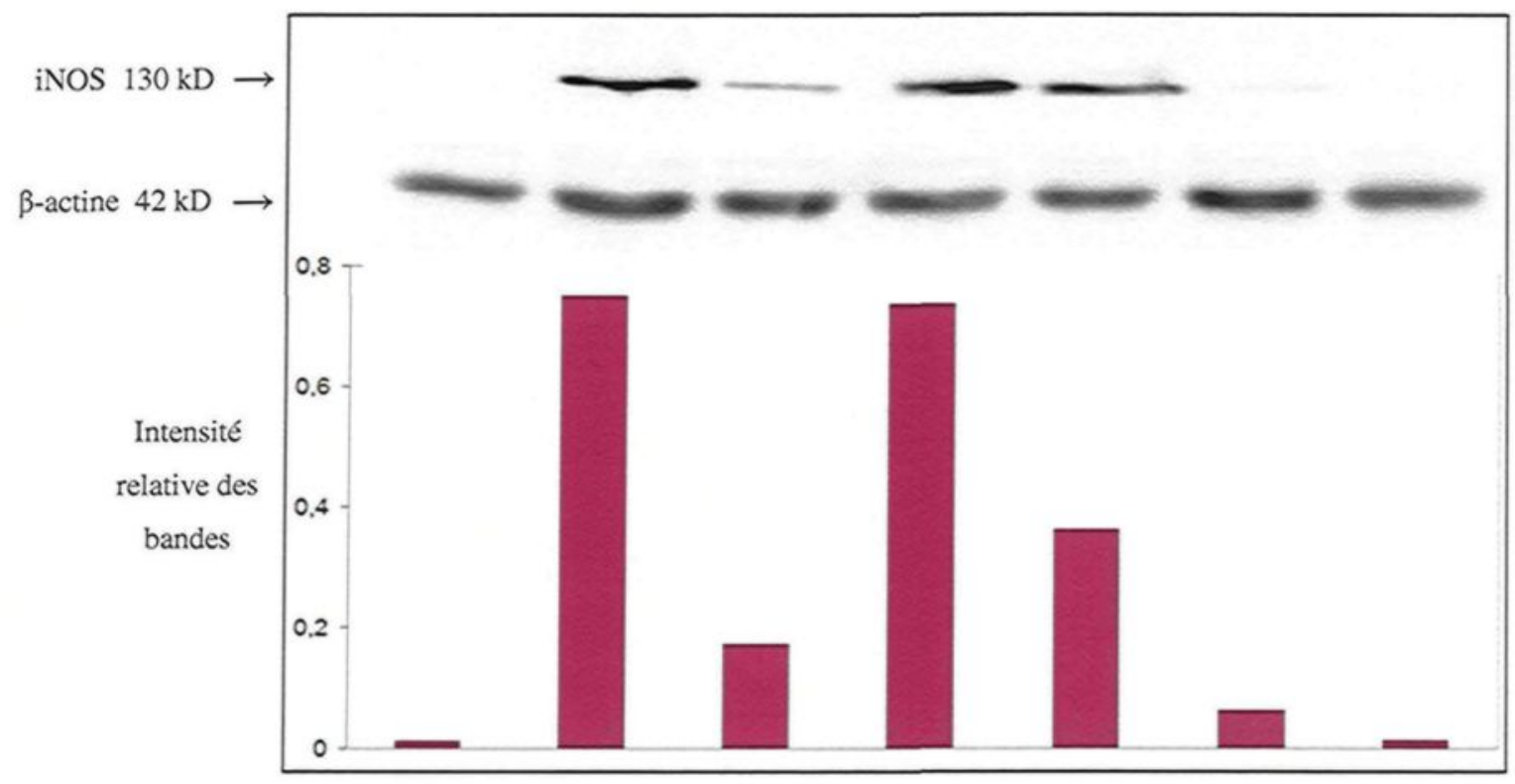

\begin{tabular}{|c|c|c|c|c|c|c|}
\hline \multicolumn{4}{|c|}{ Control } & \multicolumn{4}{c|}{ IFN- $\gamma(78 \mathrm{ug} / \mathrm{mL})+$ Quercimeritrin $(\mathrm{ug} / \mathrm{mL})$} \\
\hline DMEM & $\begin{array}{c}\text { IFN- } \gamma \\
78 \mathrm{ng} / \mathrm{mL}\end{array}$ & $\begin{array}{c}\text { L-NAME } \\
1 \mathrm{mM}\end{array}$ & 3.75 & 7.5 & 15 & 30 \\
\hline
\end{tabular}

Figure 8. Effet de la querciméritrine sur l'expression de iNOS dans les macrophages de souris RAW264.7 sous stimulation à l'IFN- $\gamma .\left({ }^{*}=\mathrm{P}<0.05\right)$ 


\subsection{Discussion}

Les macrophages jouent un rôle essentiel dans l'initiation, la maintenance et la résolution de l'inflammation (Bernstein 2008). Ils peuvent être activés dans le processus inflammatoire par des médiateurs pro-inflammatoires tels que l'IFN- $\gamma$, le granulocyte monocyte-colonie (GM-CSF), le TNF- $\alpha$, les lipopolysaccharide provenant de bactéries, les protéines de la matrice extracellulaire et d'autres médiateurs chimiques (Mosser 2003; Fujiwara and Kobayashi 2005). Lorsqu'ils sont activés, les macrophages peuvent à leur tour sécréter une panoplie de médiateurs pro ou anti-inflammatoires contribuant ainsi à l'autorégulation du processus inflammatoire. L'un des produits sécrétés par les macrophages activés est le NO (Bosca, Zeini et al. 2005; Xia and Triffitt 2006).

Le NO joue divers rôles dans les processus physiologiques et pathologiques. En fonction de sa concentration, il peut être impliqué dans la neurotransmission, la régulation des contractions du muscle lisse, la perméabilité vasculaire, ainsi que dans la réponse immunitaire (Korhonen et al. 2005). Le NO est produit par une grande variété de types cellulaires et résulte de l'oxydation de la L-arginine, processus catalysé par l'enzyme nitric oxide synthase (NOS) (Aktan 2004).

Dans l'inflammation, le NO est principalement produit par l'iNOS, la forme inductible de NOS (Aktan 2004). Le NO a plusieurs fonctions dans le système immunitaire, autant effectrice que régulatrice. C'est un puissant produit toxique contre les agents infectieux, il est inducteur ou suppresseur de l'apoptose (Kroncke et al. 2001; Bosca, Zeini et al. 2005), et joue un rôle d'immunomodulateur (Langrehr et al. 1993). En effet, le NO a un effet direct sur la modulation de la réponse immunitaire en supprimant la prolifération des lymphocytes $\mathrm{T}$ ainsi que la sécrétion de cytokines de type Th1. Il favorise donc le 
développement de la réponse Th2 (Barnes 1995), ainsi que le recrutement et la survie des éosinophiles (Hebestreit et al. 1998; Conran et al. 2001)

Chez les asthmatiques, une augmentation de la quantité de NO dans l'air exhalé est habituellement observée. De plus, le niveau de NO dans l'air exhalé est corrélé avec les symptômes cliniques de l'asthme (Lehtimaki et al. 2001; Payne et al. 2001). Par ailleurs, une augmentation de la transcription du gène codant pour l'enzyme iNOS, le NOS2, a été observé chez les asthmatiques principalement dans le macrophage et les cellules épithéliales (Hamid et al. 1993; Saleh et al. 1998).

Les résultats préliminaires de cette étude démontrent que la querciméritrine isolée à partir des feuilles de la Brasenia schreberi Gmel. (Cabombaceae) inhibe la production de NO dans les macrophages RAW264.7 stimulés avec de l'IFN- $\gamma$. Cet effet inhibiteur a été accompagné par une diminution de l'expression de la protéine iNOS, et ce de manière dose-dépendante. Cette inhibition peut s'expliquer par différents mécanismes biologiques. Une expérimentation plus approfondie s'avère nécessaire afin d'élucider les mécanismes impliqués. Cependant, ces résultats préliminaires suggèrent que l'expression d'iNOS est diminuée par la querciméritrine, et que cette inhibition est mise en évidence par la diminution de la production de NO par les macrophages. L'hypothèse formulée pour expliquer cet effet est que la querciméritrine pourrait inhiber la liaison à l'ADN d'un important facteur de transcription soit NF-kB. Ce facteur participe à la régulation de l'expression d'une multitude de gènes impliqués dans l'inflammation et est essentiel pour l'expression d'iNOS dans les macrophages stimulés avec de l'IFN- $\gamma$. Des tests supplémentaires sont par contre nécessaires afin d'explorer cet avenue. 
La suite de ce projet devrait porter sur la mesure de l'activité du facteur de transcription $\mathrm{NF}-\kappa \mathrm{B}$, ainsi que la mesure de l'expression de gènes inflammatoires dans la voie biologique de l'IFN- $\gamma$ dans les macrophages RAW 264.7, afin d'élucider les mécanismes impliqués dans l'activité de la querciméritrine. Par la suite, il serait intéressant de tester les effets de la Querciméritrine sur des macrophages alvéolaires de sujets asthmatiques allergiques et témoins. Par ailleurs, ce projet pourrait permettre de valoriser une espèce non-commerciale de la forêt boréale par son utilisation dans le traitement des pathologies inflammatoires comme l'asthme allergique. 


\section{Chapitre V: Conclusions et perspectives}

L'asthme est une maladie caractérisée par une haute prévalence mondiale. Les coûts reliés aux soins d'urgence administrés aux asthmatiques sont en constante augmentation et positionne cette affection parmi les plus coûteuses pour le système de santé. L'asthme est une affection respiratoire chronique et l'inflammation provoquée par l'interaction de différentes cellules effectrices avec la muqueuse bronchique est à l'origine de l'apparition de ces symptômes.

Le processus inflammatoire est habituellement régulé par des signaux autant pro que anti-inflammatoires. Tout débalancement entre ces deux signaux peut provoquer différents problèmes et causer des dommages à l'intégrité tissulaire. De par leurs différents rôles soit phagocyte professionnel, présentateur antigénique et immunomodulateur, les macrophages sont des cellules importantes impliquées dans l'autorégulation du processus inflammatoire.

Cette étude à permis d'améliorer nos connaissances sur le rôle du MA dans la pathologie de l'asthme et de préciser les particularités génétiques des différents phénotypes de MA (sujets asthmatiques versus témoins), permettant ainsi de mieux définir les bases moléculaires de cette affection. Plusieurs fonctions des macrophages alvéolaires permettent de croire que cette cellule pourrait être impliquée directement ou indirectement dans le développement de cette affection. L'étude de la différence d'expression génétique entre les macrophages alvéolaires des sujets atteints d'asthme allergique en comparaison avec les témoins par le biais des puces à $\mathrm{ADN}$ a donc permis d'identifier de nouveaux gènes et voies biologiques potentiellement impliqués dans cette pathologie. En effet, l'étude comparative a permis la mise en évidence de 50 gènes différemment exprimés. Dix-neuf de 
ces gènes ont été classés dans la catégorie de la réponse immunitaire ou la réponse au stress. Parmi ceux-ci, neuf font partie de la famille des HSP. Cette famille de gènes, plus connu pour leur rôle de chaperonnes, constitue donc de nouvelles cibles potentielles pour des études fonctionnelles dans une affection à caractère inflammatoire tel que l'asthme.

Ce projet de recherche a aussi permis l'évaluation de potentiel anti-inflammatoire d'un composé isolé provenant d'une espèce végétale de la forêt boréale, la querciméritrine, en utilisant le macrophage comme modèle. En effet, la capacité de la querciméritrine à inhiber l'expression de la protéine iNOS et donc la production de NO par le macrophage a été observée. Ces résultats sont cependant préliminaires et n'ont pas permis d'élucider les mécanismes responsables de la bioactivité de cette molécule. Des recherches dans ce sens constituraient donc une avenue intéressante pour la suite de ce projet. Lors de l'expérimentation de ce projet de recherche, le deuxième volet a été effectué en premier sur des macrophages RAW 264.7. Ce qui explique que le macrophage alvéolaire n'a pas été utilisé comme modèle cellulaire pour tester la molécule. L'utilisation du macrophage alvéolaire pour tester l'activité de la querciméritrine constitue donc une suite intéressante à ce projet de recherche.

Pour conclure, par leur capacité à sécréter une panoplie de molécules bioactives participant autant aux évènements favorables que défavorables durant le processus inflammatoire, les macrophages s'avèrent des modèles cellulaires intéressant pour la recherche de nouvelles avenues thérapeutiques. De ce fait, les recherches thérapeutiques ayant pour cible les macrophages ou leurs produits pourraient ouvrir de nouvelles voies pour le contrôle des maladies inflammatoires comme l'asthme. 


\section{Références}

Adcock, I. M. and Barnes, P. J. (2008). "Molecular mechanisms of corticosteroid resistance." Chest 134(2): 394-401.

Adcock, I. M. and Caramori, G. (2001). "Cross-talk between pro-inflammatory transcription factors and glucocorticoids." Immunol Cell Biol 79(4): 376-84.

Adcock, I. M., Ford, P. A., Bhavsar, P., Ahmad, T. and Chung, K. F. (2008). "Steroid resistance in asthma: mechanisms and treatment options." Curr Allergy Asthma Rep 8(2): 171-8.

Aderem, A. (2003). "Phagocytosis and the inflammatory response." J Infect Dis 187 Suppl 2: S340-5.

Aktan, F. (2004). "iNOS-mediated nitric oxide production and its regulation." Life Sci 75(6): $639-53$.

Alexis, N. E., Soukup, J., Nierkens, S. and Becker, S. (2001). "Association between airway hyperreactivity and bronchial macrophage dysfunction in individuals with mild asthma." Am J Physiol Lung Cell Mol Physiol 280(2): L369-75.

Avila, M. A., Velasco, J. A., Cansado, J. and Notario, V. (1994). "Quercetin mediates the down-regulation of mutant p53 in the human breast cancer cell line MDA-MB468." Cancer Res 54(9): 2424-8.

Balbo, P., Silvestri, M., Rossi, G. A., Crimi, E. and Burastero, S. E. (2001). "Differential role of CD80 and CD86 on alveolar macrophages in the presentation of allergen to T lymphocytes in asthma." Clin Exp Allergy 31(4): 625-36.

Barnes, P. J. (1995). "Nitric oxide and asthma." Res Immunol 146(9): 698-702. 
Barnes, P. J. (2000). "Chronic obstructive pulmonary disease." N Engl J Med 343(4): 26980.

Bateman, E. D., Hurd, S. S., Barnes, P. J., Bousquet, J., Drazen, J. M., FitzGerald, M., Gibson, P., Ohta, K., O'Byrne, P., Pedersen, S. E., Pizzichini, E., Sullivan, S. D., Wenzel, S. E. and Zar, H. J. (2008). "Global strategy for asthma management and prevention: GINA executive summary." Eur Respir J 31(1): 143-78.

Bernstein, D. I. (2008). "ABCs of Asthma." Clin Cornerstone 8(4): 9-25.

Bischoff, S. C. (2008). "Quercetin: potentials in the prevention and therapy of disease." Curr Opin Clin Nutr Metab Care 11(6): 733-40.

Bissonnette, E. (2000). "Alveolar macrophages in the pathogenesis of asthma." Recent Res. Devol. Allergy \& Clin. Immunol. 1: 129-141.

Bosca, L., Zeini, M., Traves, P. G. and Hortelano, S. (2005). "Nitric oxide and cell viability in inflammatory cells: a role for NO in macrophage function and fate." Toxicology 208(2): 249-58.

Bousquet, J., Jeffery, P. K., Busse, W. W., Johnson, M. and Vignola, A. M. (2000). "Asthma. From bronchoconstriction to airways inflammation and remodeling." Am J Respir Crit Care Med 161(5): 1720-45.

Bradding, P., Walls, A. F. and Holgate, S. T. (2006). "The role of the mast cell in the pathophysiology of asthma." J Allergy Clin Immunol 117(6): 1277-84.

Bradford, M. M. (1976). "A rapid and sensitive method for the quantitation of microgram quantities of protein utilizing the principle of protein-dye binding." Anal Biochem 72: 248-54. 
Brightling, C. E., Bradding, P., Symon, F. A., Holgate, S. T., Wardlaw, A. J. and Pavord, I. D. (2002). "Mast-cell infiltration of airway smooth muscle in asthma." N Engl J Med 346(22): 1699-705.

Bumbacea, D., Campbell, D., Nguyen, L., Carr, D., Barnes, P. J., Robinson, D. and Chung, K. F. (2004). "Parameters associated with persistent airflow obstruction in chronic severe asthma." Eur Respir J 24(1): 122-8.

Burastero, S. E., Magnani, Z., Confetti, C., Abbruzzese, L., Oddera, S., Balbo, P., Rossi, G. A. and Crimi, E. (1999). "Increased expression of the CD80 accessory molecule by alveolar macrophages in asthmatic subjects and its functional involvement in allergen presentation to autologous TH2 lymphocytes." J Allergy Clin Immunol 103(6): 1136-42.

Busse, W., Raphael, G. D., Galant, S., Kalberg, C., Goode-Sellers, S., Srebro, S., Edwards, L. and Rickard, K. (2001). "Low-dose fluticasone propionate compared with montelukast for first-line treatment of persistent asthma: a randomized clinical trial." J Allergy Clin Immunol 107(3): 461-8.

Busse, W. W. and Lemanske, R. F., Jr. (2001). "Asthma." N Engl J Med 344(5): 350-62.

Canada, S. (2000). "Prévention et prise en charge de l'asthme au Canada. Rapport

présenté au LLCM ", from http://www.phac-aspc.gc.ca/publicat/pma-pca00/index-fra.php.

Careau, E. and Bissonnette, E. Y. (2004). "Adoptive transfer of alveolar macrophages abrogates bronchial hyperresponsiveness." Am J Respir Cell Mol Biol 31(1): 22-7.

Catley, M. C., Sukkar, M. B., Chung, K. F., Jaffee, B., Liao, S. M., Coyle, A. J., Haddad el, B., Barnes, P. J. and Newton, R. (2006). "Validation of the anti-inflammatory properties of small-molecule IkappaB Kinase (IKK)-2 inhibitors by comparison with adenoviral-mediated delivery of dominant-negative IKK1 and IKK2 in human airways smooth muscle." Mol Pharmacol 70(2): 697-705. 
Chan, M. T., Leung, D. Y., Szefler, S. J. and Spahn, J. D. (1998). "Difficult-to-control asthma: clinical characteristics of steroid-insensitive asthma." J Allergy Clin Immunol 101(5): 594-601.

Chaplin, D. D. (2003). "1. Overview of the immune response." J Allergy Clin Immunol 111(2 Suppl): S442-59.

Chapman, K. R., Boulet, L. P., Rea, R. M. and Franssen, E. (2008). "Suboptimal asthma control: prevalence, detection and consequences in general practice." Eur Respir $\mathrm{J}$ 31(2): $320-5$.

Chopra, R. N., Nayar, S.L., Chopra, I.C. (1986). Glossary of Indian medicinal plants (Including supplement), Council of Scientific and Industrial Research: New Delhi, India.

Cohen-Sfady, M., Nussbaum, G., Pevsner-Fischer, M., Mor, F., Carmi, P., Zanin-Zhorov, A., Lider, O. and Cohen, I. R. (2005). "Heat shock protein 60 activates B cells via the TLR4-MyD88 pathway." J Immunol 175(6): 3594-602.

Cohn, L., Elias, J. A. and Chupp, G. L. (2004). "Asthma: mechanisms of disease persistence and progression." Annu Rev Immunol 22: 789-815.

Conran, N., Ferreira, H. H., Lorand-Metze, I., Thomazzi, S. M., Antunes, E. and de Nucci, G. (2001). "Nitric oxide regulates human eosinophil adhesion mechanisms in vitro by changing integrin expression and activity on the eosinophil cell surface." $\mathrm{Br} \mathrm{J}$ Pharmacol 134(3): 632-8.

Cosio, B. G., Mann, B., Ito, K., Jazrawi, E., Barnes, P. J., Chung, K. F. and Adcock, I. M. (2004). "Histone acetylase and deacetylase activity in alveolar macrophages and blood mononocytes in asthma." Am J Respir Crit Care Med 170(2): 141-7.

Duke, J. A. (1985). "Medicinal plants." Science 229(4718): 1036, 1038. 
Fujiwara, N. and Kobayashi, K. (2005). "Macrophages in inflammation." Curr Drug Targets Inflamm Allergy 4(3): 281-6.

Gaffin, J. M. and Phipatanakul, W. (2009). "The role of indoor allergens in the development of asthma." Curr Opin Allergy Clin Immunol 9(2): 128-35.

Gerritsen, M. E., Carley, W. W., Ranges, G. E., Shen, C. P., Phan, S. A., Ligon, G. F. and Perry, C. A. (1995). "Flavonoids inhibit cytokine-induced endothelial cell adhesion protein gene expression." Am J Pathol 147(2): 278-92.

Gordon, S. (2002). "Pattern recognition receptors: doubling up for the innate immune response." Cell 111(7): 927-30.

Green, S. J., Meltzer, M. S., Hibbs, J. B., Jr. and Nacy, C. A. (1990). "Activated macrophages destroy intracellular Leishmania major amastigotes by an L-argininedependent killing mechanism." J Immunol 144(1): 278-83.

Habich, C., Baumgart, K., Kolb, H. and Burkart, V. (2002). "The receptor for heat shock protein 60 on macrophages is saturable, specific, and distinct from receptors for other heat shock proteins." J Immunol 168(2): 569-76.

Hamid, Q., Springall, D. R., Riveros-Moreno, V., Chanez, P., Howarth, P., Redington, A., Bousquet, J., Godard, P., Holgate, S. and Polak, J. M. (1993). "Induction of nitric oxide synthase in asthma." Lancet 342(8886-8887): 1510-3.

Hartwell, J. L. (1982). Plants used against cancer. Q. P. Inc. Lawrence, MA.: pp 30-4.

Harvey, A. (2000). "Strategies for discovering drugs from previously unexplored natural products." Drug Discov Today 5(7): 294-300.

Hearing, S. D., Norman, M., Smyth, C., Foy, C. and Dayan, C. M. (1999). "Wide variation in lymphocyte steroid sensitivity among healthy human volunteers." $\mathrm{J}$ Clin Endocrinol Metab 84(11): 4149-54. 
Heaton, T., Rowe, J., Turner, S., Aalberse, R. C., de Klerk, N., Suriyaarachchi, D., Serralha, M., Holt, B. J., Hollams, E., Yerkovich, S., Holt, K., Sly, P. D., Goldblatt, J., Le Souef, P. and Holt, P. G. (2005). "An immunoepidemiological approach to asthma: identification of in-vitro $\mathrm{T}$-cell response patterns associated with different wheezing phenotypes in children." Lancet 365(9454): 142-9.

Hebestreit, H., Dibbert, B., Balatti, I., Braun, D., Schapowal, A., Blaser, K. and Simon, H. U. (1998). "Disruption of fas receptor signaling by nitric oxide in eosinophils." J Exp Med 187(3): 415-25.

Hodnick, W. F., Duval, D. L. and Pardini, R. S. (1994). "Inhibition of mitochondrial respiration and cyanide-stimulated generation of reactive oxygen species by selected flavonoids." Biochem Pharmacol 47(3): 573-80.

Hogan, S. P., Rosenberg, H. F., Moqbel, R., Phipps, S., Foster, P. S., Lacy, P., Kay, A. B. and Rothenberg, M. E. (2008). "Eosinophils: biological properties and role in health and disease." Clin Exp Allergy 38(5): 709-50.

Holt, P. G., Oliver, J., Bilyk, N., McMenamin, C., McMenamin, P. G., Kraal, G. and Thepen, T. (1993). "Downregulation of the antigen presenting cell function(s) of pulmonary dendritic cells in vivo by resident alveolar macrophages." J Exp Med 177(2): 397-407.

Honda, M., Orii, F., Ayabe, T., Imai, S., Ashida, T., Obara, T. and Kohgo, Y. (2000). "Expression of glucocorticoid receptor beta in lymphocytes of patients with glucocorticoid-resistant ulcerative colitis." Gastroenterology 118(5): 859-66.

Horwood, L. J., Fergusson, D. M. and Shannon, F. T. (1985). "Social and familial factors in the development of early childhood asthma." Pediatrics 75(5): 859-68.

http://atlas.gc.ca/site/francais/learning_resources. "Atlas du Canada ". 
Huss, K., Adkinson, N. F., Jr., Eggleston, P. A., Dawson, C., Van Natta, M. L. and Hamilton, R. G. (2001). "House dust mite and cockroach exposure are strong risk factors for positive allergy skin test responses in the Childhood Asthma Management Program." J Allergy Clin Immunol 107(1): 48-54.

Ito, K., Barnes, P. J. and Adcock, I. M. (2000). "Glucocorticoid receptor recruitment of histone deacetylase 2 inhibits interleukin-1beta-induced histone $\mathrm{H} 4$ acetylation on lysines 8 and 12." Mol Cell Biol 20(18): 6891-903.

Ito, K., Caramori, G., Lim, S., Oates, T., Chung, K. F., Barnes, P. J. and Adcock, I. M. (2002). "Expression and activity of histone deacetylases in human asthmatic airways." Am J Respir Crit Care Med 166(3): 392-6.

Jaffar, Z. H., Stanciu, L., Pandit, A., Lordan, J., Holgate, S. T. and Roberts, K. (1999). "Essential role for both CD80 and CD86 costimulation, but not CD40 interactions, in allergen-induced Th2 cytokine production from asthmatic bronchial tissue: role for alphabeta, but not gammadelta, T cells." J Immunol 163(11): 6283-91.

Jonsson, S., Musher, D. M., Goree, A. and Lawrence, E. C. (1986). "Human alveolar lining material and antibacterial defenses." Am Rev Respir Dis 133(1): 136-40.

Kaiko, G. E., Horvat, J. C., Beagley, K. W. and Hansbro, P. M. (2008). "Immunological decision-making: how does the immune system decide to mount a helper T-cell response?" Immunology 123(3): 326-38.

Kam, J. C., Szefler, S. J., Surs, W., Sher, E. R. and Leung, D. Y. (1993). "Combination IL2 and IL-4 reduces glucocorticoid receptor-binding affinity and T cell response to glucocorticoids." J Immunol 151(7): 3460-6.

Karakaya, S. (2004). "Bioavailability of phenolic compounds." Crit Rev Food Sci Nutr 44(6): 453-64.

Kelley, J. (1990). "Cytokines of the lung." Am Rev Respir Dis 141(3): 765-88. 
Kidd, P. (2003). "Th1/Th2 balance: the hypothesis, its limitations, and implications for health and disease." Altern Med Rev 8(3): 223-46.

Kopp, E. B. and Medzhitov, R. (1999). "The Toll-receptor family and control of innate immunity." Curr Opin Immunol 11(1): 13-8.

Korhonen, R., Lahti, A., Kankaanranta, H. and Moilanen, E. (2005). "Nitric oxide production and signaling in inflammation." Curr Drug Targets Inflamm Allergy 4(4): 471-9.

Kraal, G., Broug, E., Thepen, T., Van Iwaarden, J. and Persoons, J. (1997). The role of alveolar macrophages in pulmonary immune fonction. Lung macrophages and dendritic cells in health and disease. M. F. L. a. S. W. Russell. New York, Marcel Dekker Inc.: 203.

Kroncke, K. D., Fehsel, K., Suschek, C. and Kolb-Bachofen, V. (2001). "Inducible nitric oxide synthase-derived nitric oxide in gene regulation, cell death and cell survival." Int Immunopharmacol 1(8): 1407-20.

Lacy, P. and Moqbel, R. (1997). "Eokines: synthesis, storage and release from human eosinophils." Mem Inst Oswaldo Cruz 92 Suppl 2: 125-33.

Lacy, P. and Moqbel, R. (2000). "Eosinophil cytokines." Chem Immunol 76: 134-55.

Lange, P., Parner, J., Vestbo, J., Schnohr, P. and Jensen, G. (1998). "A 15-year follow-up study of ventilatory function in adults with asthma." N Engl J Med 339(17): 1194200.

Langrehr, J. M., Hoffman, R. A., Lancaster, J. R., Jr. and Simmons, R. L. (1993). "Nitric oxide--a new endogenous immunomodulator." Transplantation 55(6): 1205-12.

Legorreta, A. P., Christian-Herman, J., O'Connor, R. D., Hasan, M. M., Evans, R. and Leung, K. M. (1998). "Compliance with national asthma management guidelines 
and specialty care: a health maintenance organization experience." Arch Intern Med 158(5): 457-64.

Lehtimaki, L., Kankaanranta, H., Saarelainen, S., Hahtola, P., Jarvenpaa, R., Koivula, T., Turjanmaa, V. and Moilanen, E. (2001). "Extended exhaled NO measurement differentiates between alveolar and bronchial inflammation." Am J Respir Crit Care Med 163(7): 1557-61.

Lemanske, R. F., Jr. and Busse, W. W. (2003). "Asthma." J Allergy Clin Immunol 111(2 Suppl): S502-19.

Leung, D. Y. and Bloom, J. W. (2003). "Update on glucocorticoid action and resistance." J Allergy Clin Immunol 111(1): 3-22; quiz 23.

Lohmann-Matthes, M. L., Steinmuller, C. and Franke-Ullmann, G. (1994). "Pulmonary macrophages." Eur Respir J 7(9): 1678-89.

Louten, J., Boniface, K. and de Waal Malefyt, R. (2009). "Development and function of TH17 cells in health and disease." J Allergy Clin Immunol 123(5): 1004-11.

Maddox, L. and Schwartz, D. A. (2002). "The pathophysiology of asthma." Annu Rev Med 53: 477-98.

Marie-Victorin (1964). La Flore laurentienne, Les presses de l'université de Montréal

Martin, R. J., Szefler, S. J., King, T. S., Kraft, M., Boushey, H. A., Chinchilli, V. M., Craig, T. J., Dimango, E. A., Deykin, A., Fahy, J. V., Israel, E., Lazarus, S. C., Lemanske, R. F., Jr., Leone, F. T., Pesola, G. R., Peters, S. P., Sorkness, C. A., Szwejbka, L. A. and Wechsler, M. E. (2007). "The Predicting Response to Inhaled Corticosteroid Efficacy (PRICE) trial." J Allergy Clin Immunol 119(1): 73-80. 
Masoli, M., Fabian, D., Holt, S. and Beasley, R. (2004). "The global burden of asthma: executive summary of the GINA Dissemination Committee report." Allergy 59(5): 469-78.

Matthews, J. G., Ito, K., Barnes, P. J. and Adcock, I. M. (2004). "Defective glucocorticoid receptor nuclear translocation and altered histone acetylation patterns in glucocorticoid-resistant patients." J Allergy Clin Immunol 113(6): 1100-8.

Metzger, W. J., Hunninghake, G. W. and Richerson, H. B. (1985). "Late asthmatic responses: inquiry into mechanisms and significance." Clin Rev Allergy 3(2): 14565.

Mills, C. D., Kincaid, K., Alt, J. M., Heilman, M. J. and Hill, A. M. (2000). "M-1/M-2 macrophages and the Th1/Th2 paradigm." J Immunol 164(12): 6166-73.

Moore, W. C. and Peters, S. P. (2006). "Severe asthma: an overview." J Allergy Clin Immunol 117(3): 487-94; quiz 495.

Mora, A., Paya, M., Rios, J. L. and Alcaraz, M. J. (1990). "Structure-activity relationships of polymethoxyflavones and other flavonoids as inhibitors of non-enzymic lipid peroxidation." Biochem Pharmacol 40(4): 793-7.

Moser, M. and Murphy, K. M. (2000). "Dendritic cell regulation of TH1-TH2 development." Nat Immunol 1(3): 199-205.

Mosser, D. M. (2003). "The many faces of macrophage activation." J Leukoc Biol 73(2): 209-12.

Nakajima, H. and Takatsu, K. (2007). "Role of cytokines in allergic airway inflammation." Int Arch Allergy Immunol 142(4): 265-73.

Ngoc, P. L., Gold, D. R., Tzianabos, A. O., Weiss, S. T. and Celedon, J. C. (2005). "Cytokines, allergy, and asthma." Curr Opin Allergy Clin Immunol 5(2): 161-6. 
Ober, C. (2005). "Perspectives on the past decade of asthma genetics." J Allergy Clin Immunol 116(2): 274-8.

Olivieri, D., Chetta, A., Del Donno, M., Bertorelli, G., Casalini, A., Pesci, A., Testi, R. and Foresi, A. (1997). "Effect of short-term treatment with low-dose inhaled fluticasone propionate on airway inflammation and remodeling in mild asthma: a placebocontrolled study." Am J Respir Crit Care Med 155(6): 1864-71.

Palecanda, A. and Kobzik, L. (2001). "Receptors for unopsonized particles: the role of alveolar macrophage scavenger receptors." Curr Mol Med 1(5): 589-95.

Payne, D. N., Adcock, I. M., Wilson, N. M., Oates, T., Scallan, M. and Bush, A. (2001). "Relationship between exhaled nitric oxide and mucosal eosinophilic inflammation in children with difficult asthma, after treatment with oral prednisolone." Am $\mathrm{J}$ Respir Crit Care Med 164(8 Pt 1): 1376-81.

Peiser, L., Mukhopadhyay, S. and Gordon, S. (2002). "Scavenger receptors in innate immunity." Curr Opin Immunol 14(1): 123-8.

Peters-Golden, M. (2004). "The alveolar macrophage: the forgotten cell in asthma." Am J Respir Cell Mol Biol 31(1): 3-7.

Pockley, A. G., Muthana, M. and Calderwood, S. K. (2008). "The dual immunoregulatory roles of stress proteins." Trends Biochem Sci 33(2): 71-9.

Rahman, I., S. K. Biswas, et al. (2006). "Regulation of inflammation and redox signaling by dietary polyphenols." Biochem Pharmacol 72(11): 1439-52.

Report, E. P. (2007). "Expert Panel Report 3 (EPR-3): Guidelines for the Diagnosis and Management of Asthma-Summary Report 2007." J Allergy Clin Immunol 120(5 Supp1): S94-138. 
Robinson, D. S., Campbell, D. A., Durham, S. R., Pfeffer, J., Barnes, P. J. and Chung, K. F. (2003). "Systematic assessment of difficult-to-treat asthma." Eur Respir J 22(3): 478-83.

Saleh, D., Ernst, P., Lim, S., Barnes, P. J. and Giaid, A. (1998). "Increased formation of the potent oxidant peroxynitrite in the airways of asthmatic patients is associated with induction of nitric oxide synthase: effect of inhaled glucocorticoid." Faseb J 12(11): 929-37.

Sampson, A. P. (2000). "The role of eosinophils and neutrophils in inflammation." Clin Exp Allergy 30 Suppl 1: 22-7.

Sauk, J. J., Nikitakis, N. and Siavash, H. (2005). "Hsp47 a novel collagen binding serpin chaperone, autoantigen and therapeutic target." Front Biosci 10: 107-18.

Savill, J. S., Wyllie, A. H., Henson, J. E., Walport, M. J., Henson, P. M. and Haslett, C. (1989). "Macrophage phagocytosis of aging neutrophils in inflammation. Programmed cell death in the neutrophil leads to its recognition by macrophages." $\mathrm{J}$ Clin Invest 83(3): 865-75.

Schwartz, H. J., Lowell, F. C. and Melby, J. C. (1968). "Steroid resistance in bronchial asthma." Ann Intern Med 69(3): 493-9.

Sher, E. R., Leung, D. Y., Surs, W., Kam, J. C., Zieg, G., Kamada, A. K. and Szefler, S. J. (1994). "Steroid-resistant asthma. Cellular mechanisms contributing to inadequate response to glucocorticoid therapy." J Clin Invest 93(1): 33-9.

Shurin, M. R., Lu, L., Kalinski, P., Stewart-Akers, A. M. and Lotze, M. T. (1999). "Th1/Th2 balance in cancer, transplantation and pregnancy." Springer Semin Immunopathol 21(3): 339-59. 
Sirois, J. and Bissonnette, E. Y. (2001). "Alveolar macrophages of allergic resistant and susceptible strains of rats show distinct cytokine profiles." Clin Exp Immunol 126(1): 9-15.

Sobande, P. O. and Kercsmar, C. M. (2008). "Inhaled corticosteroids in asthma management." Respir Care 53(5): 625-33; discussion 633-4.

Solheim, E., Sudmann, B., Bang, G. and Sudmann, E. (2000). "Biocompatibility and effect on osteogenesis of poly(ortho ester) compared to poly(DL-lactic acid)." J Biomed Mater Res 49(2): 257-63.

Stevenson, D. D. and Szczeklik, A. (2006). "Clinical and pathologic perspectives on aspirin sensitivity and asthma." J Allergy Clin Immunol 118(4): 773-86; quiz 787-8.

Strickland, I., Kisich, K., Hauk, P. J., Vottero, A., Chrousos, G. P., Klemm, D. J. and Leung, D. Y. (2001). "High constitutive glucocorticoid receptor beta in human neutrophils enables them to reduce their spontaneous rate of cell death in response to corticosteroids." J Exp Med 193(5): 585-93.

Suissa, S., Ernst, P., Benayoun, S., Baltzan, M. and Cai, B. (2000). "Low-dose inhaled corticosteroids and the prevention of death from asthma." $N$ Engl J Med 343(5): $332-6$.

Tantisira, K. G. and Weiss, S. T. (2006). "The pharmacogenetics of asthma therapy." Curr Drug Targets 7(12): 1697-708.

Thepen, T., McMenamin, C., Oliver, J., Kraal, G. and Holt, P. G. (1991). "Regulation of immune response to inhaled antigen by alveolar macrophages: differential effects of in vivo alveolar macrophage elimination on the induction of tolerance vs. immunity." Eur J Immunol 21(11): 2845-50. 
Thepen, T., Van Rooijen, N. and Kraal, G. (1989). "Alveolar macrophage elimination in vivo is associated with an increase in pulmonary immune response in mice." $\mathrm{J}$ Exp Med 170(2): 499-509.

Tillie-Leblond, I., Iliescu, C. and Deschildre, A. (2004). "[Physiopathology of inflammatory events in asthma]." Arch Pediatr 11 Suppl 2: 58s-64s.

Tsan, M. F. and Gao, B. (2004). "Cytokine function of heat shock proteins." Am J Physiol Cell Physiol 286(4): C739-44.

Tsan, M. F. and Gao, B. (2004). "Heat shock protein and innate immunity." Cell Mol Immunol 1(4): 274-9.

van Schaardenburg, D. (1995). "Rheumatoid arthritis in the elderly. Prevalence and optimal management." Drugs Aging 7(1): 30-7.

Verstraelen, S., Bloemen, K., Nelissen, I., Witters, H., Schoeters, G. and Van Den Heuvel, R. (2008). "Cell types involved in allergic asthma and their use in in vitro models to assess respiratory sensitization." Toxicol In Vitro 22(6): 1419-31.

Vignola, A. M., Mirabella, F., Costanzo, G., Di Giorgi, R., Gjomarkaj, M., Bellia, V. and Bonsignore, G. (2003). "Airway remodeling in asthma." Chest 123(3 Suppl): 417S$22 \mathrm{~S}$.

Warrier, M. R. and Hershey, G. K. (2008). "Asthma genetics: personalizing medicine." J Asthma 45(4): 257-64.

Webster, J. C., Oakley, R. H., Jewell, C. M. and Cidlowski, J. A. (2001). "Proinflammatory cytokines regulate human glucocorticoid receptor gene expression and lead to the accumulation of the dominant negative beta isoform: a mechanism for the generation of glucocorticoid resistance." Proc Natl Acad Sci U S A 98(12): 686570 . 
Wenzel, S. E. (2006). "Asthma: defining of the persistent adult phenotypes." Lancet 368(9537): 804-13.

Williams, L. K., Pladevall, M., Xi, H., Peterson, E. L., Joseph, C., Lafata, J. E., Ownby, D. R. and Johnson, C. C. (2004). "Relationship between adherence to inhaled corticosteroids and poor outcomes among adults with asthma." J Allergy Clin Immunol 114(6): 1288-93.

Williams, T. J. (2004). "The eosinophil enigma." J Clin Invest 113(4): 507-9.

Wilson, A. G. (2008). "Epigenetic regulation of gene expression in the inflammatory response and relevance to common diseases." J Periodontol 79(8 Suppl): 1514-9.

Xia, Z. and Triffitt, J. T. (2006). "A review on macrophage responses to biomaterials." Biomed Mater 1(1): R1-9.

Yokoe, T., Suzuki, N., Minoguchi, K., Adachi, M. and Sakane, T. (2001). "Analysis of IL12 receptor beta 2 chain expression of circulating $T$ lymphocytes in patients with atopic asthma." Cell Immunol 208(1):34-42.

Zamze, S., Martinez-Pomares, L., Jones, H., Taylor, P. R., Stillion, R. J., Gordon, S. and Wong, S. Y. (2002). "Recognition of bacterial capsular polysaccharides and lipopolysaccharides by the macrophage mannose receptor." J Biol Chem 277(44): 41613-23.

Zanin-Zhorov, A., Nussbaum, G., Franitza, S., Cohen, I. R. and Lider, O. (2003). "T cells respond to heat shock protein 60 via TLR2: activation of adhesion and inhibition of chemokine receptors." Faseb J 17(11): 1567-9. 